University of Redlands

\title{
Improving Health Care Network Adequacy Through Spatial Analysis Utilizing GIS Technology
}

A Major Individual Project submitted in partial satisfaction of the requirements for the degree of Master of Science in Geographic Information Systems

\author{
by \\ Ashley Pervorse
}

Fang Ren, Ph.D., Committee Chair

Douglas Flewelling, Ph.D.

August 2020 
Improving Health Care Network Adequacy Through Spatial Analysis Utilizing GIS Technology

Copyright (C) 2020

by

Ashley Pervorse 
The report of Ashley Pervorse is approved.
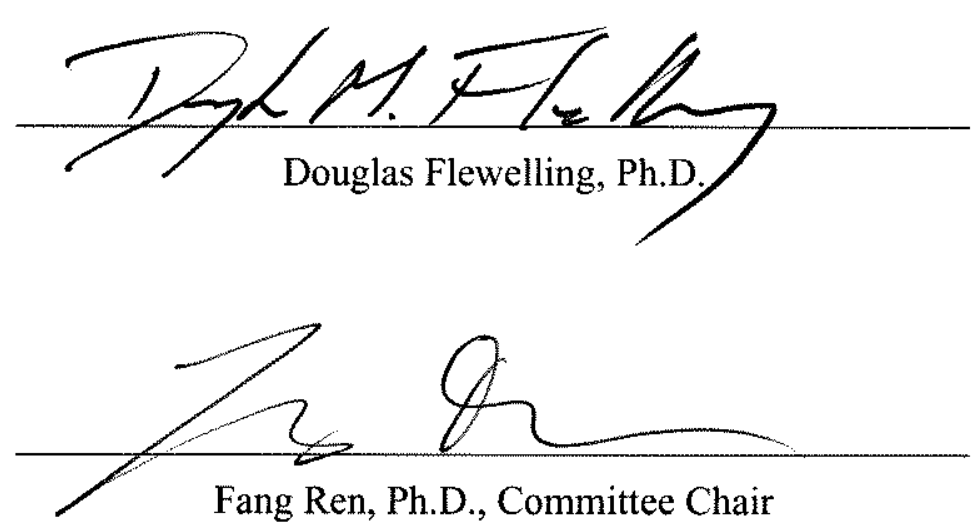

August 2020 



\section{Acknowledgements}

I would like to thank my advisor Dr. Fang Ren who always encouraged me to improve my knowledge and to challenge myself even when I thought I was not capable of doing the tasks. She taught me to change the way I thought about hardships and she taught me to not only learn, but to slow down to truly understand everything. Her expert guidance helped me grow in many ways.

I would like to thank Douglas Flewelling for being a mentor to me through the school year. I appreciated his positive attitude and his willingness to always help.

I would like to thank Charlie Frye who was a great mentor to me throughout this process. His influence and enthusiasm on the subject matter, made me passionate about GIS. He showed me a side of GIS that I had not seen before and his knowledge and understanding of the subject is admirable. I could always count on him to be forthright about my work and my future in the GIS field. Anyone would be lucky to have someone like Charlie in their lives. I feel blessed that Charlie was willing to share his expertise with the students in the GIS program.

I would like to thank my parents and my sister, Hayleigh. You are my hero and my greatest mentor, thank you for standing by my side through this process, for helping me when I came to trials I didn't think I would pass, and for encouraging me to go through this program.

I would like to thank God. Without him and his calming presence there is no way I would have made it through this. He kept me strong and focused when I did not think I could be. The blessings He has brought into my life because of this program is immeasurable. 



\begin{abstract}
Improving Health Care Network Adequacy Through Spatial Analysis Utilizing GIS Technology

by

Ashley Pervorse
\end{abstract}

\begin{abstract}
Network adequacy is a set of regulations a provider's office must follow. Requirements are dependent on what funding they are receiving from the government, insurance companies, and other paying entities. Network adequacy at a provider's office should be able to prove that they are providing their patients reasonable access to care. Generating these reports is currently a timely and costly process. Using GIS can improve the efficiency of generating and turning in their network adequacy reports to the required entities which would help save time and money. Having a way for providers offices to spend less time on these reports would allow for them to have more time to give to patients. Utilizing GIS to see the providers accessibility to patients can also show health care facilities where there are underserved areas, which would allow them to build new locations and add new providers. This paper shows the benefit of integrating GIS into the health field and how both provider facilities and patients can gain from this integration. Using the two-step floating catchment area method combined with ArcGIS Pro proved to be beneficial to calculating network adequacy and can be seen in the results of this paper.
\end{abstract}





\section{Table of Contents}

Chapter 1 - Introduction ................................................................................................. 1

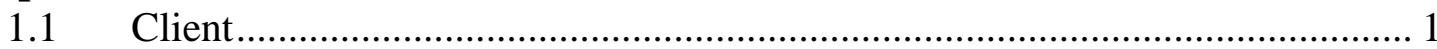

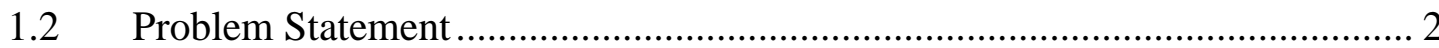

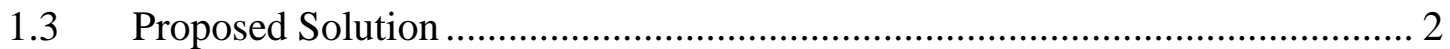

1.3.1 Goals and Objectives ............................................................................. 2

1.3.2 Scope

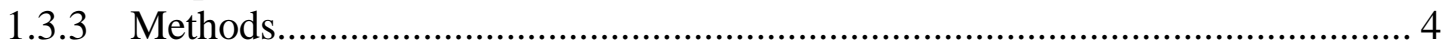

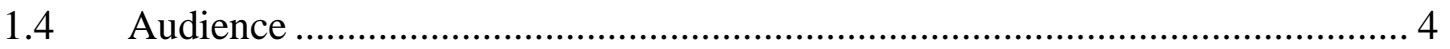

1.5 Overview of the Rest of this Report .............................................................. 5

Chapter 2 - Background and Literature Review ........................................................... 7

$2.1 \quad$ Network Adequacy Calculation ............................................................... 7

2.2 Two-Step Floating Catchment Area Method .................................................. 8

2.3 Washington D.C Regulations............................................................... 10

2.4 ArcGIS Platform Tools ……………………......................................... 10

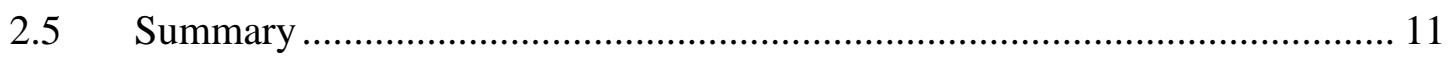

Chapter 3 - Systems Analysis and Design......................................................................... 13

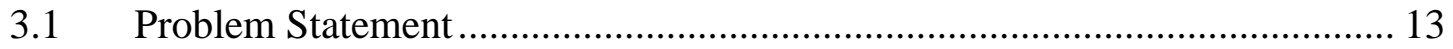

3.2 Requirements Analysis …………………………............................... 13

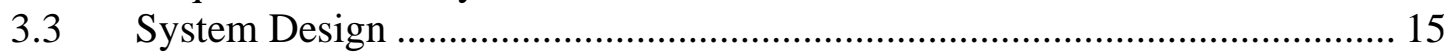

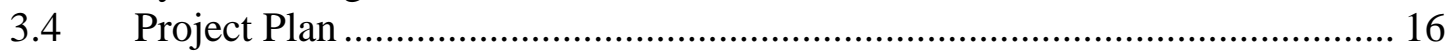

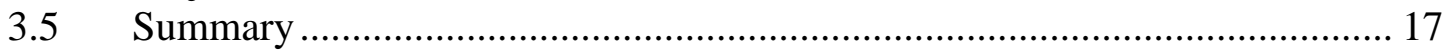

Chapter 4 - Database Design................................................................................................... 19

4.1 Conceptual Data Model ....................................................................... 19

4.2 Logical Data Model …………………............................................... 20

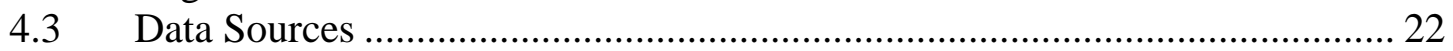

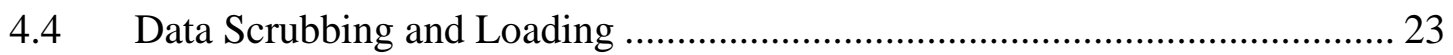

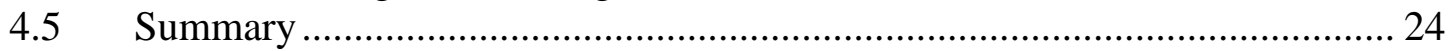

Chapter 5 - Implementation............................................................................................... 25

$5.1 \quad$ Network Analyst and Data Preparation .................................................... 25

5.2 Calculating Catchment Area _...................................................................... 28

5.3 Two-Step Floating Catchment Area (2SFCA) ............................................. 29

$5.4 \quad$ Creating Tasks for Users............................................................................ 36

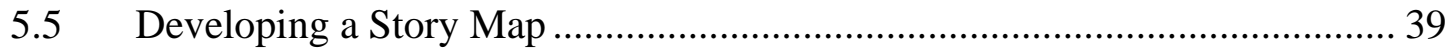

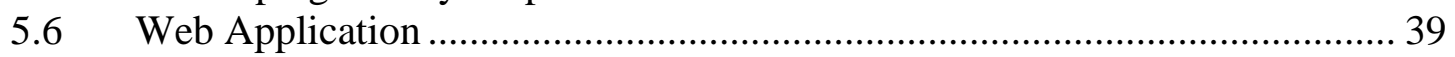

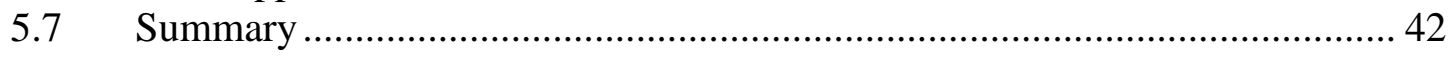

Chapter 6 - Results and Analysis......................................................................................... 43

$6.1 \quad$ Network Analysis using the 2SFCA Results ............................................... 43

$6.2 \quad$ Using Working Tasks ............................................................................... 48

6.3 Story Map for Spatial Accessibility to Medical Services ................................ 52

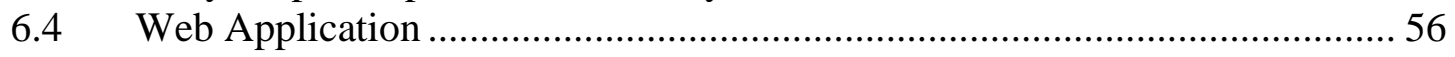

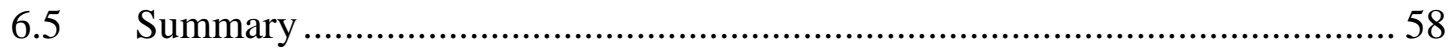


Chapter 7 - Conclusions and Future Work ........................................................... 59

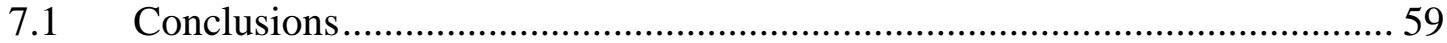

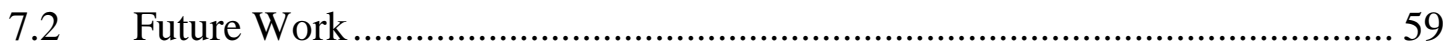

Works Cited ................................................................................................................... 61

Appendix A. ModelBuilder into Tasks .................................................................. 63

Appendix B. Story Map................................................................................................. 70

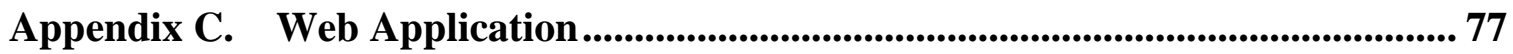




\section{Table of Figures}

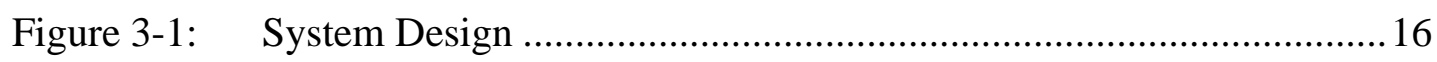

Figure 4-1: Conceptual Data Model for Esri ....................................................... 19

Figure 4-2: Logical Data Model …………………….................................... 21

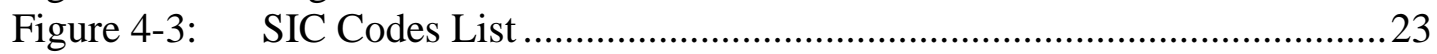

Figure 4-4: Example of Census Data..............................................................2

Figure 5-1: ArcGIS Pro Network Analyst Ribbon …………………………..... 26

Figure 5-2: Added Insurance to Providers table ……………………………......2

Figure 5-3: Calculation used to get a random number..........................................2 28

Figure 5-4: Example of the Service Area Tool Bar ...............................................2

Figure 5-5: A Five-Minute Service Area ……………......................................

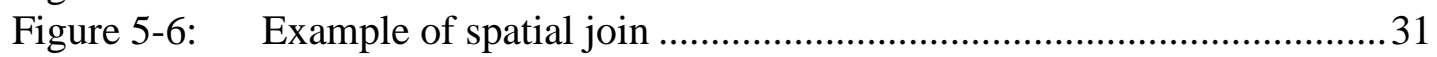

Figure 5-7: Example of adding ProToPop field................................................... 32

Figure 5-8: $\quad$ Step 1 of the 2SFCA Method Workflow ………………….................. 33

Figure 5-9: $\quad$ Spatial join for second step of 2SFCA method.......................................34

Figure 5-10: Step 2 of the 2SFCA Method Workflow ……………………….......... 35

Figure 5-11: Feature Layer Name Changes ...........................................................36

Figure 5-10: Example of ModelBuilder.............................................................. 37

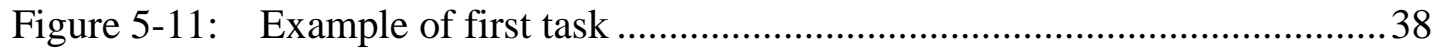

Figure 5-12: Example of Business Analyst widget ...............................................4 40

Figure 5-13: Example of directions from WebApp Builder .....................................4 41

Figure 6-1: $\quad$ Patient Accessibility at Different Time Thresholds.............................4 44

Figure 6-2: Patient Accessibility Example ………………………………….....4 45

Figure 6-3: Patient Accessibility Table Example …………………………….....4 46

Figure 6-4: Provider Service Area ................................................................ 47

Figure 6-5: Provider Service Area Table ......................................................... 47

Figure 6-6: Intro to Tasks ..............................................................................

Figure 6-7: Step 1 of Tasks: Provider to Patient Ratio ............................................51

Figure 6-8: Step 2 of Tasks: Patient Accessibility ................................................52

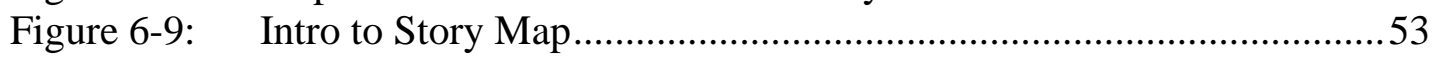

Figure 6-10: Sidecar in Story Map ..................................................................5

Figure 6-11: Task in Story Map.....................................................................5

Figure 6-12: Introduction to the WebApp in the Story Map ..................................56

Figure 6-13: Example of a patient using the Near Me tool .....................................57

Figure 6-14: Example of a provider using the Near Me tool....................................57 



\section{List of Tables}

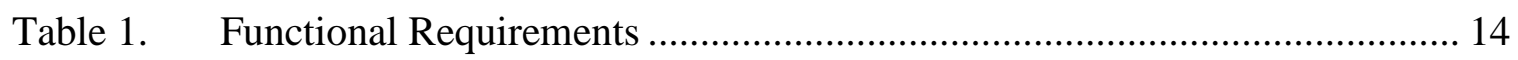

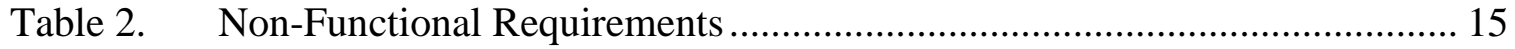

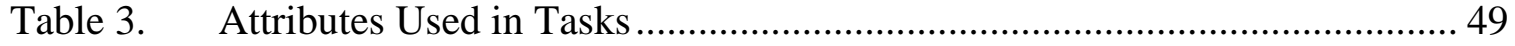





\section{List of Acronyms and Definitions}

$\begin{array}{ll}\text { 2SFCA } & \text { Two-Step Floating Catchment Area } \\ \text { AGOL } & \text { ArcGIS Online } \\ \text { BA } & \text { Business Analyst } \\ \text { CMS } & \text { Centers for Medicare \& Medicaid Services } \\ \text { DHCS } & \text { Department of Health Care Services } \\ \text { GIS } & \text { Geographic Information System } \\ \text { HBX } & \text { Health Benefit Exchange Authority } \\ \text { OB/GYN } & \text { Obstetrician-Gynecologists } \\ \text { PCP } & \text { Primary Care Physician } \\ \text { SIC } & \text { Standard Industrial Classification }\end{array}$





\section{Chapter 1 - Introduction}

Network adequacy is a system that health payors and regulators are required to meet if they receive money from Centers for Medicare \& Medicaid Services (CMS). CMS is part of the U.S Department of Health and Human Services. The idea is that network adequacy will make patients' lives easier by helping them find more efficient routes to get to the providers that they need. Network adequacy helps determine which emergency room or hospital will be the least distance and best option for that patient, what specialists the patient will have available to them, and what type of transportation is needed or available for each location. The network, in network adequacy, refers to the specific network or travel specifications that the CMS or other entities has chosen. Finding the information required by the CMS protocol, such as distances and time between patients and the care, can be difficult. However, the providers must present this information to the CMS regarding how easily accessible medical care is for their patients and to make sure that each providers network has been certified.

An important factor in evaluating network adequacy is the ease of access to care. A well-known method, two-step floating catchment area (2SFCA) is commonly used to evaluate the ease of access to care (Luo \& Wang, 2003). The 2SFCA is a model of spatial interaction used to measure spatial accessibility to providers. Specifically, it assesses how hard or easy it is for a patient to get to a provider's location. This could include disabilities, distance, travel mode, and how many provider options the patient has. Having a good application or program in place for health payors to evaluate spatial accessibility of the patients would be extremely beneficial.

Due to the intensity of creating these reports and the complexity of the math involved, a lot of providers and regulators will outsource their work to other companies. This in turn increases cost, time, and resources used. In the accessibility literature, GIS has been proved useful by integrating multiple sources of data for the analysis. A few examples of GIS being used to improve accessibility are; how GIS and ArcGIS helped London see different patterns of spatial accessibility using different transportation modes throughout their city. This information helped them create different possibilities to increase the use of low-carbon forms of transportation (Ford, Barr, Dawson, \& James, 2015). Finland also used GIS to calculate the population and accessibility change through the years 1970-2007 (Kotavaara, Antikainen, \& Rusanen, 2011). Utilizing the GIS technology, health care organizations would be able to generate network adequacy reports economically and quickly. This project focuses on highlighting the possibility of leveraging Esri's technology as a bridge between spatial analysis and the methods health care organizations can use to meet CMS regulations.

\subsection{Client}

The client for this project was Esri which is a company that was founded by Jack and Laura Dangermond along with others and is based in Redlands California. Since opening, the company has become the global leader in GIS since opening in 1969. Esri has become a global company having 49 different offices in 73 different countries. They have built the world's most powerful mapping software called ArcGIS. Esri has goals to continue to 
show why the power behind GIS and their software can improve the way the world spatially analyzes problems. The contact for this project was Este Geraghty, the Chief Medical Officer and Health Solutions Director at Esri, who provided the data as well as defined the goals and expectations that should be answered by this project. Esri has a goal to show that GIS can be useful in helping health care facilities improve their network adequacy using spatial analysis tools through ArcGIS.

\subsection{Problem Statement}

The health field has been known for not having a good system for efficiently getting patients where they need to be. Often, a patient has difficulties finding the type of doctor needed, where the providers are located, and if the providers will accept the their insurance. Network adequacy focuses on the last two of those problems, both having to do with the transportation and the ease of access to offices. Patients need an easy method to find the nearest provider, whether it is a primary care physician or a specialist. Patients also need to know the fastest route to their provider's office and how many other options there are. However, getting the reports regarding patient accessibility required by the network adequacy regulation for healthcare providers is not straightforward and is costly. As such, this project focused on addressing the challenges experienced by healthcare providers and offered them a method to enhance their workflow to evaluate spatial accessibility of patients to the medical facilities.

\subsection{Proposed Solution}

To meet the requirements of network adequacy, there needs to be a plan and program in place that can allow for providers and users to submit the required reports in a satisfactory amount of time. Using GIS can help create a solution. Specifically, using the data from Business Analyst Desktop and Esri products, including ArcGIS Pro, this project would create a program that allows the users to input the required data and have an output that can then be submitted to the payor from whom they are receiving financial aid.

\subsubsection{Goals and Objectives}

The main goal of this project was to show how GIS can improve network adequacy analysis and facilitate the patients to locate the providers that meet their needs. There were two specific objectives. The first one was to streamline network adequacy using ArcGIS Pro and the second one was to develop a marketing presentation through a story map and web application, using a specific case study area. In doing so, this project was able to show that not only was GIS vital to improving network adequacy, but also showed the value of using Esri products.

\subsubsection{Scope}

In network adequacy for healthcare, there are a lot of components; which provider is being assessed, what type of area the provider is serving, which state the provider is in, which insurance companies the provider is working with, and others. The main one this 
project focused on was the travel burden a patient goes through to reach their providers. Based on the client's needs, one important deliverable of the project was to produce a report in the form of a story map showing the method behind finding the patient accessibility. This would allow the client to show the report to potential buyers in the health field that are looking to improve their network adequacy. The story map would provide the calculation of network adequacy conducted in this project by showing not only the process and the outcome, but also a web application a user can explore. The client would also receive tasks created in ArcGIS Pro for them to show proof of concept. This project focused on Washington D.C which can be seen in Figure 1-1 and the specific providers within that area. Primary care physicians (PCP), cardiologists, and obstetriciangynecologists $(\mathrm{OB} / \mathrm{GYN})$ were included in the stud

\section{Washington D.C. Boundary}

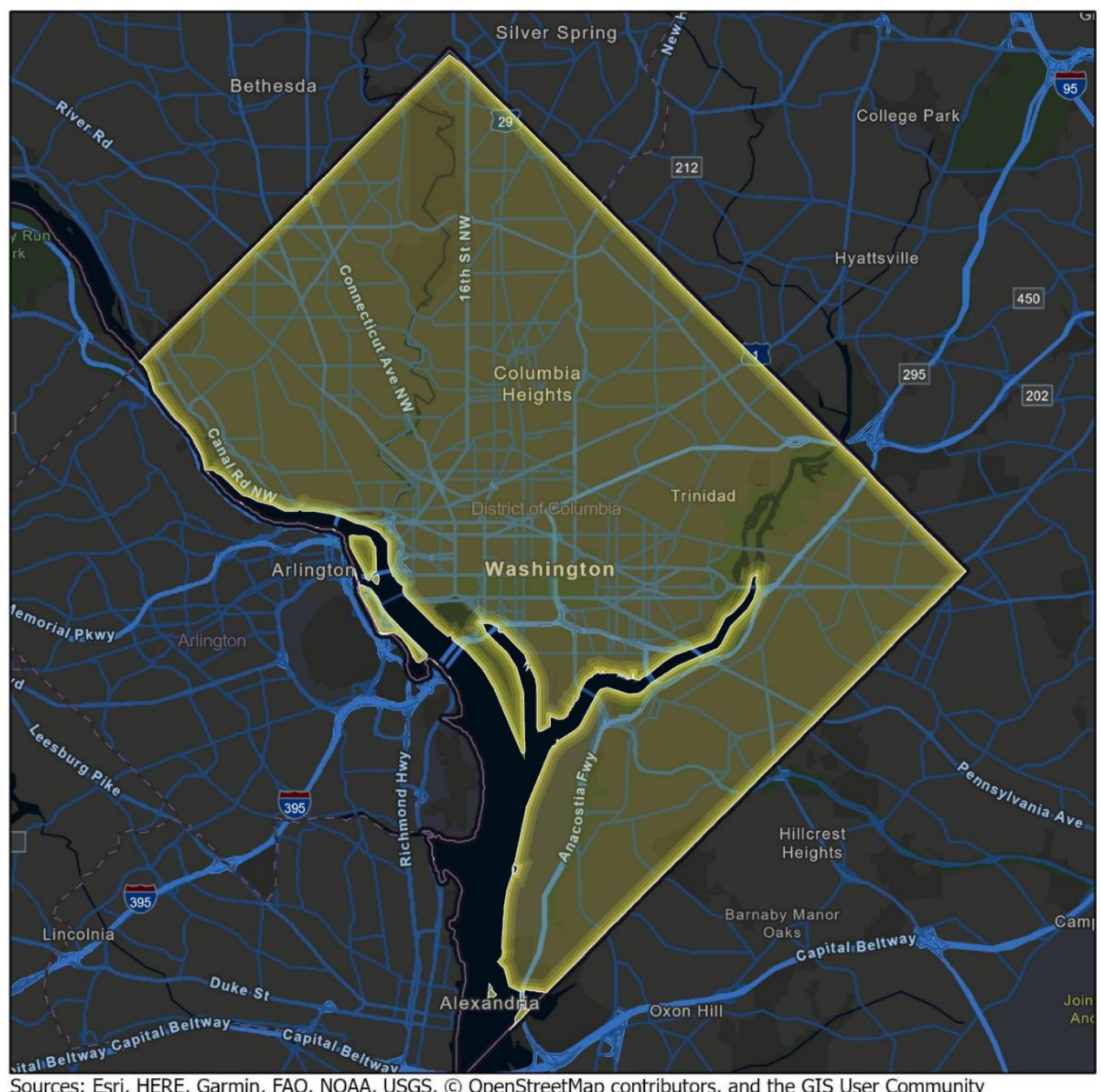

Figure 1-1: Study Area: Washington D.C 


\subsubsection{Methods}

This project had four main steps, comprising data collection and analysis, developing a task, creating a story map, and creating a web application. For the first step, Business Analyst (BA) data was used to evaluate and find the data files that had the information necessary for this project. After finding a data set that had the correct providers' name, location, and specialty type, the census block groups level data were gathered as possible patient locations. Once all the data was extracted, the analysis was possible.

After research and formulating a secure understanding of network adequacy and the 2SFCA, the data collection and analysis could begin. The project used the data from the BA extension in ArcPro and the ArcGIS Online Database. Since Washington D.C. was the focus area, the data needed to be inside of that boundary. This project mainly focused on using the network analyst tools to help find routes from patient to provider. To combine the use of the 2SFCA method and the ArcGIS network analyst tools, the service area tool was used to calculate drive times. The calculated drive time was used in combination with the provider and patient data to calculate the accessibility ratios. This was done to get two results: the provider service area to their possible patients, and the patient's accessibility to their desired provider location. After this calculation was completed and tested, the second step could happen.

The second step was to create tasks in ArcGIS Pro that would allow the client to run the 2SFCA analysis. The tasks in ArcGIS Pro are a tool that is used to mimic calculations and analyses so that the same steps are done every time to assure there are less errors. The first task created allows for parameters to be entered for the patients and the providers and then it runs the calculation to get the provider to patient ratio. The second task allows the user to input that new table which was created from task 1 to get patient accessibility to the providers in their desired travel time. When both steps are complete, the user would have the results of the 2SFCA method within a couple of minutes.

For the third step, a Story Map was created and presented. The Story Map allows users to read about the analyses of the project and to experience interactive web maps and a web application.

When the Story Map was completed, the fourth and final step was to create a web application using ArcGIS Online (AGOL) WebApp Builder. This is an online based tool that allows for the creation of a web application without needing to have a deep understanding of programming or graphic design. It allows for the user to input a map they have published to AGOL and to add widgets to that map that allows for different kinds of analyses. This is discussed in more details in chapter 5.

\subsection{Audience}

The audience for this project is people who are working in the health field or those who receive healthcare services. The audience does not need to have a deep understanding of GIS, only a basic knowledge of what spatial analysis is so they can understand how it can help. After reading this paper, the audience should be able to understand how healthcare can benefit from using GIS, ArcGIS and other applications through Esri. The product at the end of the project is an application that Esri could use to sell to the health payors and regulators to improve their network adequacy using GIS. 


\subsection{Overview of the Rest of this Report}

Discovering the difficulties patients face to meet with their providers will help improve network adequacy because it will allow for providers and hospitals to work with the CMS to get the providers expenses covered.

Following this chapter there will be six chapters that will explore the analyses and the details of how network adequacy can be enhanced if combined with the powerful tools of GIS. Chapter 2 will review literature of what network adequacy is, why it is important and how it can be improved as well as ways that people have tried to improve it in the past. Chapter 3 will give a synopsis the requirements of the project, the design of the system, and the project plan. Chapter 4 will review the database design and it will provide the information about the data that was used. Chapter 5 will discuss how the project was executed and will show how the analyses were processed throughout the project. Chapter 6 will provide the results of the project and go further into detail on the analyses showed. Chapter 7 will have the conclusions from the analyses, what worked and what failed, and how this can be applied to today and the future. 



\section{Chapter 2 - Background and Literature Review}

Network adequacy is a set of rules that healthcare facilities are required to meet if they receive money from various entities such as the Department of Health Care Services (DHCS), Medicare, and Medicaid. For example, if an OB/GYN is working in the state of California and receiving money from Medicaid, the doctor must be within the network adequacy standards of time and distance. California standards state that an OB/GYN must be 10 miles or 30 minutes from the patient's residence. Depending on the type of county (rural, small, medium, or large), the OB/GYN office will have different mile and time standards that the office must meet (Department of Health and Human Services, 2018). That is one example of the many requirements that an office must follow being in network with only Medicaid. Most provider offices are in network with more than one insurance company; this chapter will dive deeper into the complexities that being in multiple networks can bring.

Depending on where the healthcare facilities are getting money from, they must report their network adequacy more than once a year. The amount of work that healthcare professionals must take to meet requirements for network adequacy proves to be a challenge without help from outside facilities. There are ways that GIS can help these facilities run reports with accuracy and ease in order to submit the reports on time. For example, "Esri provides a suite of tools and capabilities that help health plan administrators ensure access to care and services for their members that not only meet regulatory requirements but also help build, promote, and sustain population health" (Geraghty, 2018, p. 4).

GIS can help reduce the time it takes to send network adequacy reports and continue receiving funds from the DHCS. Using Esri products and programs, such as Business Analyst, ArcGIS Online, WebApp Builder, and Story Map, will add to the improvements of adequacy for healthcare providers and facilities. If health facilities can spend less time working on these reports and meeting the requirements of network adequacy, they could spend more time focusing on patient care and satisfaction. To know how to improve network adequacy, there must be an understanding of concepts that this chapter will go over.

This chapter will begin with analyzing past work done to improve network adequacy and how it will be used to help this project. Next, the two-step floating catchment area (2SFCA) method will be described to show how spatial indexing can aide in current accessibility issues faced by patients struggling to receive access to their providers. After going over the 2SFCA, it is vital to understand the regulations that providers must follow depending on what type of care they give, their location, and the funding they are receiving. This project is specifically focusing on Washington D.C., so in this chapter the examples will be taken from there. Finally, there will be an introduction of tools used to show network analyst in ArcGIS Pro.

\subsection{Network Adequacy Calculation}

The main concern of network adequacy is with accessibility to health care facilities. Its standards focus on two main issues: time and distance. Time in this standard is the total number of minutes that it would take for a patient to travel from their residence to their 
closest provider. Distance is the total number of miles a patient must travel in order to get to the site of that nearest provider. The states are the entities that choose the required time, while the insurance company of the patient is the entity that chooses what the minimum distance can be; therefore, it can differ from state to state.

Using GIS to calculate network adequacy can help hospitals and healthcare organizations quickly evaluate how easy it is for their patients to access their services. What was once the standard travel time method to a provider's location is no longer being accepted, it is now required to add walking distance and drive time distance to estimate the route being taken by patients to the facility. Calculating this would be possible if you have the right data, the right tools, and the needed background knowledge about what the providers' network distance is. This workflow, however, presents to be challenging for healthcare providers, which indicates a great need for an automated workflow that they can apply to conduct the analysis.

According to Esri, regulatory agencies are now requiring a higher level of accuracy in their reports compared to earlier iterations, the increasing complexity of the problem was also shown in Luo \& Wangs 2SFCA method. The complexity of this has also been stated by many others, including Georgetown University Health Policy Institute who state that "Network adequacy has been among the more challenging to implement criteria for health plan certification under the Affordable Care Act (ACA)" (Corlette, 2017).

This complexity has led to a more complicated report that can be solved using math. In an article written by Geraghty (2018), she discusses an example of what the math looks like when examining the possibilities between two health insurance companies. In this example, there are 350 providers each having 40 specialties and two insurances (Medicare and Medicaid), which yields 28,000(350*40*2) distinct provider-insurance locations. Assume there are 1.2 million members with the insurance, about 33.6 billion calculations would be expected to generate the network adequacy reports for all members. Obviously, this is a very time-consuming task, which can become much easier with the aid of GIS. This is where GIS can be integrated to help and where technology is clearly needed.

\subsection{Two-Step Floating Catchment Area Method}

This section discusses how the two-step floating catchment method was used in the past, and how it can be applied to the problem this project is looking at. One of the most difficult things about accurately measuring the spatial accessibility of a patient is to consider the competition for the same provider from other patients, as well as the travel burden to visit this provider. The two-step floating catchment area method takes that problem and calculates a specified travel zone or catchment area for both providers and patients. It evaluates the accessibility to the doctor the patients have by discounting the availability of the doctor by other potential patients that live in the service area of this doctor.

Before the 2SFCA method was created, there was one popular way to find the accessibility that the population had to providers in their area. It was simply the shortage of health professionals in areas. The measure of accessibility was looking at what the Department of Health and Human Services were looking at to deduce if there was a shortage in accessibility. This method is limited; for example, patients do not always have the same access to physicians within the same catchment area, and patients in the 
catchment area are not always willing to travel outside of it. To better capture the travel time and physician capacity at the medical facility, Luo \& Wang (2003) first proposed the two-step floating catchment area (2SFCA), to evaluate spatial accessibility of patients to medical facilities, which was later improved by Luo \& Qi (2009). The 2SFCA method does look at those issues and calculates them into the equation of the accessibility. The 2SFCA method takes the size of a catchment area that is served by a medical facility and evaluates which patients are in an acceptable travel time and distance from their provider using a math equation.

According to the Medical Dictionary for the Health Professions and Nursing (https://medical-dictionary.thefreedictionary.com/catchment+area) a catchment area is "Geographic jurisdiction of a community mental health center; its boundaries delimit the population of people who qualify for mental health services provided by that particular center". The 2SFCA focuses on two main factors, the physician supply, and the population demand. These are both spatial entities that had to be evaluated and given accurate spatial distribution which can be difficult to correctly calculate. (McGrail, 2012).

The calculation of the 2SFCA requires a lot of math that many facilities may not want to handle for each provider they have in their company. Luo \& Wang (2003) created the 2SFCA method calculation. The calculation processes are explained in Equation (1) and Equation (2). The first step is used to determine an initial ratio to each service area at the physician (supply) location to measure the supply availability. For each physician location $j$, all demand locations $k$ that are within a certain time threshold distance $d_{o}$ to calculate the supply-to-demand ratio $R_{j}$ within the catchment area chosen. Equation (1) shows where $P_{k}$ is the population of $\mathrm{k}$ whose population fall inside the catchment area $\left(d_{k j}\right.$ $\leq d_{0}$ ), $S_{j}$ is the number of providers at location $j$, and $d_{k j}$ is the travel time between $k$ and $j$. This result yields whether a provider's office is considered accessible or not.

$$
R_{j}=\frac{S_{j}}{\sum_{k_{\left\{d_{k} \leq d_{0}\right)}} P_{k}}
$$

Equation (2) is the second calculation in the 2SFCA method. In this part of the equation, for the population $i$, the equation will search all provider locations $(j)$ that are in the travel time $\left(d_{0}\right)$ from the catchment area $i$, and then it will sum the provider-topopulation ratios $\left(R_{j}\right) . A \frac{F}{i}$ is the accessibility patients have to the providers based on location $i$.

$$
A_{i}^{F}=\sum_{j \in\left\{d_{i j} \leq d_{0}\right\}} R_{j}=\sum_{j \in\left\{d_{i j} \leq d_{0}\right\}} \frac{S_{j}}{\sum_{k_{\left\{d_{k} \leq d_{0}\right)}} P_{k}}
$$

Using the 2SFCA method could be made easy with ArcGIS Pro. ArcGIS contains the tools that can be used to help do the calculations while allowing the parameters to be set up by the users. ArcGIS Pro can calculate where the patients are, where the providers are, and who is in network with them depending on what travel time the patients are willing to drive. If one wants to go further into the directions, with the right data, ArcGIS 
Pro can also account for if the patient does not have a car and needs to take buses and walk to the providers office. It will output the providers that the patient is willing to travel to and give directions on how to get there.

\subsection{Washington D.C Regulations}

In 2012 Health Benefit Exchange Authority (HBX) was established to help with the development of the Affordable Care Act (Health Benefit Exchange Authority, 2012). HBX created an on-line health insurance marketplace called the DC Health Link, which made it simple and easy for all people to get insurance. The DC health Link offers insurance through three UnitedHealth companies, two Aetna companies, CareFirst BlueCrossBlueShield and Kaiser. Patrons can also use private insurance companies (i.e. Medicare and Medicaid) that are not contracted with DC Health Link. That means that there are more than seven different regulations that medical facilities could have to follow.

When looking at a cardiologist in DC, it is important to know which insurance companies this provider is in network with. It could be as little as one if this provider only accepts patients who have Kaiser insurance. If the providers are only in network with that one company, they only have one set of regulations that they must follow.

This project is looking at more than just a cardiologist who is in network with one insurance company. The project is also looking at primary care physicians (PCP) as well as OB/GYNs in D.C. Each of those providers could be in network with different insurance companies and needing to submit several reports to each insurer they use. (Health Benefit Exchange Authority). Instead of creating one report after another, using technology and GIS can help create one report that gives you all the answers needed to send to the insurance companies. The report can show how many people are in the correct time and distance ranges. The report can also show the locations not in the required time and distance ranges. With this information, medical offices can determine if they need to consider opening new locations or hire more providers in order to improve patient accessibility.

\subsection{ArcGIS Platform Tools}

To complete the analyses required in this project, using the AcrGIS platform tools is required. In this section, the tools that have been proven to be useful in network analyst will be described. When using ArcGIS pro, there are different extensions and licenses that can be added to the program. The network analyst extension allows users to calculate time and distance over a street network. Some examples of functions are Create Service Area and Calculate Closest Facility. WebApp Builder for ArcGIS online is the second useful tool to create a web application that a provider and patient can make use of. Patients could put in the type of doctor they are looking for, what type of insurance they have, and how far they are willing to travel and get a result of all the providers that fall under those categories. Providers could determine which patients are underserved by using the web application.

Taking a deeper look into the network analyst extension shows how it has been used to solve time and distance issues in the past and how it can be used to improve network adequacy. In a more recent Esri White Paper about finding testing sites during the 
COVID-19 pandemic (Esri, 2020), the authors used the network analyst extension to find testing sites, who in the population would be able to use them, and the boundaries. Their output and findings were a similar process to what this project will be looking for. For example, the service area can be generated for each healthcare provider with a specific travel limit and all the patients that fall in this service area can be identified and individual travel time can also be further calculated.

Knowing who are located in a service area is not the only goal as it is important to understand these people's characteristics and their neighborhoods. Taravat (2009) emphasizes the importance of analyzing geodemographic dynamics in a service area. He argues "[GIS] can identify catchment areas of health centres and also locate suitable sites for a new health facility. Health services delivered at home can be scheduled in a more efficient manner by analyzing transportation factors and street patterns, and by recommending the most efficient route. GIS Provides accurate and timely information about where health services are located and instructions and maps on how to get there." Knowing which areas are being served well and which areas are not, can help create ways to fix those areas that need better service. Whether it is building a new office or finding a way to extend the offices network, it would be simple to see which areas need to be changed. It is important to use ArcGIS tools and GIS knowledge together to create methods that can be used to improve network adequacy properly and effectively.

After network adequacy is analyzed, the results need to be conveyed to a general audience. In this case, WebApp Builder for ArcGIS appears to be a very useful technology. In an article written about the usefulness of the WebApp Builder, the author writes about how it is a tool that is the jack of all trades, it can be used for so many different reasons and it can be shown in many different ways. It can easily be changed for whatever audience it is being shown to and it is easy to use. Anyone would be able to create the web application and have fun while doing it. It is a quick and easy way to create web applications and it is a tool many companies could gain from (Law, 2019).This approach will allow both healthcare professionals and patients to use to see who are in their network/insurance coverage and the distance between them.

\subsection{Summary}

There are many sources out there that will dive deeper into why GIS is necessary and how it is dynamic to making important changes to how network adequacy is viewed and dealt with. Through research and literature review for this project, one thing was made clear; GIS is needed in healthcare. It not only aids in faster and more efficient health mapping and analysis, but GIS also gives healthcare professionals access to large volumes of data all in one place. It provides the tools necessary to display and manage healthcare. The possibilities of GIS helping the health field is limitless and should be evaluated by all healthcare professionals. 



\section{Chapter 3 - Systems Analysis and Design}

This chapter dives into the system design and requirements for the project. The breakdown of the chapter is separated by four sections. Section 3.1 addresses the problem. Section 3.2 discusses both functional and non-functional requirements. Section 3.3 shows the system design, ties it to the requirements, and shows how these were accomplished. In the last section 3.4 , the project plan is discussed along with any changes that happened throughout the timeline of the project.

\subsection{Problem Statement}

In almost every healthcare system there is a set of regulations that needs to be followed. These rules are set by network adequacy. To evaluate network adequacy, it is important to calculate travel time and distance of a patient to their desired provider. However, calculating the travel time and distance can be a challenge. If the providers office does not have the correct tools to run the analysis and the deep understanding of spatial analysis, it can be difficult to create the calculations to show their network adequacy and accessibility to the patients they serve. One example of a problem that arises from not being able to create network adequacy reports, is when a provider must report to an entity like the CMS but are unable to create these calculations and reports in a reasonable time. The inability to create these analyses with ease can prove to take up time in the providers offices that would be better spent helping their patients. If providers offices and others had the ability to generate network adequacy easily, there would be more time available for them to spend on their patients.

\subsection{Requirements Analysis}

This project had two types of requirements, functional and non-functional. The difference between the two is that functional requirements are what must be completed to create the output that the client wants, while non-functional requirements are not required as an output, but they will add quality to the project. The client was mainly interested in having an output of three different network-based analyses for a patient to visit three different types of providers in Washington D.C. and to see if that patient is within their network, therefore meeting the network adequacy requirements. Table 1 shows the functional requirements of this project. 
Table 1. Functional Requirements

\begin{tabular}{|l|l|}
\hline Requirement & Description \\
\hline $\begin{array}{l}\text { Boundary and Census Data for } \\
\text { Washington D.C }\end{array}$ & $\begin{array}{l}\text { Must have a layer for the D.C Boundary } \\
\text { and census block data that the client agrees } \\
\text { on to be used as the analysis data }\end{array}$ \\
\hline $\begin{array}{l}\text { Run Analysis of Service Area and } \\
\text { 2SFCA }\end{array}$ & $\begin{array}{l}\text { Must run each type of analysis with no } \\
\text { errors. }\end{array}$ \\
\hline Patient Accessibility Task & $\begin{array}{l}\text { Must create a task in ArcGIS Pro that } \\
\text { allows user to run the 2SFCA method to } \\
\text { get patient accessibility. }\end{array}$ \\
\hline Story Map to show Analysis & $\begin{array}{l}\text { Must create a story map that has } \\
\text { everything that was done on the project to } \\
\text { show users and buyers what can be done } \\
\text { with the tool created. }\end{array}$ \\
\hline Web Application & $\begin{array}{l}\text { Must create a web application for both the } \\
\text { client and public to use to show how GIS } \\
\text { can improve network adequacy. }\end{array}$ \\
\hline
\end{tabular}

The first requirement was to create the Washington D.C boundary in ArcGIS Pro, find the data of the specialty providers needed, and find the census data for that area. Once the provider information was found, creating a selection that only had the specialties needed was done.

The second functional requirement was to use the street network of Washington D.C. to do route analysis to conduct the shortest path, service area, and accessibility analyses. The shortest path analysis was to find the path and direction for a patient to the nearest provider of their choice. The service area analysis was used to calculate the service area of the providers. The output returned polygons of the area the provider could serve depending on the minute cutoff the user inputs into the tool. This tool was used for the patients as well to calculate which providers were in a desired travel time from their home which allowed the calculation of the provider accessibility to the patients.

The third functional requirement was to create a task in ArcGIS Pro that allows the user to run the 2SFCA method. This task allows for the user to get the provider to patient ratio and the patient accessibility ratio. The task allows for user to run this analysis while avoiding error.

The fourth functional requirement was to create a story map for the client to evaluate and share with future interested parties in the combination of GIS and the health field. To create the story map, having access to ArcGIS Online (AGOL) was needed. Having access to AGOL allowed for the story map to be made as well as having access to uploading the maps created in ArcGIS Pro to the online content. This allowed for the map with the data from the project to be embedded into the story map. For this requirement to be approved by the client, the story map had to show the project's problem and goal as well as show how Esri technology and GIS can improve network adequacy.

The fifth functional requirement was creating a web application. This was done through AGOL as well. It used the map that was published from ArcGIS Pro and took the 
information from that map to create widgets on the map. Widgets are essentially tools that the user can explore to find information about the map. It ranges from drive time to infographics to reports about areas that the user is interest in.

Table 2 shows the non-functional requirements. Each nonfunctional requirement is a tool or a dataset that was needed for this project to be successful. Each tool that was used is technology created by Esri and the analyses would not have been possible without access to each of these.

\section{Table 2. Non-Functional Requirements}

\begin{tabular}{|l|l|}
\hline Requirement & Description \\
\hline Access to ArcGIS Pro & $\begin{array}{l}\text { Must have access to ArcGIS Pro to run } \\
\text { the analyses the client required }\end{array}$ \\
\hline $\begin{array}{l}\text { Accessible to the public through ArcGIS } \\
\text { Online }\end{array}$ & $\begin{array}{l}\text { Must have a published story map and } \\
\text { web application for public use }\end{array}$ \\
\hline Access to Business Analyst & $\begin{array}{l}\text { Must have access to Business Analyst } \\
\text { extension to run retrieve the data for this } \\
\text { project }\end{array}$ \\
\hline Access to Network Analyst & $\begin{array}{l}\text { Must have the license needed to use and } \\
\text { run the Network Analyst extension } \\
\text { through ArcGIS Pro }\end{array}$ \\
\hline Usable credits through ESRI & $\begin{array}{l}\text { Must have credits to run certain network } \\
\text { analyst tools through ArcGIS Pro. }\end{array}$ \\
\hline
\end{tabular}

\subsection{System Design}

To have a better understanding of the project, a system design was created to the client's approval. The system design was determined by the requirements of the client. The start of the system design was the data and it ended with the web application that was published onto ArcGIS Online. Figure 3-1 shows the design of the system. 


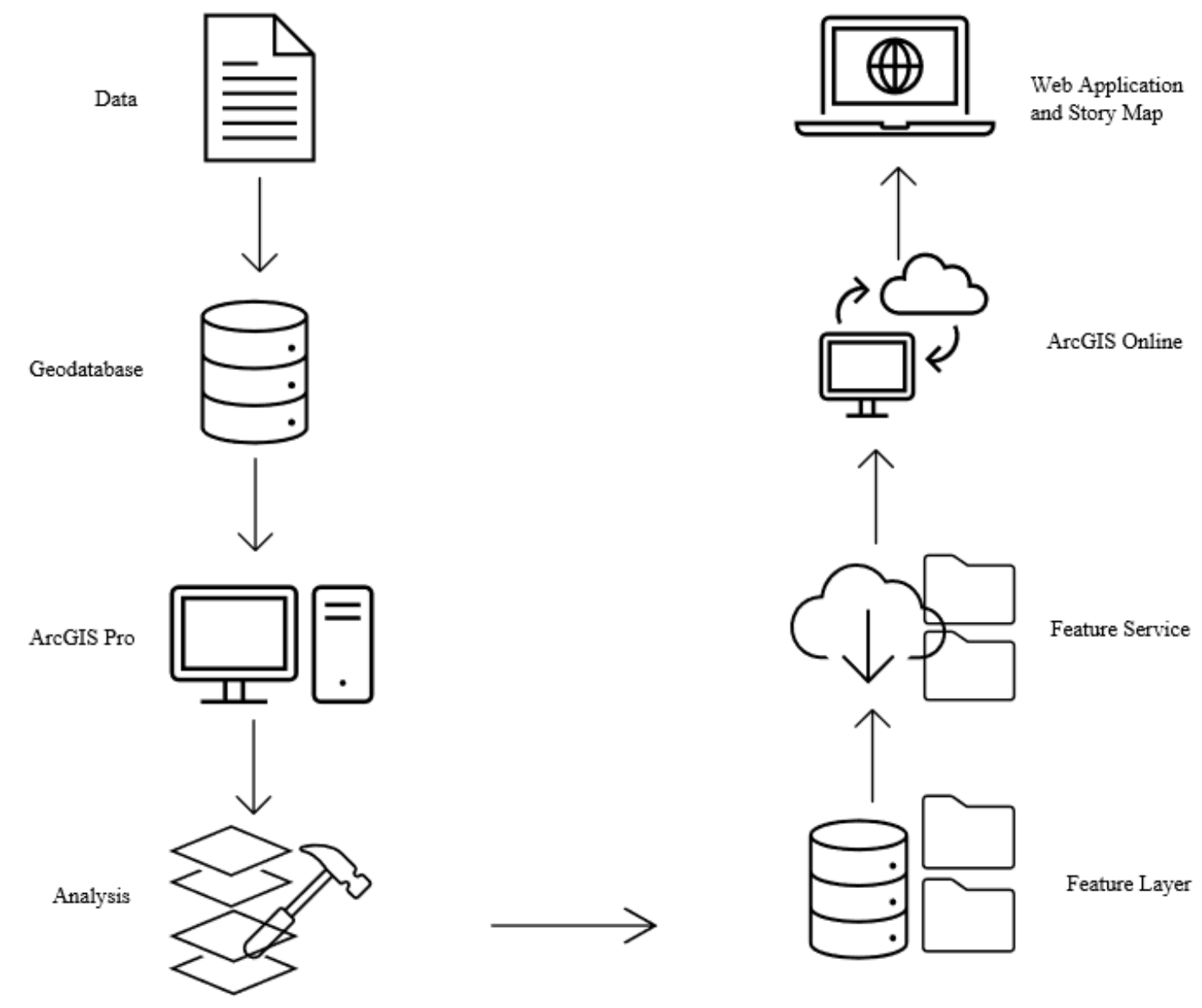

Figure 3-1: System Design

The project started with collecting the correct data from the ArcGIS Pro extension called Business Analyst and then that data was stored in its own geodatabase. Once the data was stored, the geodatabase was used to create different types of analyses in ArcGIS Pro using the Network Analysis extension. The different analyses that were done included the service area and the 2SFCA. Once those feature layers were created, they were shared with ArcGIS Online by creating a feature service. The feature service layers were used to create a story map and web application using WebApp Builder.

\subsection{Project Plan}

This project had four major phases: plan, design and develop, testing, and deployment. The most essential phase was planning. It is vital for all projects to establish an overall understanding of what the client wants as the outcome. To plan the project properly, one must know what the requirements are, where the data will be coming from, if there are any licenses that are needed and how long this process should take. In the original plan, getting the license should have only taken a week at most. Due to unforeseen issues with 
getting the license, getting the data, and getting it all installed onto the computer that was used for this project, it took much longer than the original plan had determined. In the future, it would be advised to have the client make sure everything is accessible before agreeing to start on the project. That way there is less of a chance to fall behind on the projects schedule. This was a good example as to why creating risk analysis on projects is a wise step to take and should have been added to the project plan.

There were two main constraints within this project; getting the data from the client and getting the license needed to use BA, which is the program needed to access the necessary data. This also led to being dependent on the client throughout this project. Without help and communication from the client, it was impossible to get the data and licensing needed, which made having a positive relationship with the client imperative. The school has provided access to ArcGIS Pro and ArcGIS Online, which were the two programs needed to create the analyses, story map, and web application needed to complete the project. Since they were provided by the school, these programs were dependent on computer compatibility and a reliable internet connection.

After planning the project and going over the risks, the next step was to outline the design of the project. The design of this project was creating a map of Washington D.C that included the applicable providers and the correct census data layer. This was done by using tools in ArcGIS Pro to select attributes by location and then creating a new feature layer from that selection. Once the design was completed, the development of the project could start. In the development phase successfully running the 2SFCA method was done. When the 2SFCA method was complete, a task was made with steps that allowed for users to mimic the analysis process. Once the task was complete, a story map was made to show each type of analyses as well as the web application. After testing had been done, the final step of the project plan was to deploy the web application and story map to the client.

\subsection{Summary}

This chapter discussed the system design and analysis. It started with restating the problem that this project is looking at; the chapter then went over the functional and nonfunctional requirements that had to be met. These were requirements needed to make the project successful. The design of the system for the project was then discussed, followed by what components were needed to complete the project. 



\section{Chapter 4 - Database Design}

This chapter dives into the description of the database design and the data used in the project. The database design supports what the client had as requirements and was a necessary part of the project. The database was designed to show how GIS can solve the issues surrounding network adequacy with spatial analysis. It is important to show how the database was designed and how it helps fulfill the goals of the project.

Section 4.1 will discuss the conceptual data model, Section 4.2 will illuminate on what the logical data model is, Section 4.3 will have a list of the data sources as well as a description of each, Section 4.4 explains what scrubbing data is and how much of it had to be done on this project and what loading methods were used, and lastly, Section 4.5 will summarize the chapter.

\subsection{Conceptual Data Model}

The conceptual data model shows the entities that the client was interested in and the relationships they had to each other. Figure 4-1 shows how these relationships were connected and the flow of processes that were used in order to run the analyses for this project successfully.

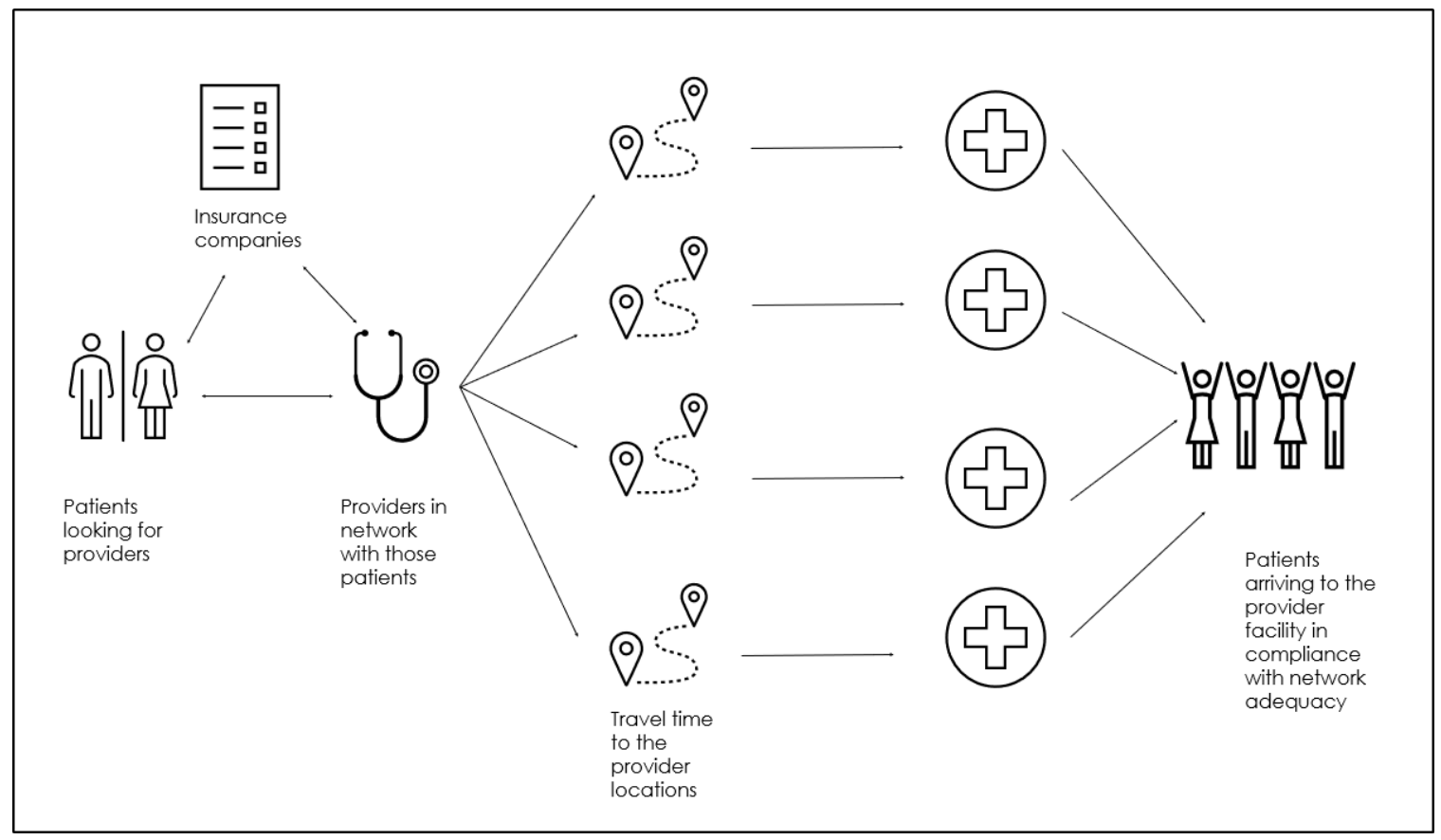

Figure 4-1: Conceptual Data Model for Esri

The conceptual data model includes three main ideas: providers meeting the requirements of network adequacy for their patients, taking into account which insurance the patients have and which insurance companies the providers are in system with, the travel time to get from the patient's location to the provider's locations, and patients arriving to the facility of their choice in the required travel period. The travel time in this 
project refers to the drive time from point $\mathrm{A}$ to point $\mathrm{B}$. When looking at the full picture of network adequacy, it requires that providers and regulators have the ability to not only calculate drive time, but to also include all travel types and burdens. However, for the time allotted for this project and the resources required to run that type of analyses, the project only focused on drive time.

\subsection{Logical Data Model}

The conceptual data model described and showed the large-scale entities and interactions in the data model. It showed the story of what this project was and how it was accomplished. The logical data model shows the data used and what types of data were used. The logical model also illuminates on how the data was organized and stored inside of the system that was used.

The logical model is the geodatabase model implemented in the project. As shown in Figure 4-2, there is a network dataset which is taken from BA and called Route_ND, then the four feature classes are added (Provider_Service, DC_block_pop_FIPS, DC_Border, and Patient_Accessibility). The network dataset and the feature classes are both stored in one geodatabase. 


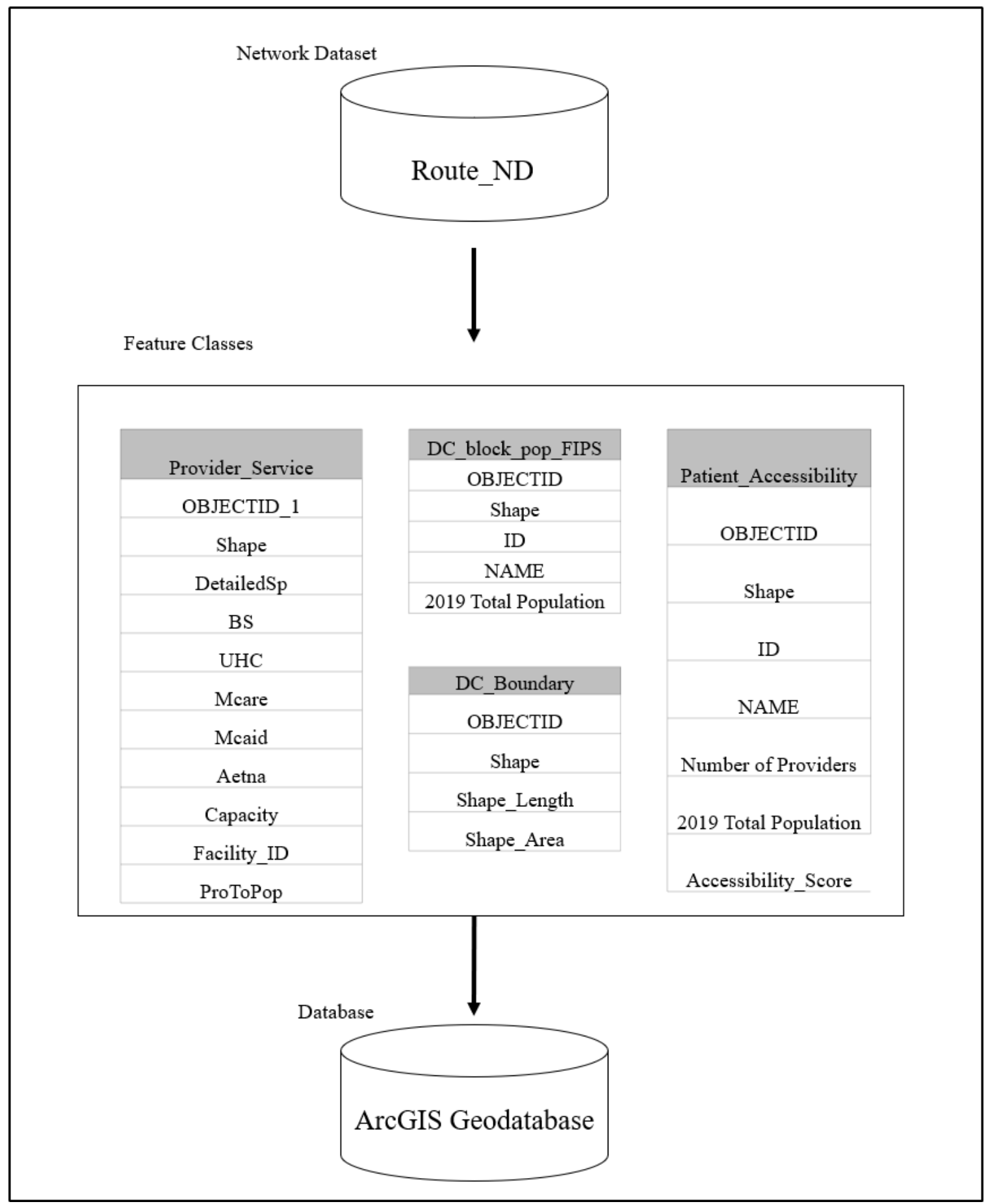

Figure 4-2: $\quad$ Logical Data Model

Each feature class has important attributes in them. The Provider_Service has attributes pertaining to the type of specialist at each point (DetailedSp), which insurance that location takes (BS,UHC, Mcare, MCaid, and Aetna), the number of providers at each location(Capacity), and the provider to population ratio (ProToPop). 
The DC_Boundary has attributes that are specifically about the clipped boundary of Washington D.C. This allowed for all the original points to be integrated into that boundary.

The DC_block_pop_FIPS feature class has attributes about each census block group point. This project used block group centroids due to not having access to actual patient data. This allowed for the analyses to work while abiding by any privacy laws connected with patient information. The most important attribute in this feature class that was used was the 2019 Total Population.

The fourth feature class was the Patient_Accessibility. This feature class had capacity to show the patients how many providers are at each location within a specific travel area. This capacity from the Provider_Service feature class was summed during a spatial join of the second step in the 2SFCA method to get an accurate number of providers (Number of Providers) that serve the population. The most important field in this feature class is the Accessibility_Score. This is the score of what type of accessibility patients have to the providers. The accessibility score was the last output from the analyses. This field allows for the patients to see what type of competition they would have to see a provider of their choice using the Accessibilty_Score.

\subsection{Data Sources}

The data used for this project all came from the client's street data and census database, which came from an extension to ArcGIS Pro called Business Analyst. Business Analyst (BA) is annually updated demographic data, including nationwide business points, streets, drive-time solvers, address locators, shopping centers, and summary reports all in one extension.

Once the BA extension was ready for use, it was important to decide on the census geography and select the providers of interest. It was decided to use census block group level data instead of block data to reduce the numbers of service areas required, which is important for those who may consume credits to run the analysis online. There are 450 block groups in the study area.

To decide which data for the providers to use, the support documents through Esri had a list of franchises to choose from. Based on the information from that support site, the Standard Industrial Classification (SIC) code 801101 was chosen as it had the correct providers needed for the project. Figure 4-3 shows the code selection taken from the Esri support website. The highlighted codes are the providers this project was focusing on, and in the next section the franchise letters, $\mathrm{C}, \mathrm{H}$, and $\mathrm{N}$ were used for further data processing. 


\begin{tabular}{|lll|}
\hline 801101 & $\$$ & PAIN MANAGEMENT \\
801101 & A & ALLERGY \& IMMUNOLOGY \\
801101 & B & HEMATOLOGY \\
801101 & C & CARDIOLOGY \\
801101 & D & DERMATOLOGY \\
801101 & E & ENDOCRINOLOGY \\
801101 & F & FAMILY PRACTICE \\
801101 & G & GASTROENTEROLOGY \\
801101 & H & GENERAL PRACTICE \\
801101 & I & PROCTOLOGY \\
801101 & J & INFECTIOUS DISEASES \\
801101 & K & INTERNAL MEDICINE \\
801101 & L & NEPHROLOGY \\
801101 & M & NEUROLOGY \\
801101 & N & OB/GYN \\
801101 & O & ONCOLOGY \\
801101 & P & OPHTHALMOLOGY \\
801101 & Q & PATHOLOGY \\
\hline
\end{tabular}

Figure 4-3: SIC Codes List

Esri, using BA, had all the data necessary to use on the project. Once the data and the sources had been chosen for the project, scrubbing, and loading the data became possible. In the next section there will be examples of what the scrubbing looked like for this project and the steps necessary to make the data acceptable for the client.

\subsection{Data Scrubbing and Loading}

The data for this project did not have a lot of scrubbing and loading that needed to be done. It mainly had to be found, clipped to the correct extent, and created into new feature layers. To use the data, the Business Analyst license was needed and then there were two new feature layers that were created. One feature layer had the correct census data in it, for this project the census block group level was used. The other feature layer needed to contain the correct providers.

The process of editing feature datasets was first taking the data from an extension of ArcGIS Pro BA. From this, the features from the census data and facility data were found. After finding the correct data set, the census data was clipped to the area of Washington D.C and saved as its own layer. Once that data had been cleaned and organized, the network dataset was added to the geodatabase. This was also taken from BA, but it was found in the Route section of the data and this project used the North American Route which is called Route_ND.

Since only the total population was needed, the field called POP_C was chosen based off the description Esri gave it in the metadata. This can be seen in Figure 4-4. 
Providers were chosen by the SIC number that medical facilities are given, and then selecting the correct facility number by using the select layer by attribute geoprocessing tool.

\begin{tabular}{|c|c|c|c|c|c|c|c|c|c|c|c|c|}
\hline Field: & 国 & Selection: & oom To 是 Switch & Clear 㞔 & lete 宣 & py & & & & & & \\
\hline 4 OBJECTID & Shape & FIPS & STATE_NAME & ST_ABBREV & POP_C & $\mathrm{HH}_{-} \mathrm{C}$ & HU_C & BUS_C_CY & POP_W & HH_W & HU_W & POP_W_CY \\
\hline 1 & Point & 110010008014008 & District of Columbia & DC & 0 & 0 & 0 & 1 & 0 & 0 & 0 & 0 \\
\hline 2 & Point & 110010001001000 & District of Columbia & DC & 324 & 188 & 207 & 57 & 0.24125 & 0.263306 & 0.261034 & 0.24125 \\
\hline 3 & Point & 110010001001001 & District of Columbia & DC & 30 & 13 & 14 & 6 & 0.022338 & 0.018207 & 0.017654 & 0.022338 \\
\hline 4 & Point & 110010001001002 & District of Columbia & DC & 122 & 69 & 70 & 6 & 0.090841 & 0.096639 & 0.088272 & 0.090841 \\
\hline 5 & Point & 110010001001003 & District of Columbia & DC & 141 & 78 & 81 & 2 & 0.104989 & 0.109244 & 0.102144 & 0.104989 \\
\hline 6 & Point & 110010001001004 & District of Columbia & DC & 78 & 46 & 56 & 2 & 0.058079 & 0.064426 & 0.070618 & 0.058079 \\
\hline 7 & Point & 110010001001005 & District of Columbia & DC & 31 & 16 & 20 & 3 & 0.023083 & 0.022409 & 0.025221 & 0.023083 \\
\hline 8 & Point & 110010001001006 & District of Columbia & DC & 108 & 56 & 64 & 35 & 0.080417 & 0.078431 & 0.080706 & 0.080417 \\
\hline 9 & Point & 110010001001007 & District of Columbia & DC & 38 & 22 & 26 & 0 & 0.028295 & 0.030812 & 0.032787 & 0.028295 \\
\hline 10 & Point & 110010001001008 & District of Columbia & DC & 50 & 24 & 25 & 1 & 0.03723 & 0.033613 & 0.031526 & 0.03723 \\
\hline 11 & Point & 110010001001009 & District of Columbia & DC & 114 & 57 & 66 & 1 & 0.084885 & 0.079832 & 0.083228 & 0.084885 \\
\hline 12 & Point & 110010001001010 & District of Columbia & DC & 133 & 70 & 80 & 2 & 0.099032 & 0.098039 & 0.100883 & 0.099032 \\
\hline
\end{tabular}

Figure 4-4: Example of Census Data

After the new feature layers were created, all the data was clipped to Washington D.C. Once the data had been clipped, it was all added to the map and was able to be used in doing the analyses needed for the project.

The next part of the scrubbing happened to the provider data. It was vital to this project to add insurance information to each provider for the web application. It is important to state that this information was created for the purpose of completing this project. The data is not correct and should not be used as fact.

\subsection{Summary}

This chapter discussed the database requirements for the project. It gave descriptions and figures of a conceptual data model and a logical data model created for the client.

Conceptual data models are designed to demonstrate bigger picture components of the database for the project and the relationship between those components. This chapter showed how the design connected the concepts, the data, and the analysis through figure 4-1. Logical models are designed to display the data that was used in the project, what would be stored in the database, and how it would be stored. Once the conceptual and logical database models were described and displayed, the scrubbing and loading of the data was explained. This chapter was vital to the project to understand the data that was used, and how it was used to have a precise and usable database. 


\section{Chapter 5 - Implementation}

This chapter will discuss the analyses that were performed to complete this project. It will go over each step and have details regarding the processes and the tools used to execute what was required by the client. In this chapter, each section will discuss a different analysis. Section 5.1 will review Network Analyst and data preparation, what tools and processes were used to get the data ready for the analyses, and how the tools were selected for the project. Section 5.2 moves onto the Service Area tool and how it was vital for the analyses of this project. Section 5.3 dives into the more complicated of the analyses, the Two Step Floating catchment area method (2SFCA). Section 5.4 discusses the task that was required to be created for users to replicate the analyses. Section 5.5 explains the story map that was created for this project. Section 5.6 discusses the web application created for the client, how it was created, and how the application could be used. The chapter ends with a summary in section 5.7.

\subsection{Network Analyst and Data Preparation}

Network Analyst is an extension of ArcGIS Pro that can be obtained through a license and it can be used to determine routes and distances between locations using different tools. There are tools inside of the extension and some examples are: Route, Service Area, Closest Facility, Location-Allocation and Origin-Destination Cost Matrix. Figure 5-1 shows what it looks like in ArcGIS Pro on the ribbon at the top of the screen. In this project, only the Service Area tool was used. 


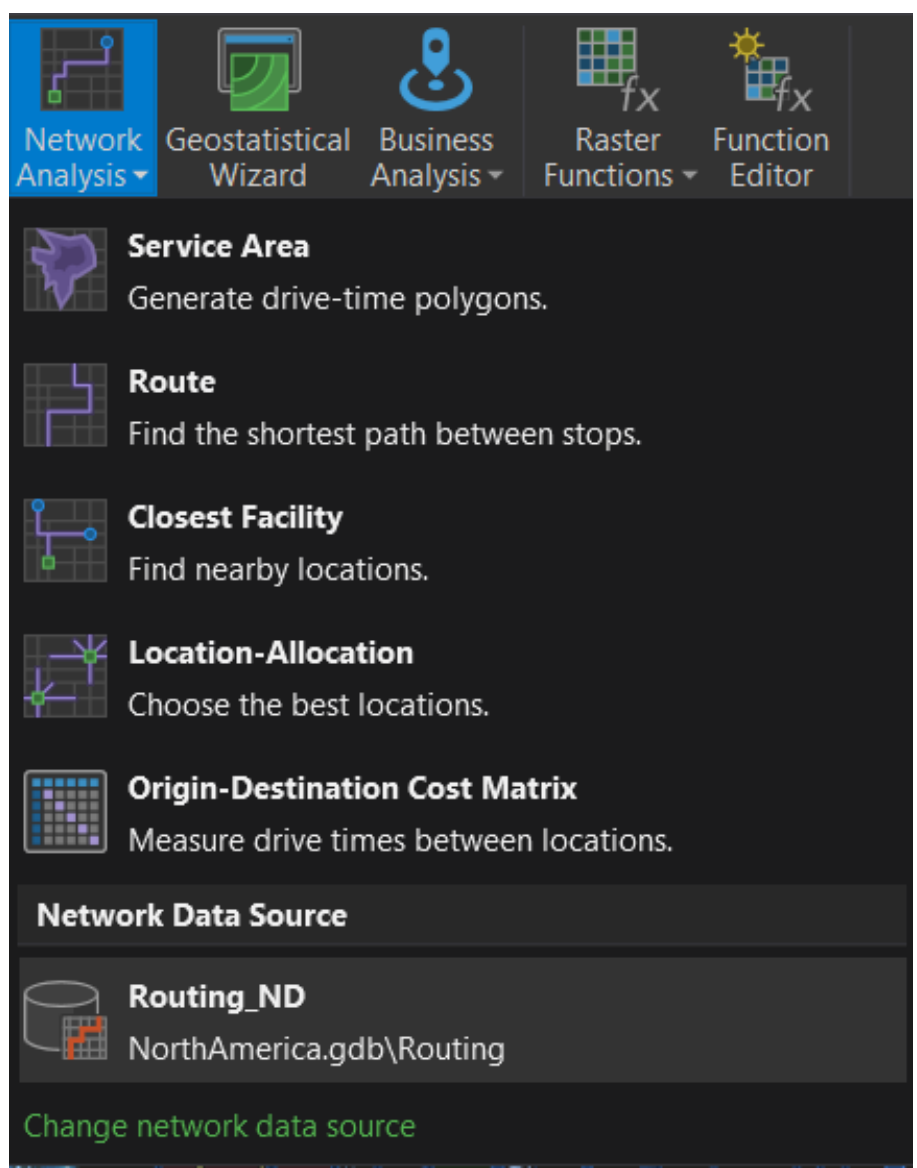

Figure 5-1: ArcGIS Pro Network Analyst Ribbon

The Business Analyst (BA)extension has a network dataset already created for the United States, which was used for the project, with the name Route_ND. Before running any of the tools in Network Analyst, it was vital to double check that the correct route was selected. If it were not, Esri credits would be consumed and if the user does not have enough credits, the tool will not run. If the user has a network dataset that has all the network information needed, the internal network dataset can be selected and used instead of the online network through ArcGIS Pro. A second important issue to note was that the output of the tools in Network Analyst did not match the coordinate system the current map was set to. The user will need to change the coordinate system once the analysis is complete. This is done by using the project geoprocessing tool.

After the network had been set up, preparing the data took place. It was imperative for this project to have insurance types for the providers and to have each provider's location. In the original data taken from BA, the data had every provider listed as a separate record and multiple providers may share the same locations. There were a total number of 506 providers. To get an accurate amount of locations that patients could travel to, the providers' who shared the same locations had to be combined. To aggregate all the locations to the same point, each provider was first given a XY location, based on which all providers were dissolved into distinctive points, resulting in a total number of 172 facility locations. Once the 172 points were created, a new field was created called FacilityIDLocation. This was created so that each provider had their own unique ID for 
their location. The 172 points were then joined to the provider layer through a spatial join with "identical to" as the spatial relationship. Once the spatial join was complete, each provider in the provider feature class had the corresponding FacilityIDLocation value assigned. Then the provider feature class was dissolved one more time by using the FacilityLocationID and the DetailedSpec (Detailed Specialty). In doing so, the count of each type of providers at the same location was calculated through "dissolve", and this count field was the renamed to Capacity to make it more self-explanatory. The final output Original_Provider_Locations contains 205 distinct providers by location and specialty. This means some facility locations have multiple categories of providers and each category of providers is treated as a distinct provider.

The last step of the data preparation was to add five new fields to each provider location that were for mock insurance acceptance. Figure 5-2 shows the edits that were made to the provider table.

\begin{tabular}{|c|c|c|c|c|c|c|c|}
\hline$\checkmark$ & $\square$ & BlueShield & BS & Short & $\checkmark$ & $\square$ & Numeric \\
\hline$\checkmark$ & $\square$ & UnitedHealthCare & UHC & Short & $\checkmark$ & $\square$ & Numeric \\
\hline$\checkmark$ & $\square$ & Medicare & MCare & Short & $\checkmark$ & $\square$ & Numeric \\
\hline$\checkmark$ & $\square$ & Medicaid & MCaid & Short & $\checkmark$ & $\square$ & Numeric \\
\hline$\checkmark$ & $\square$ & Aetna & Aetna & Short & $\checkmark$ & $\square$ & Numeric \\
\hline
\end{tabular}

Figure 5-2: Added Insurance to Providers table

The different insurance options were given a random number of 0 or 1;0 meaning that the office at that location did not accept the patient's insurance, and 1 meaning that they did accept the patient's insurance. Figure 5-3 shows the code used to calculate each field to get the random number of 0 or 1 . 


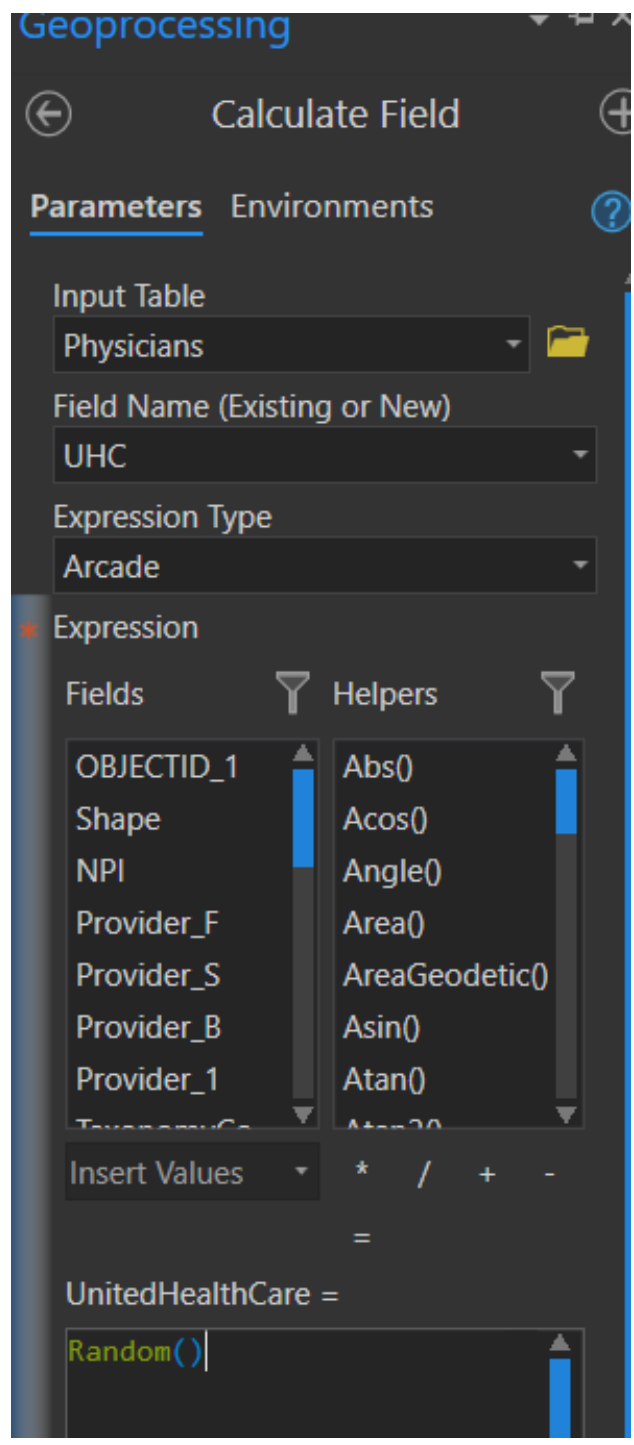

Figure 5-3: Calculation used to get a random number

The data was now prepared and ready to use for analyses.

\subsection{Calculating Catchment Area}

The second analysis in this project was using the Service Area tool through the Network Analyst extension to calculate the catchment areas. A catchment area refers to a travel zone with a time or distance threshold, which is equivalent to the concept of service area in Network Analyst. To use the service area tool, the user inputs the "Facilities" which in this project were the providers with a unique combination of location and specialty. Once the user inputs the providers into the tool, the next step is to choose the drive time cutoff. In this project the times of 5, 10, and 15 minutes were chosen. Figure 5-4 shows an example of what the analysis tool bar looks like as well as the different options that were available. 


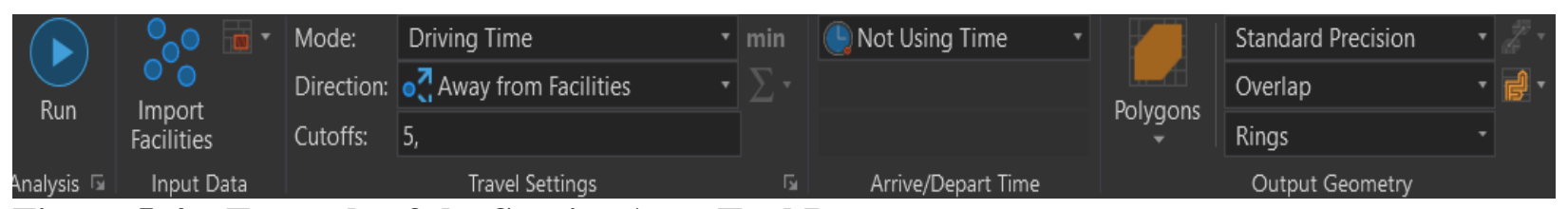

Figure 5-4: Example of the Service Area Tool Bar

Once the tool was run, one of the outputs was polygons, representing the service area for each provider given the 5-minute drive time which was chosen by the user. Using this service area polygon layer, providers would be able to see which patients live within the catchment area and know whether their office was meeting the network adequacy requirements.

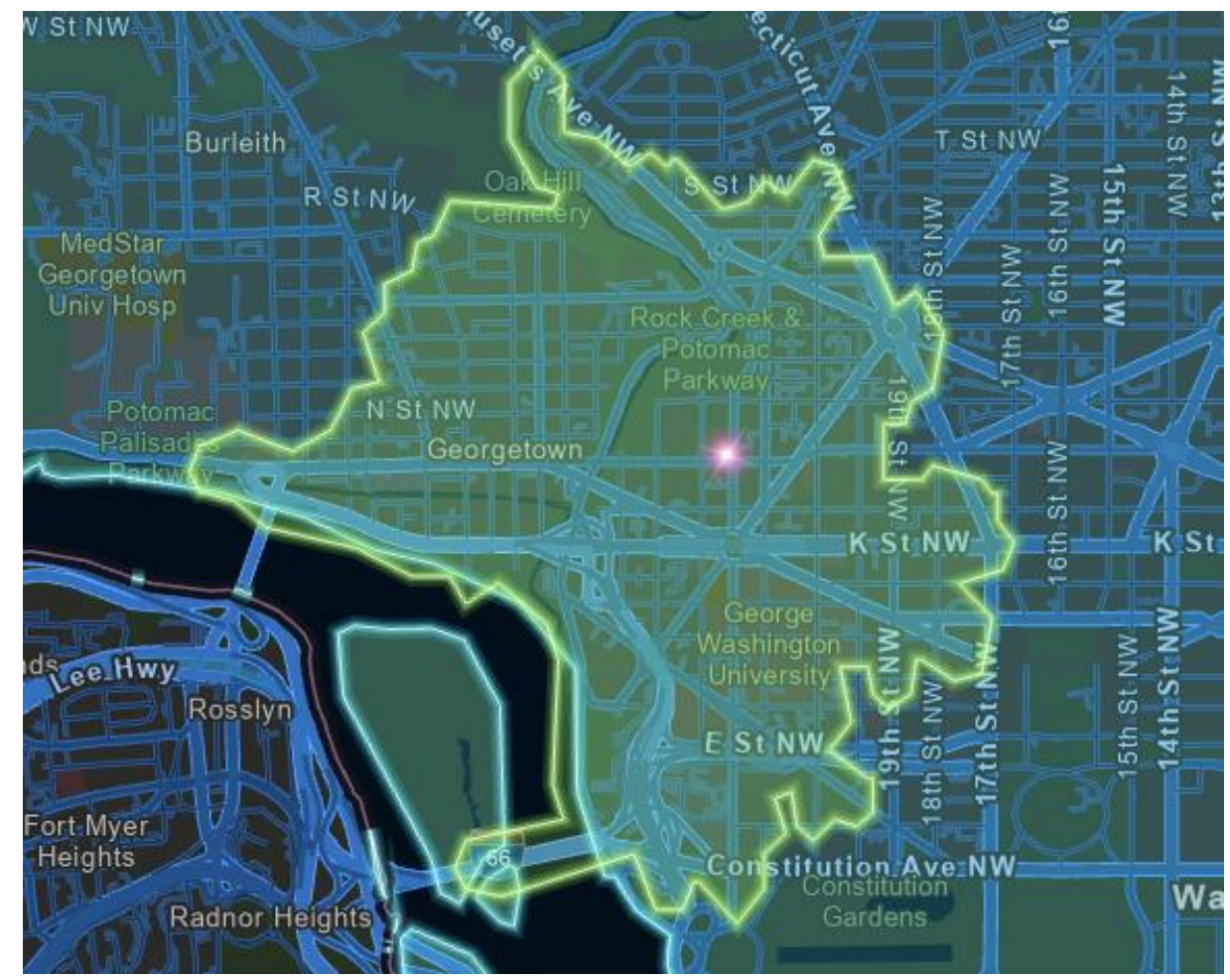

Figure 5-5: A Five-Minute Service Area

Figure 5-5 shows the results of a 5-minute drive time polygon for a Kaiser Permanente location in Washington D.C. The Service Area tool proved to be a very powerful, straightforward, and simple tool to use. Using this tool helped leap into the two-step floating catchment area method and gave this project a great way to not only run the analyses needed, but also provided a way to show the results in a universal method.

\subsection{Two-Step Floating Catchment Area (2SFCA)}

The next step of analyses was to implement the 2SFCA. This method was discussed in Chapter 2 and had two main steps that needed to be addressed in the analysis. The first 
step was to get the provider-to-population ratio within the specific catchment area, which was the drive time of 5, 10, or 15 minutes. The second step of this process was to calculate the patient accessibility score by summing up the provider-to-population ratio of the providers that fall in their travel zone. This essentially means that the outcome of running the 2SFCA method will include two components; it will allow providers to see how accessible they are to the patients in their area, and it will allow patients to see which providers they will likely be able to see.

To start the process, the first step was to change the coordinate system of the providers and the census block groups because the original data were in the geographic coordinate system. The coordinate system that was chosen was the NAD 1983 State Plane Maryland FIPS 1900 (meters) which was based on the information given by Esri on their ArcGIS REST API. The importance of having the correct coordinate system at the start was to make sure all the polygons and lines of the project lined up correctly. If each feature layer in the project was to be in a different coordinate system, that would cause issues in the data output and could give false results.

Once all the data layers were in the correct coordinate system, the next step was to run a Service Area analyses for the providers with a 5-minute drive time. This created a new feature layer that had 205 service area polygons and was named Service_Area_Providers_5mins. Then the new layer was projected into the correct coordinate system using the Project tool and then the name was changed to Service_Area_Providers_5mins_FIPS. The next step was to spatially join the census block group layer to the projected service area polygons. In doing so, the total population (POP_C) that fall in the same service area can be summarized using the "sum" function (Figure 5-6). 


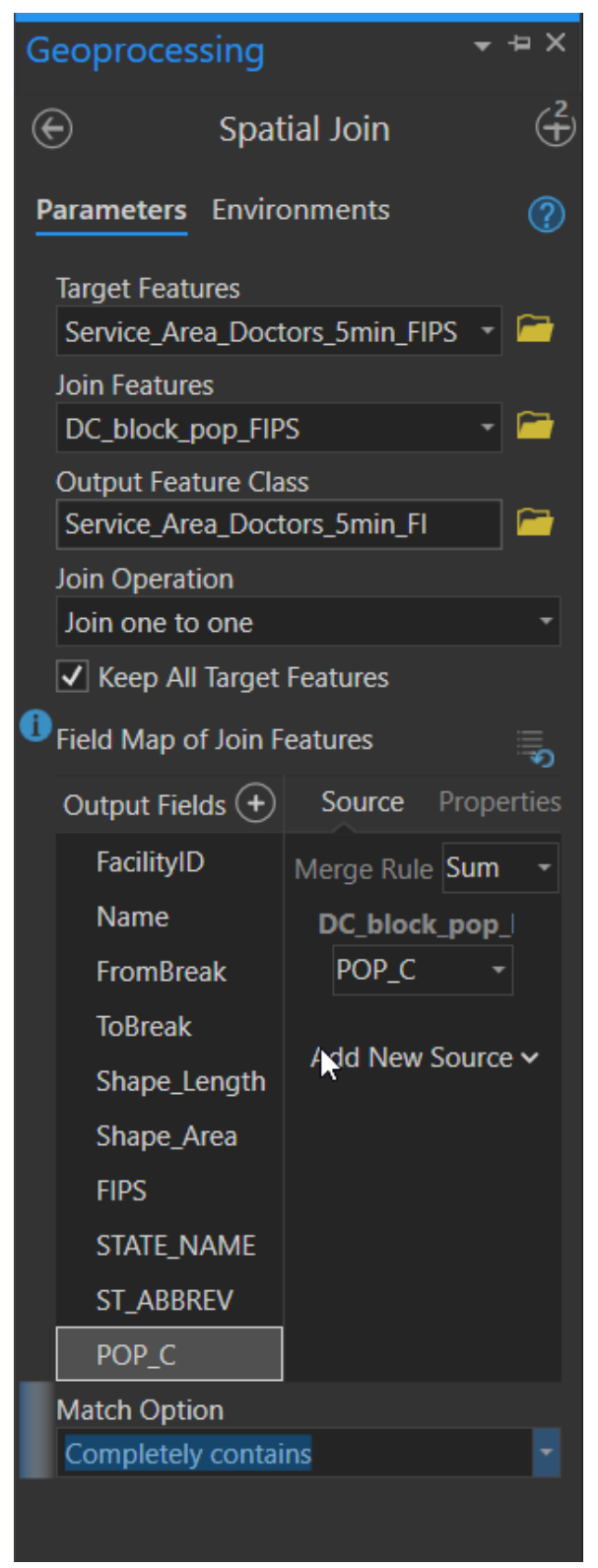

\section{Figure 5-6: Example of spatial join}

Once the spatial join was completed, the fields of the feature layer were edited. This was done so that unwanted fields were not showing up in the attribute table. It was important to keep the table as clean as possible with only the necessary fields in it. Figure 5-7 shows the edits that were made to the Service_Area_5mins_FIPS attribute table. The POP_C field name was changed to Sum_Block_Pop with the alias of Sum and the field Pro_to_Pop was created with the alias of ProToPop. 


\begin{tabular}{|c|c|c|c|c|c|c|c|c|}
\hline Field Name & Alias & Data Type & $\checkmark$ Allow NULL & Highlight & Number Format & Domain & Default & Length \\
\hline OBJECTID & OBJECTID & Object ID & $\square$ & $\square$ & Numeric & & & \\
\hline Shape & Shape & Geometry & $\checkmark$ & $\square$ & & & & \\
\hline Join_Count & Join_Count & Long & $\checkmark$ & $\square$ & Numeric & & & \\
\hline TARGET_FID & TARGET_FID & Long & $\sqrt{ }$ & $\square$ & Numeric & & & \\
\hline FacilityID & FacilityID & Long & $\checkmark$ & $\square$ & Numeric & & & \\
\hline Name & Name & Text & $\checkmark$ & $\square$ & & & & 1024 \\
\hline Sum_Block_Pop & Sum & Double & $\checkmark$ & $\square$ & Numeric & & & \\
\hline Shape_Length & Shape_Length & Double & $\checkmark$ & $\square$ & Numeric & & & \\
\hline Shape_Area & Shape_Area & Double & $\checkmark$ & $\square$ & Numeric & & & \\
\hline Pro_to_Pop & ProToPop & Double & $\checkmark$ & $\square$ & & & & \\
\hline
\end{tabular}

Figure 5-7: Example of adding ProToPop field

A tabular join was done to join the Service_Area_5mins_FIPS back to the original provider layer because the calculation of the ProToPop field needed to use the Capacity attribute. Once the tabular join was exported into a new layer (tabular joins are temporary), the ProToPop field was calculated by dividing the Capacity by the Sum_Block_Pop. The ProToPop shows the ratio between capacity of a provider and the population in its catchment area. A higher ratio means patients in the catchment area have less competition to receive the service; or availability of the providers is higher.

Figure 5-8 shows the workflow of each step that takes place in the first step of the analysis for the 2SFCA method. 


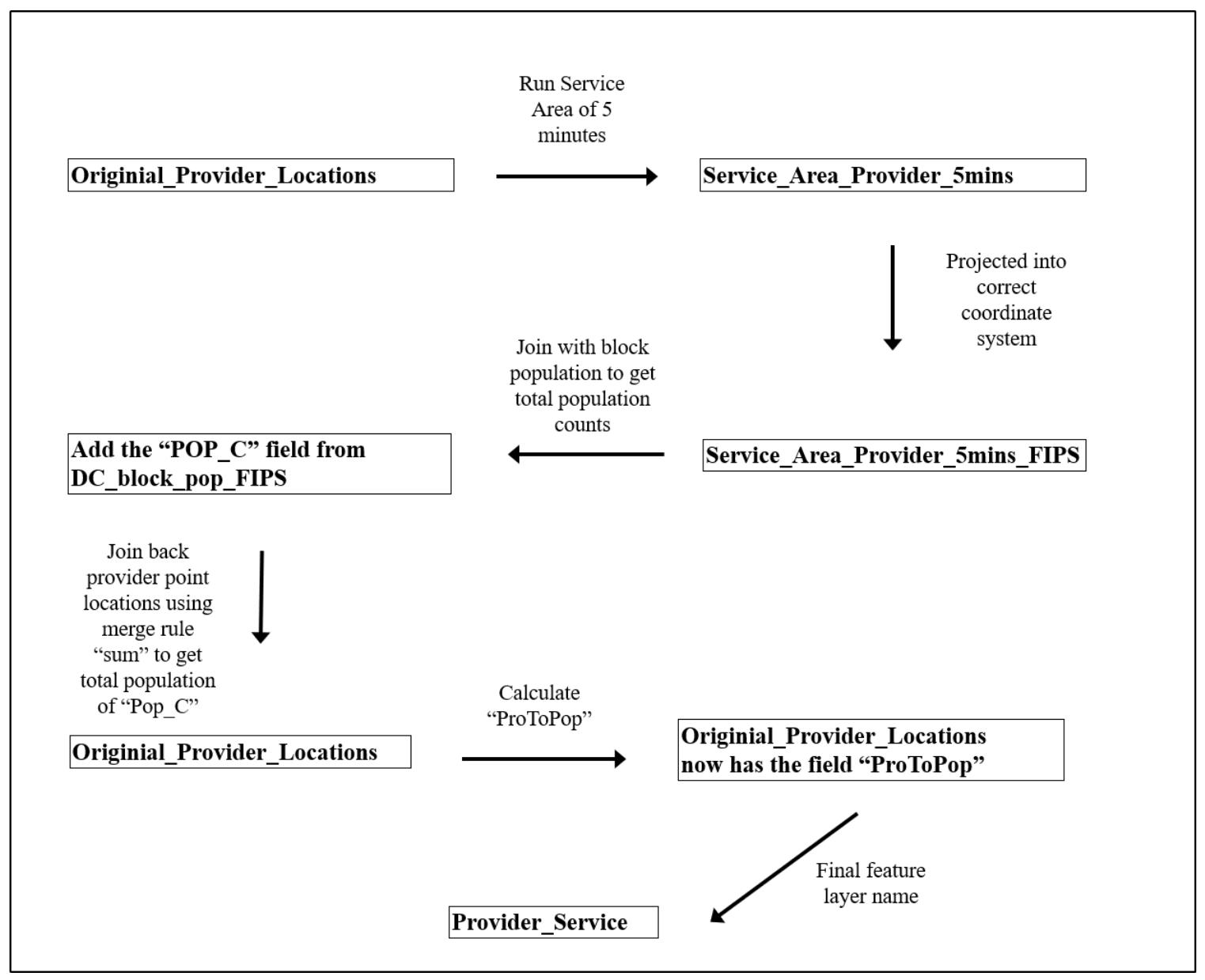

Figure 5-8: Step 1 of the 2SFCA Method Workflow

The second step of the 2SFCA method was very similar to the first step in terms of calculating the 5-miniute service area polygons. But in the second step, the service areas were created based on the patient locations. Since the real data of patients was not available, the centroids of the census block groups were used as possible patient locations in this analysis. Therefore, the input for the facilities was, DC_block_pop_FIPS, and the service area result was called TravelAreaPatients. Once the tool ran, the polygons were exported into a new layer, and then projected into the right coordinate systems. This new layer was named TravelBlockGroups_5Mins_FIPS. To obtain the sum of provider-topopulation ratios for each polygon, a spatial join was undertaken (Figure 5-6). In Figure 5-9 it is important to note the "providertopopulation" was later changed to ProToPop and that was the final name for the field. This operation identified all the providers that fall in each service area of a population center and summarized the individual provider-topopulation ratios. 


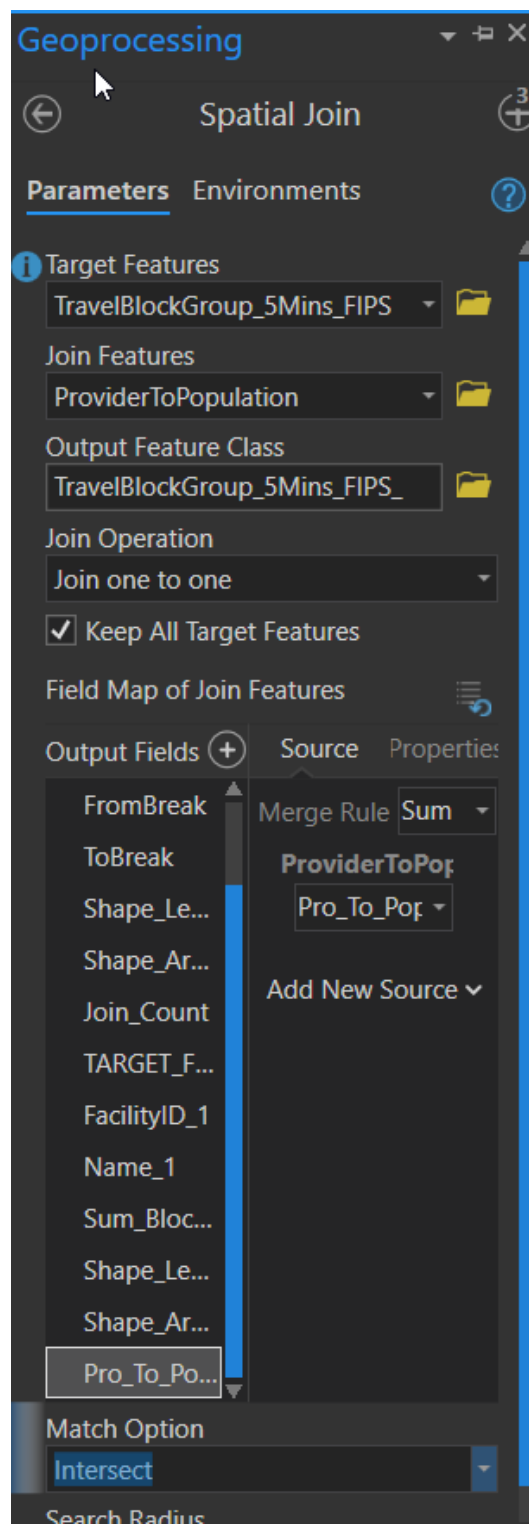

Figure 5-9: Spatial join for second step of 2SFCA method

Another tabular join was taken to join the TravelBlockGroups_5Mins_FIPS back to the original census block group centroids layer (or the patient data if used). This allowed for the accessibility score to be added to the patient/population point data for the mapping purpose. The joined layer was then exported as the final patient/population layer named "Patient_Accessibility".

Figure 5-10 shows the workflow of the second step of the 2SFCA method. It is like figure 5-8 with the main differences being in the feature layers and classes that were chosen to be analyzed. 


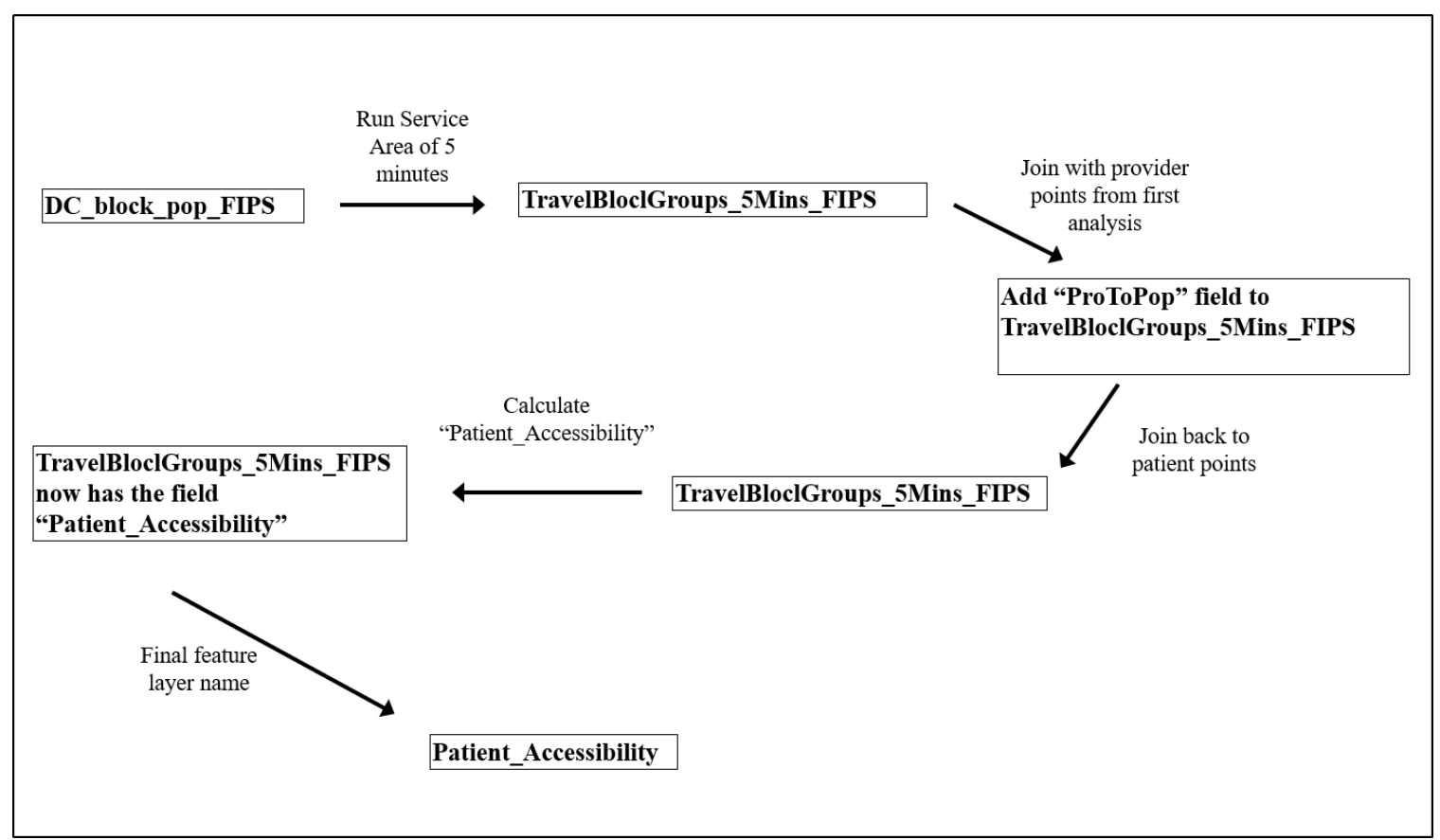

Figure 5-10: Step 2 of the 2SFCA Method Workflow

The names of the feature layers were changed after this section of the analyses was done so that the names would be more straightforward to a user and to the client. In Figure 5-11 the diagram shows the original names to the changed names of the feature layers that were used in the rest of the project. 


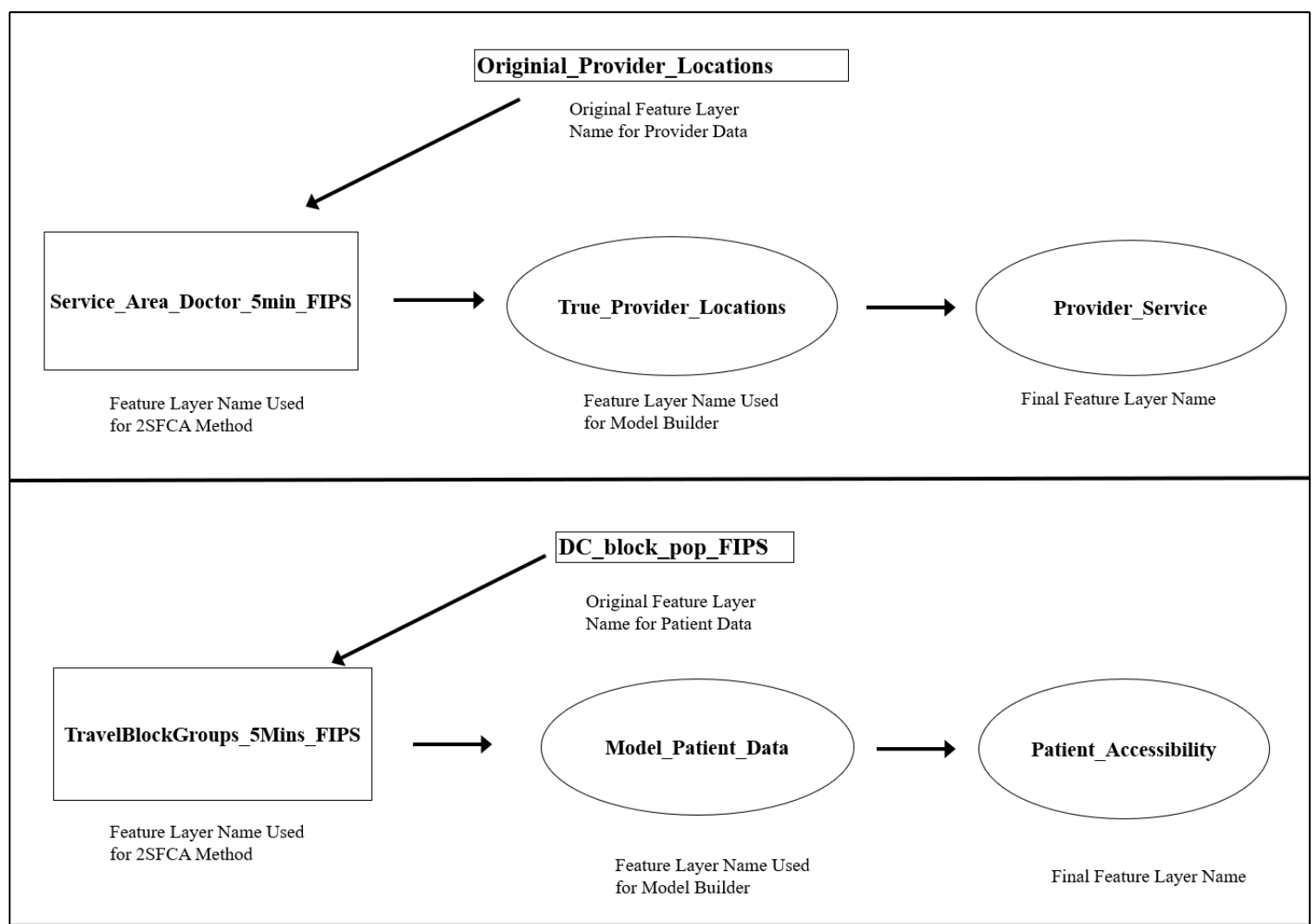

Figure 5-11: Feature Layer Name Changes

The feature layers that are in the rectangles are the original layer names of the data before any analyses was done on them. Those layers were then given new names to be used in model builder which helped create the tasks for the client (True_Provider_Locations and Model_Patient_Data). The final ovals in Figure 5-11 shows the final feature layer names that were given to the client that had the final fields of ProToPop and Patient_Accessibility.

\subsection{Creating Tasks for Users}

Section 5.3 explained the process involved in the 2SFCA analysis. To make this process repeatable for other datasets, a task was developed in ArcGIS Pro to streamline the workflow. The task feature is a tool that creates a workflow that can be used by any end user. To create this task for this project, ModelBuilder was used to first create the workflow. Figure 5-10 it shows a part of the models that were used for the task. In Appendix A the full models can be viewed. 


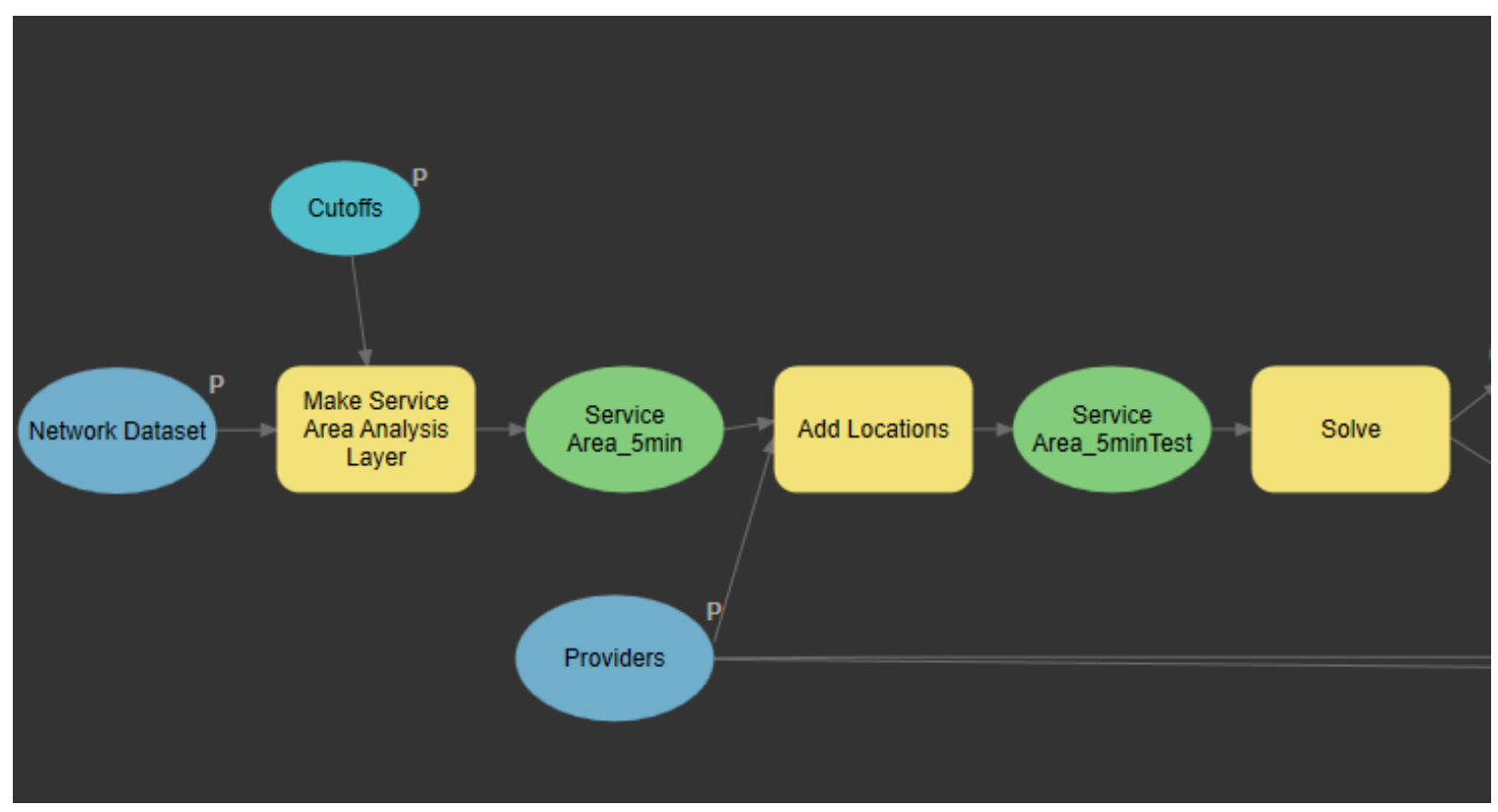

Figure 5-10: Example of ModelBuilder

Once the model was completed, it could be added into the task steps for the client to use. The task had two steps that followed the 2SFCA method. The first step ran the analysis on the providers to get their service area and the provider to population ratio that they serve, and the second step focused on the patients and what their provider accessibility score was. An important note about the model builder and tasks is that the feature layer names in the tasks are different than the data used in the first analyses. Each feature layer was taken from the original geodatabase, copied, and given new names. This allowed for testing of the model builder and tasks to happen without affecting or editing the final data from the 2SFCA analysis. Figure 5-11 shows the interface of the task. The full task will be shown with the model in Appendix A. 


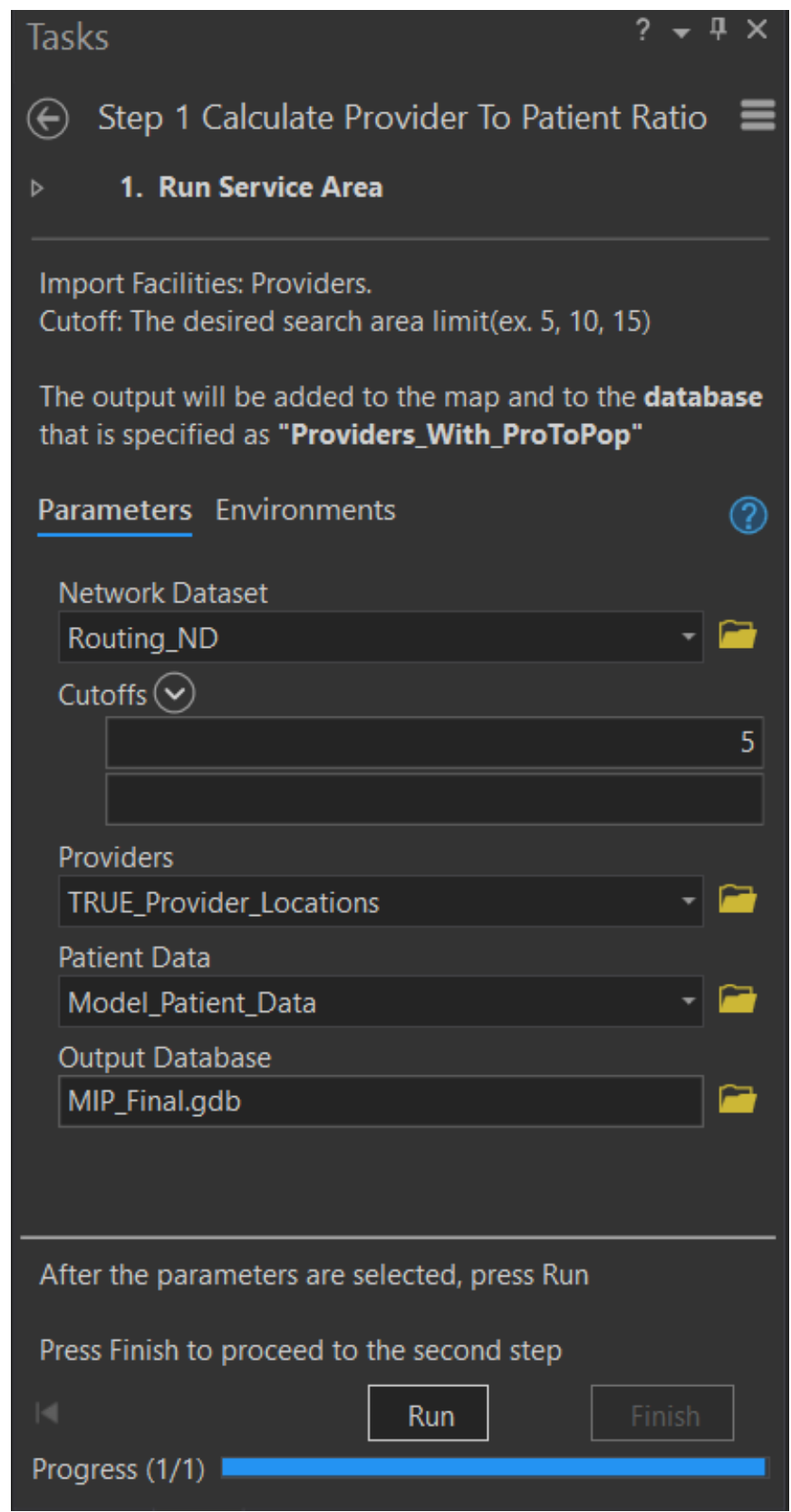

\section{Figure 5-11: Example of first task}

To transfer the model into a task, there is a tool when creating the tasks that records the process of a geoprocessing tool. This is done by selecting to record, and then selecting the model that was created for the task. It is then input into the task and the creator of the task can edit each step. It is intuitive to edit and the creator can add information about each step so the user can understand what is need for the task to run successfully. 


\subsection{Developing a Story Map}

The story map for this project was created to show the client and other users what process was done to get the results. Story Maps are a form of presentation that a user can create through ArcGIS Online. It allows the user to present the information they have in the form of an interactive story. The story map that was created for this project explained how the 2SFCA method could improve network adequacy in the health field. It used a template called the sidecar, which allowed for the reader to explore the tools used as well as the maps created. Specifically, the user was able to explore the accessibility distribution in the study area and use the web application to obtain network adequacy measures. In Appendix B, the link for the story map as well as snap shots of the story map can be found.

Once the story map was completed, it was published publicly for the client to use and share to show the process that had been taken to meet the requirements given.

\subsection{Web Application}

The web application needed a geoprocessing tool with which the patients can search for what type of provider they wanted and if that provider accepted their insurance. The geoprocessing tool was created in ArcGIS Pro by using ModelBuilder.

However, there was an issue with publishing the geoprocessing tool to ArcGIS online due to using the network analyst extension in ArcGIS Pro. This meant that the geoprocessing tool could not be published online. Due to this limitation, a widget called Near Me on WebApp Builder was used instead, as it could run what the unpublishable geoprocessing tool was created to do.

The web application had three main widgets attached to it along with an interactive map. The widgets that were used were: Business Analyst, Directions, and Near Me. In this application the Business Analyst widget allows for the user to get infographics and reports based on the area the user has selected. This can show them information from census data, to health care, to income, and so much more. It allows the user to choose an address or place, the travel range (ex. 10 miles around the chosen location), drive time or walk time, and if the user wants the infographic reports. Lastly the user chooses what type of report they want from a preconditioned list (ex. commute profile, demographic summary, etc.). Figure 5-12 is an example of the infographic report a user could download if they were interested in healthcare and insurance in their area. 


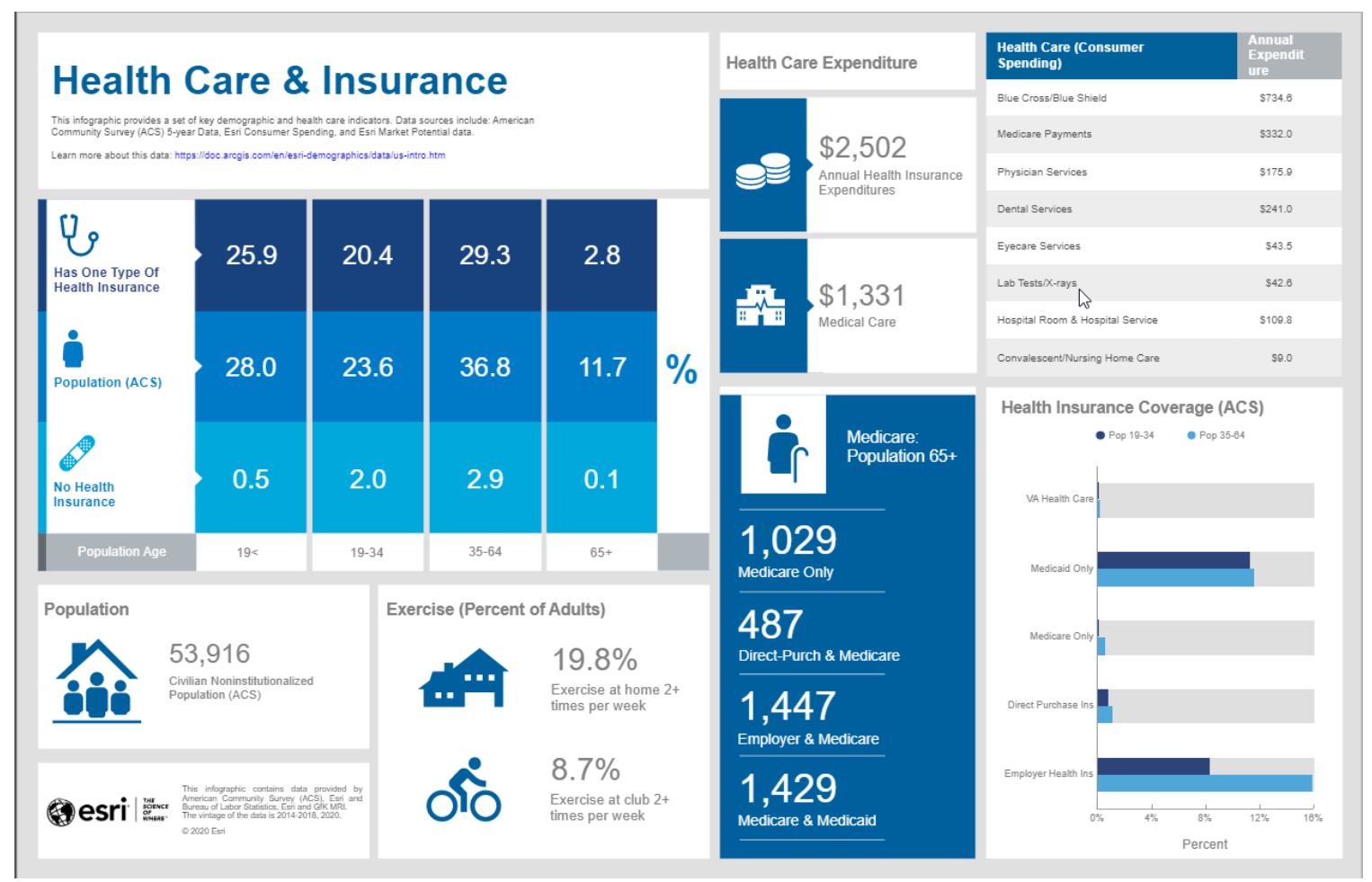

Figure 5-12: Example of Business Analyst widget

The second widget that was used was Directions. This widget allows the user to choose any point on the map and get directions to or from that point. Figure 5-13 is an example of what a user could query. It shows the user starting at point 1 and driving to point 2 . The output gives the directions along with how long it would take to get there. 


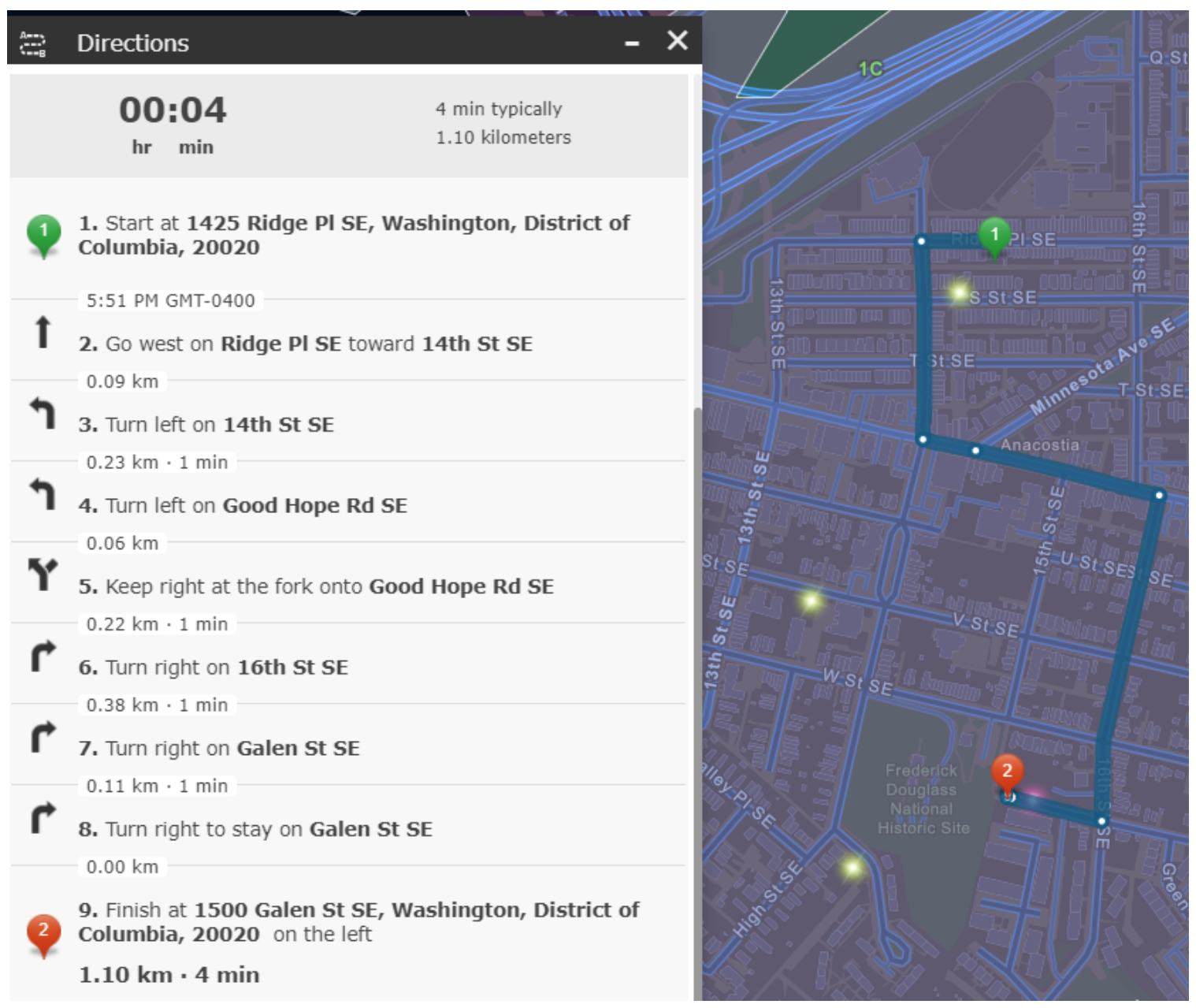

Figure 5-13: Example of directions from WebApp Builder

The third widget that was used was called Near Me, which can be edited and configured to have the information the creator wants in it. For this project it needed to have providers, insurance type, and an option to choose mileage. The widget allowed for users to successfully complete each of these steps:

- Choose mileage they were willing to travel

○ Example: 5 - 10 miles

- Choose which type of provider they want to see

- Example: Cardiologist

- Choose which insurance type the chosen provider needs to accept

○ Example: Medicare

- Generate a drive time report from the location of the user's choice

$\circ$ Example: The user can pinpoint their exact location and get travel time and directions to the provider's office they choose.

The web application and the widgets used were all necessary to prove the power of using GIS in combination with the health field. It showed the user that something complicated like finding a provider who will accept their insurance and is in network with them, can be put into an online program so they can find that information with ease. One main goal of this project was to create an application to not only make the providers' 
offices more efficient with generating network adequacy reports, but it was to create proof that GIS can also greatly improve patient's lives and accessibility to their healthcare. The web application allows for users to experience efficiency and ease of access.

Once all the widgets were tested and proved to work, the web application was published and added to the story map. The story map was then provided to the client to complete the requirements of this project. The web application can be further explored in Appendix $\mathrm{C}$, which also has a link that takes the read to the published application.

\subsection{Summary}

This chapter discussed the analyses that were performed in this project. The project had two main analyses: Service Area and 2SFCA. This chapter dove into each of the analysis types, explained what they are, how they were used and how each tool was connected to this project. Once the explanation of the analyses had been discussed, the implementation of the task and what was needed for it to be successful was discussed. After the task was explored, the creation of the story map was introduced and explained. Lastly, the web application development was explored, what widgets were added to it, how the geoprocessing tool was created, the fact that the tool did not work and how that was addressed, and the final output of the web application. In Chapter 6, the final output is displayed and presented for each analysis. 


\section{Chapter 6 - Results and Analysis}

This chapter will describe the results and analysis for this project. The client, Esri, had a goal to show that network adequacy could be improved through Esri developed GIS technologies. Specifically, the client wanted to obtain a story map that can show the streamlined data analysis processes, proving that Esri technologies can improve network adequacy for healthcare providers. The results of the analyses and the story map will be discussed in this chapter and discussed in detail as to what was successful and what had to be reevaluated or dismissed. In section 6.1, the results of the 2SFCA for network adequacy will be described, section 6.2 demonstrates the task that was created for the client to use to test on their own data, section 6.3 will dive into the process of making the story map and what was included, section 6.4 will explain the web application and the widgets used and edited to create the tools necessary for users, and section 6.5 will summarize this chapter.

\subsection{Network Analysis using the 2SFCA Results}

This project focused on using network analysis in combination with the 2SFCA method to show that GIS can help improve network adequacy for both provider and patient. Using Esri software, ArcGIS Pro, this analysis was made simpler and was proven to work successfully. The client wanted to create a way for regulators and providers to see that GIS can help with network adequacy, and this project showed that it does help significantly. Figure 6-1 shows the spatial accessibility map focusing on 1 of the 450 census block groups. 


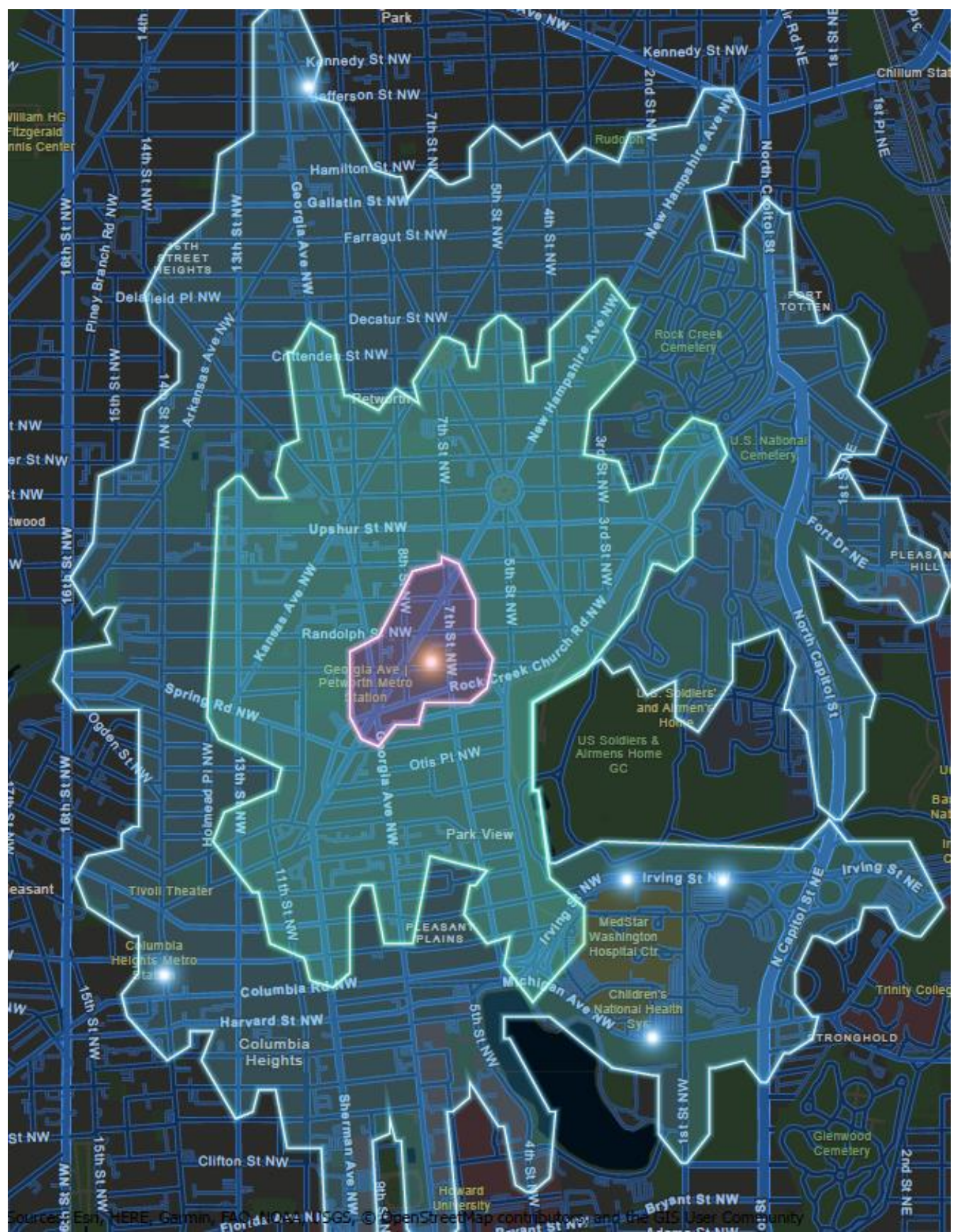

Figure 6-1: Patient Accessibility at Different Time Thresholds

The map shows the accessibility that one census block group has to OB/GYNs. There are three different travel time polygons, the smallest being one minute, the middle being three minutes and the largest being five minutes. The patients who are located at this population center have no access to OB/GYNs within 1-minute and 3-minutes travel zones. There are five provider options and four locations in the 5-minute travel zone. If the patients want to compare the availability among these providers, they can look at the attribute table of the provider layer. This example is under the impression that everything 
runs smoothly for the patient to get to the desired provider location, meaning there is nothing slowing down the travel time.

Figure 6-2 shows the patient accessibility results in all of Washington D.C. This shows which census block groups have good accessibility to the providers. This example has a patient accessibility to Cardiologists. The larger circles mean that the providers have high availability there, meaning that the patients will have less competition to be seen there.

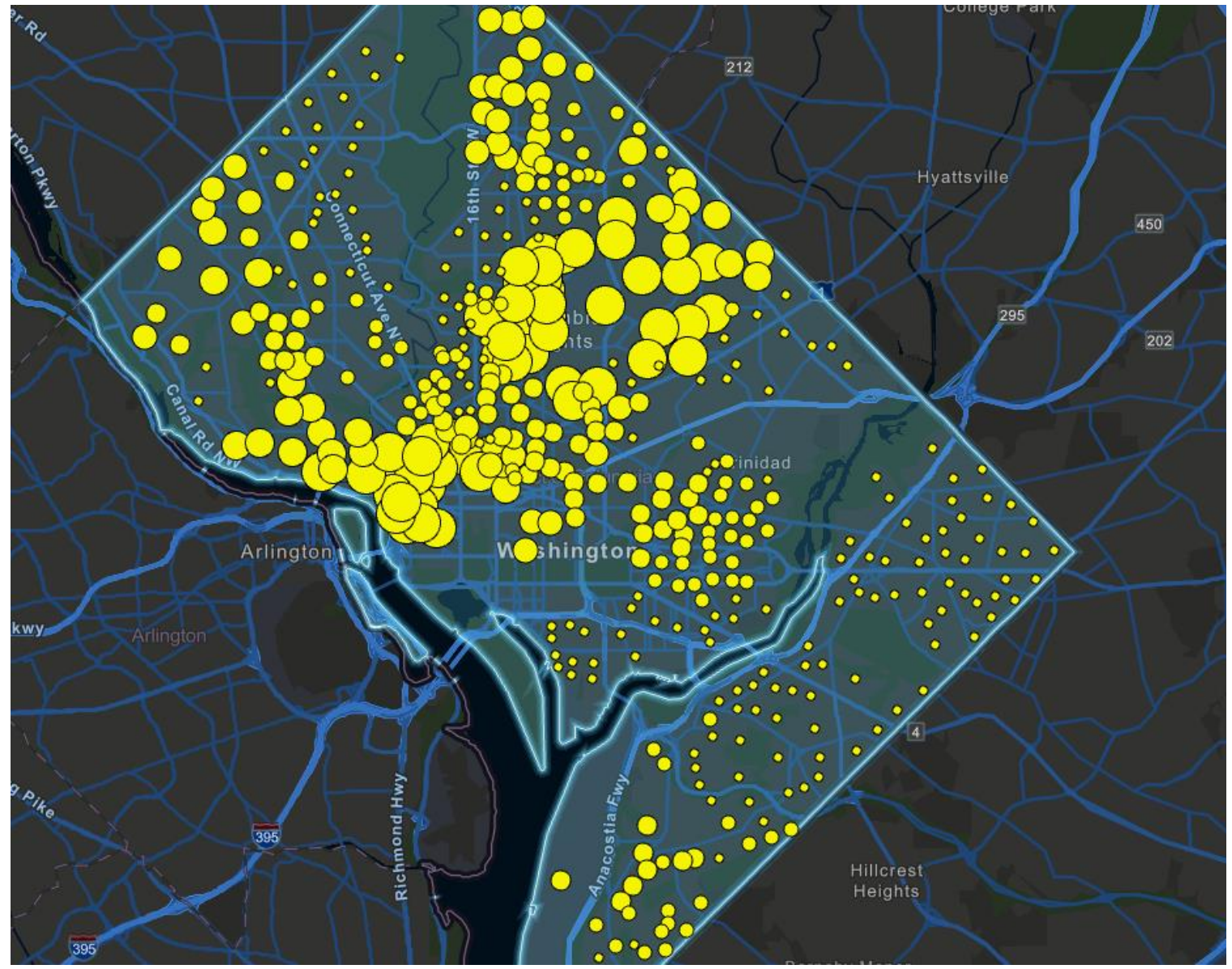

Figure 6-2: Patient Accessibility Example

Figure 6-3 shows the information of the patient accessibility to the cardiologists. The 2019 Total population indicates how many people live within 5-minute catchment area of these providers and the last attribute "Accessibility Score" shows its ratio of capacity to the population. The higher accessibility is, the greater the doctor availability is. In this example below, it shows how many providers are available to each block group location. For the patients at OBJECTID1, they have a low accessibility score to the cardiologists in that catchment area, this could encourage them to travel outside of the 5-minute catchment area if they need to be seen by a cardiologist quickly. 


\begin{tabular}{|c|c|c|c|c|c|c|c|}
\hline$\triangle$ OBJECTID & Shape & ID & NAME & 2019 Total Population & DetailedSp & Capacity & Accessibility \\
\hline 1 & Point & 110010001001 & 110010001.001 & 1449 & Cardiovascular Disease & 9 & 0.000374 \\
\hline 2 & Point & 110010001002 & 110010001.002 & 1504 & Cardiovascular Disease & 25 & 0.00081 \\
\hline 3 & Point & 110010001003 & 110010001.003 & 1249 & Cardiovascular Disease & 11 & 0.000447 \\
\hline 4 & Point & 110010001004 & 110010001.004 & 1168 & Cardiovascular Disease & 26 & 0.000858 \\
\hline 5 & Point & 110010002011 & 110010002.011 & 3907 & Cardiovascular Disease & 9 & 0.000374 \\
\hline 6 & Point & 110010002021 & 110010002.021 & 1259 & Cardiovascular Disease & 9 & 0.000374 \\
\hline 7 & Point & 110010002022 & 110010002.022 & 854 & Cardiovascular Disease & 9 & 0.000374 \\
\hline 8 & Point & 110010002023 & 110010002.023 & 1221 & Cardiovascular Disease & 9 & 0.000374 \\
\hline 9 & Point & 110010002024 & 110010002.024 & 2536 & Cardiovascular Disease & 31 & 0.001095 \\
\hline 10 & Point & 110010003001 & 110010003.001 & 1330 & Cardiovascular Disease & 9 & 0.000374 \\
\hline 11 & Point & 110010003002 & 110010003.002 & 1588 & No Provider Available & 0 & 0 \\
\hline
\end{tabular}

\section{Figure 6-3: Patient Accessibility Table Example}

Providers can look at their service area to patients using the same technique. In Figure 6-4 the map shows the providers locations and their service areas. The bigger the circle, the larger the population they reach. This could help provider see where they have high competition and where they have underserved areas. The map shows all provider types and all locations in Washington D.C. 


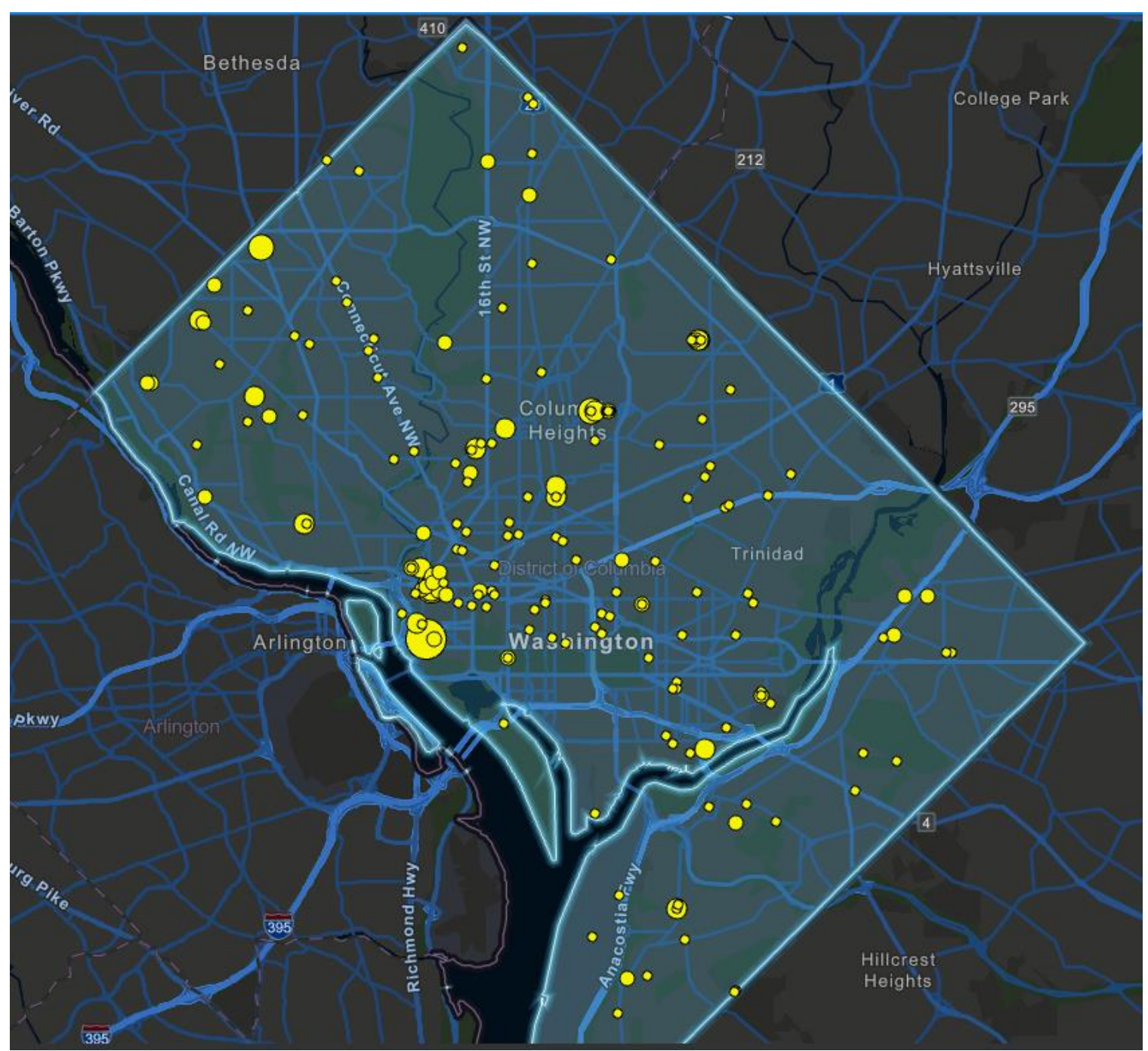

\section{Figure 6-4: Provider Service Area}

Figure 6-5 is part of the attribute table that helps explain the points on the map in Figure 6-4. It is very similar to the patient accessibility. The 2019 Total Population shows the census block group that the providers serve in a 5-miute travel time. The capacity shows how many providers of that specialty are at that location, and the ProToPop shows the providers accessibility to the patients in the catchment area.

\begin{tabular}{|c|c|c|c|c|c|c|}
\hline OBJECTID_1 & Shape & DetailedSp & FacilityLocationID & Capacity & 2019 Total Population & Provider to Population Ratio \\
\hline 1 & Point & Family Medicine & 1 & 1 & 15916 & 0.000063 \\
\hline 2 & Point & General Practice & 1 & 1 & 15916 & 0.000063 \\
\hline 3 & Point & Cardiovascular Disease & 2 & 2 & 26667 & 0.000075 \\
\hline 4 & Point & Family Medicine & 3 & 1 & 25433 & 0.000039 \\
\hline 5 & Point & Family Medicine & 4 & 6 & 29082 & 0.000206 \\
\hline 6 & Point & Cardiovascular Disease & 5 & 1 & 12420 & 0.000081 \\
\hline 7 & Point & General Practice & 6 & 2 & 27458 & 0.000073 \\
\hline 8 & Point & Cardiovascular Disease & 7 & 1 & 13544 & 0.000074 \\
\hline 9 & Point & Family Medicine & 8 & 1 & 17811 & 0.000056 \\
\hline 10 & Point & General Practice & 9 & 1 & 23773 & 0.000042 \\
\hline
\end{tabular}

Figure 6-5: Provider Service Area Table 
In summary, this project demonstrates that Network Analyst is helpful in finding the service areas for providers and the accessibility for patients. This tool could also be used by medical offices to find out which patients they are serving within the travel time required by the state and other regulators. If the provider facilities interested in improving network adequacy owned Esri software, they could quickly run the analysis to save time and eventually money to send out the reports that were discussed in Chapter 1.

\subsection{Using Working Tasks}

Although this project was able to complete the analysis and arrive at the results it was hoping for, it was important to show the client that it was possible for someone without a GIS background to perform the analysis. Therefore, the task was created in ArcGIS Pro to incorporate the two steps. The first step was doing the first part of the analysis that was shown in Chapter 5, and the second step was completing the calculation of the accessibility scores. It is important for the user to have the right fields in their data for the tasks to run correctly. Below there is a key for the attributes that the user needs have in their data.

- Provider Table:

- Capacity: the number of providers of a particular type at each location

- LocationID

○ Specialty

- Insurance $=0$ if the location does not accept the insurance, 1 if the location does accept it.

- Patient Table:

○ Population $=$ this is the most important field for this table. It is used to calculate the provider to population field which has the field name of ProToPop.

Table 3 shows the attribute table headings for both provider and population layers. This table shows only examples of what attributes should be in the users data in order to use the task created. 
Table 3. Attributes Used in Tasks

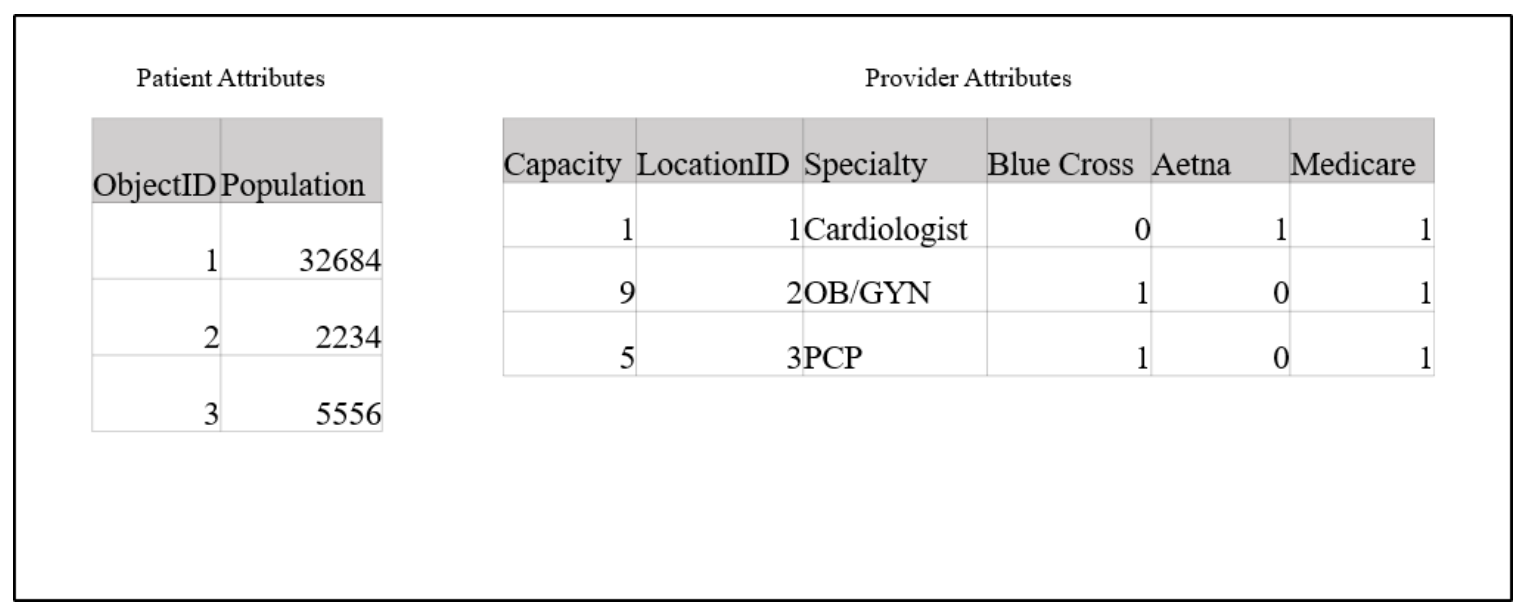

The task was first created in ModelBuilder to assure that the workflow was correct. There were parameters added to certain inputs so that the user could add their own data to the task to achieve the results of any provider locations and population they need to assess. Two models were created, one for the provider service area and one for patient accessibility. Once the models ran smoothly and gave the desired output, they were input into two different tasks; calculate provider to patient ratio and calculate the patient accessibility. In Figure 6-6, 6-7, and 6-8 are an example of what each task looks like when the user is prompted to input their own data. 


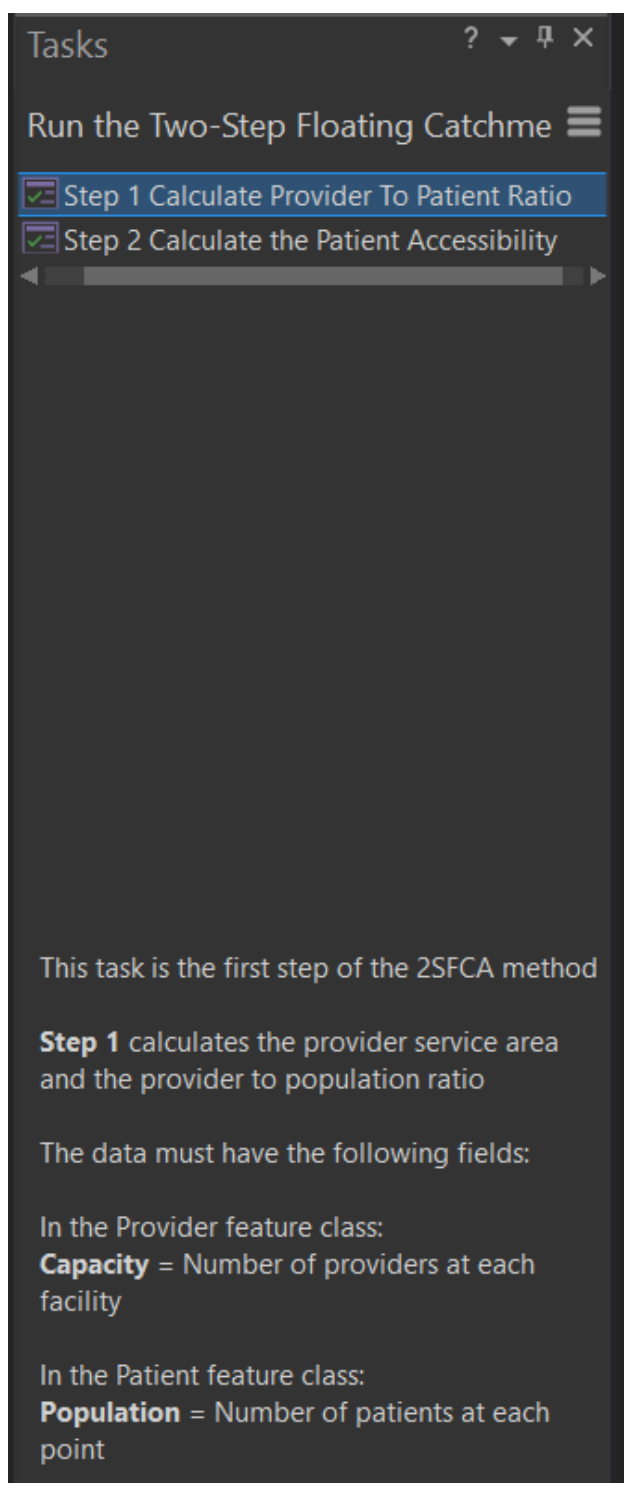

Figure 6-6: Intro to Tasks

When the user opens the task, the first thing to come up is an intro as to what the tool is, there is an explanation to what the first step will do, and what features the provider table will need to have as well as what the patient table needs to have. Figure 6-7 shows what step 1 takes the user through. 


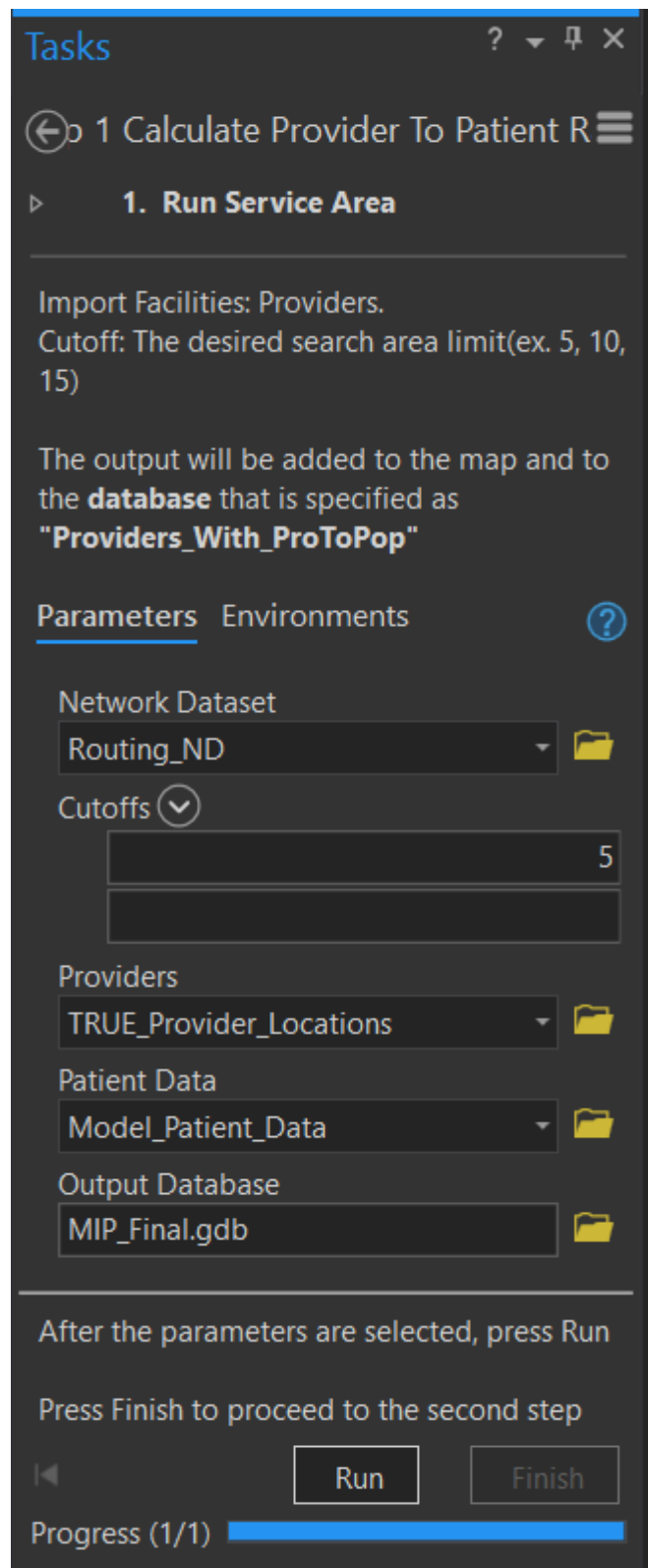

\section{Figure 6-7: Step 1 of Tasks: Provider to Patient Ratio}

The first step, Calculate Provider to Patient Ratio, takes the user through the first step of the 2SFCA method and creates a new table that has the ProToPop field in it. It is output into the user's geodatabase. In Figure 6-8 the second step of the 2SFCA is run, the user must input the new table from step 1 into this step and choose which providers the user is interested in seeing the patient accessibility to. 


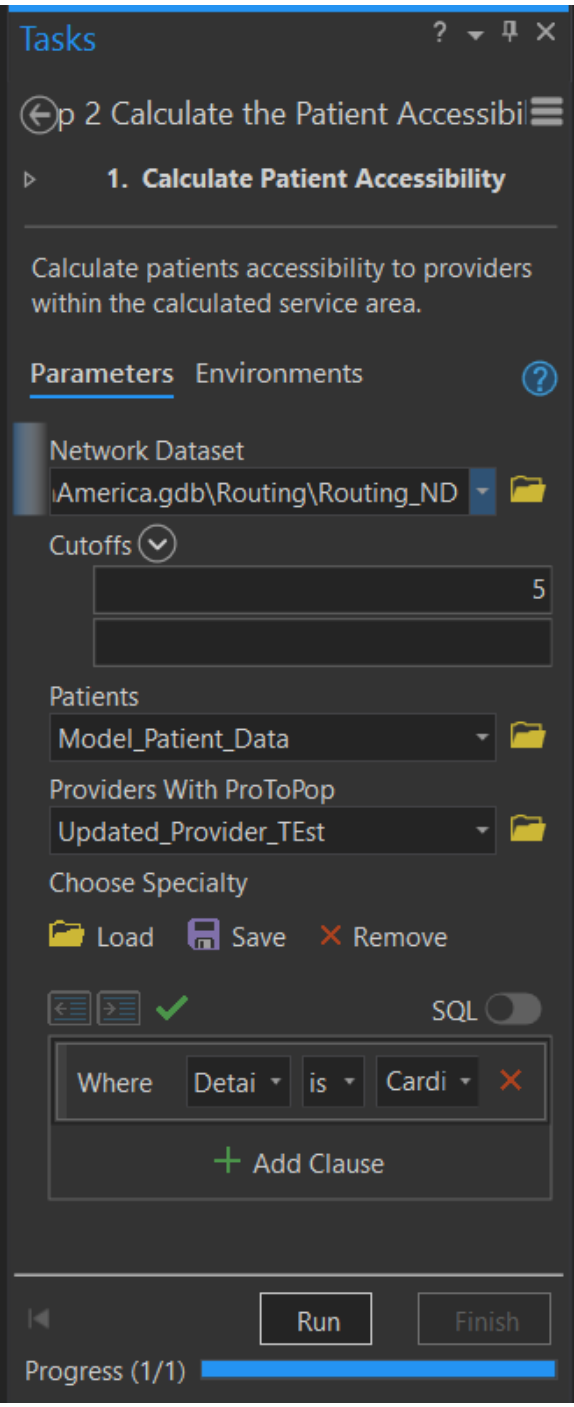

Figure 6-8: Step 2 of Tasks: Patient Accessibility

The tasks in this project proved to run smoothly and gave the required output that the client desired. These tasks can be used by any user that has the correct data set with the correct fields in their data, as well as access to BA and Network Analyst. The tasks were exported into a tool that was given to the client to not only provide proof of the tools' efficiency, but also to provide another way to show how GIS can help improve network adequacy. This would not require users to have an extensive GIS background.

\subsection{Story Map for Spatial Accessibility to Medical Services}

For this project, the client wanted a report to show the process of what was done in the analyses, how it could be helpful to provider and patients, and why using Esri technology improves calculating network adequacy. The report was done in the form of a story map, which is a great application on ArcGIS Online. It is intuitive, simple to edit, and creates a flowing story of any topic the user wants to discuss. The story map was capable of 
embedding web applications, maps, websites, and other online resources into the story so that the user can easily access what the creator is discussing.

This story map was created to convey what this project entailed to a reader who has no background in GIS. In this story map, the embedded features include a web map, a web application, and a side car that takes the user through the analysis steps. Figure 6-9 is the start of the story map which is an introduction about what the problem is, how it is being addressed through GIS, and what methods were used.

\section{Why is Spatial Accessibility Important?}

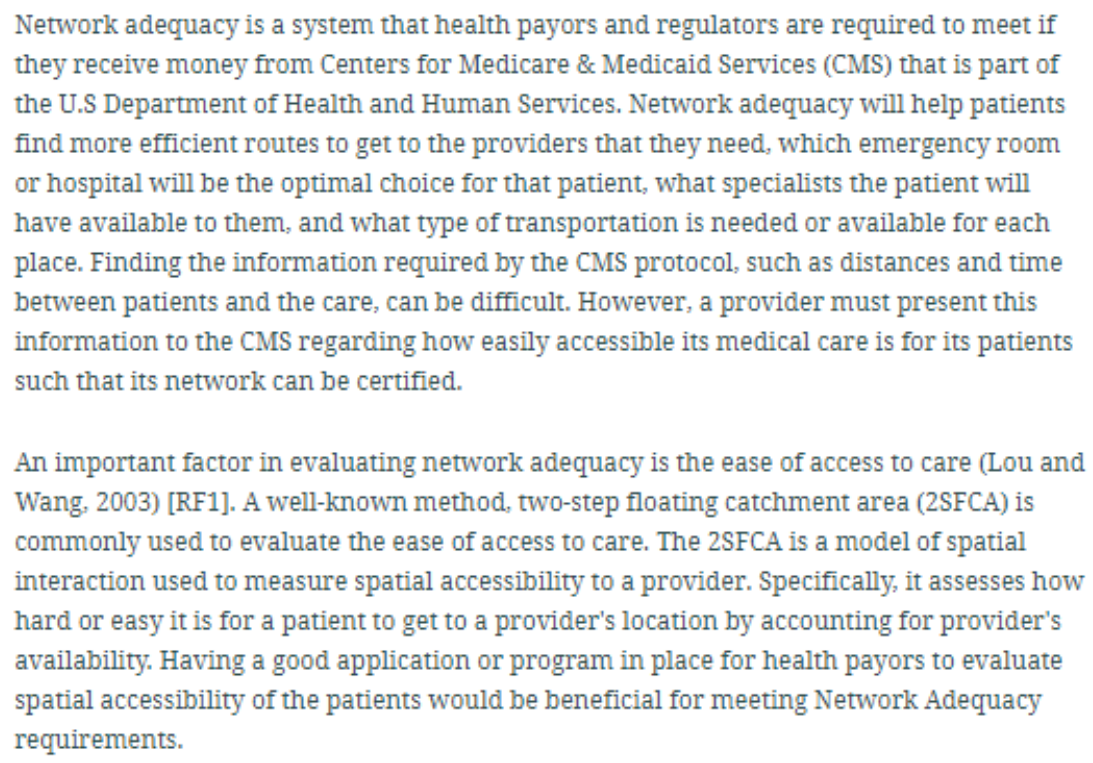

\section{Why combine GIS and Health Care?}

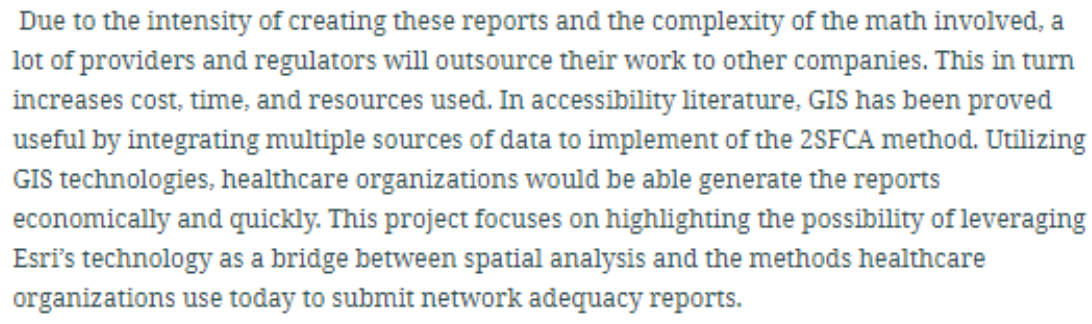

Figure 6-9: Intro to Story Map

Figure 6-10 shows the sidecar of the story map, there are 7 sections of the sidecar, each slide goes through part of the analyses. A sidecar is an addition in the story map that allows the user to slide through different slides. In this case, the sidecar goes through the analyses that were done. 


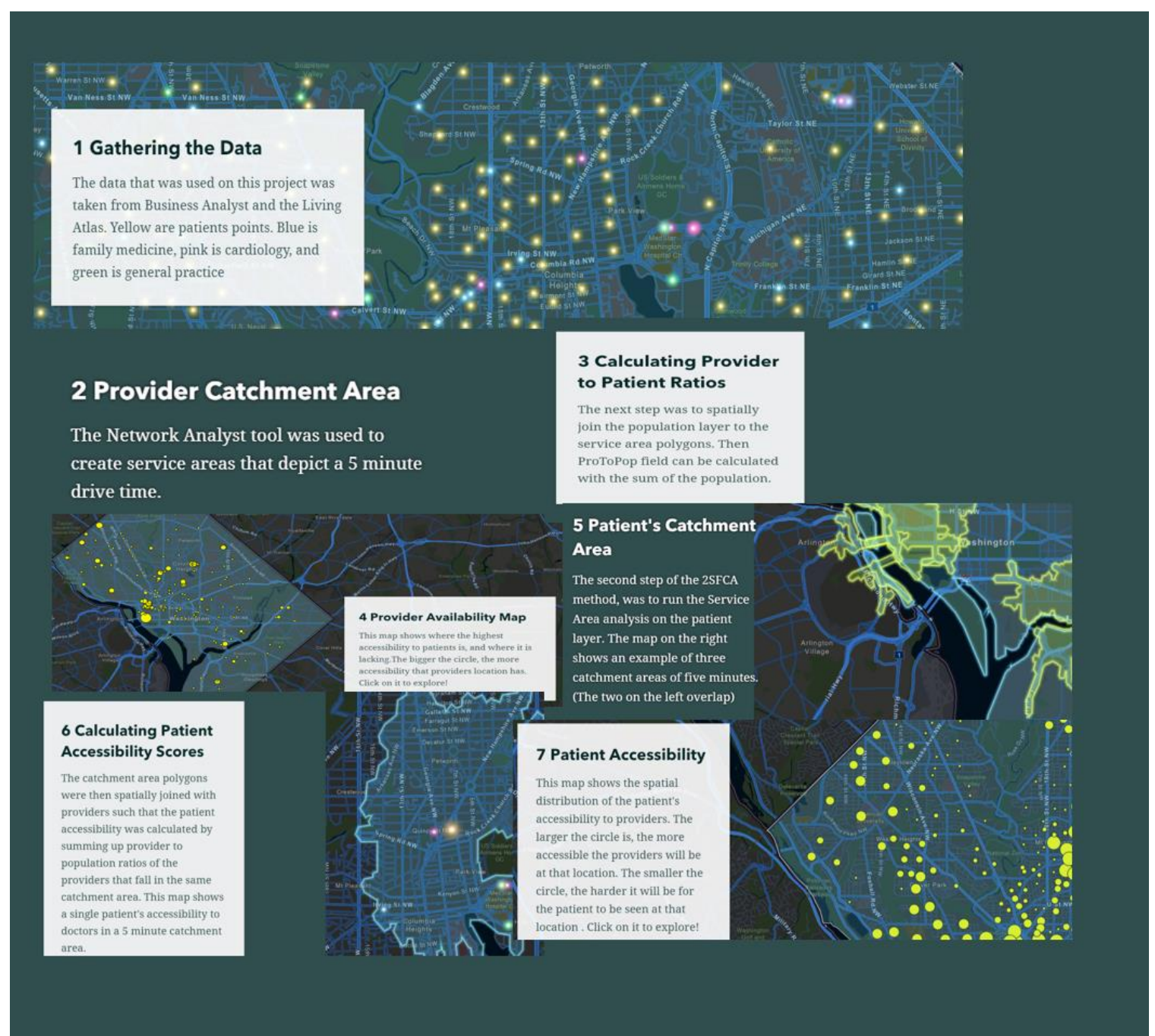

\section{Figure 6-10: Sidecar in Story Map}

Figure 6-11 shows the task that was created for this project. The tasks are shown on the story map so the user can see another reason why ArcGIS Pro would be a useful tool to have to improve health care network adequacy. 


\section{Creating Tasks to Mimic Analyses}

As a part of this project, creating a way for a future user to run the same analysis was vital. This was done by creating a task in ArcGIS Pro. This task allows for the user to run through the 2SFCA method with their own data. Below are pictures of the task.

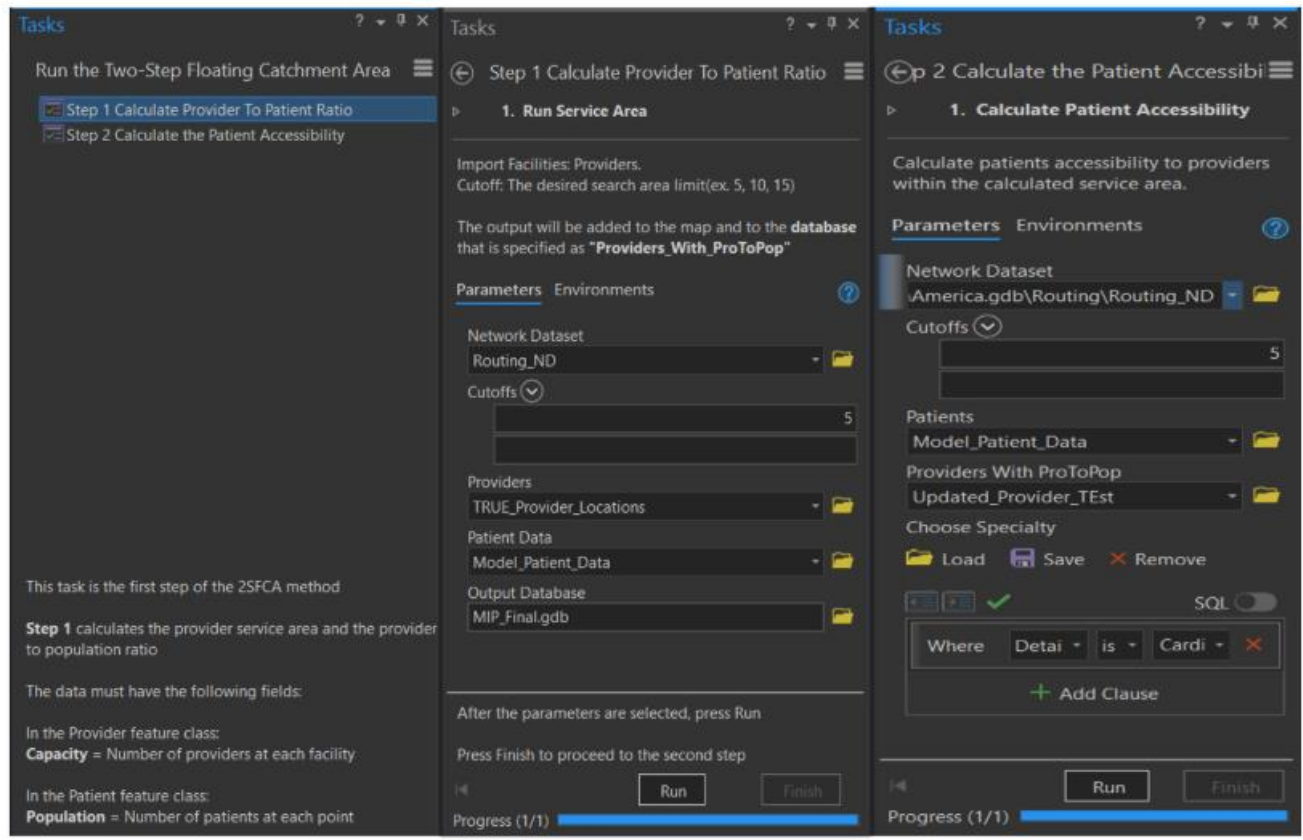

Figure 6-11: Task in Story Map

Figure 6-12 shows a link that can take the user to the web application, which will be explained in the next section. The whole story map that was created for this project can be viewed in Appendix B. 


\section{Take Time to Explore the Web Application and See the Accessibility in Washington D.C.}

Click on the image below to open up the web application that was created in tandem with this project. There you can see an example of how this could be useful to users who are looking for a nearby provider that accepts the insurance they have. Make sure to open the application in a new tab to use it full screen!

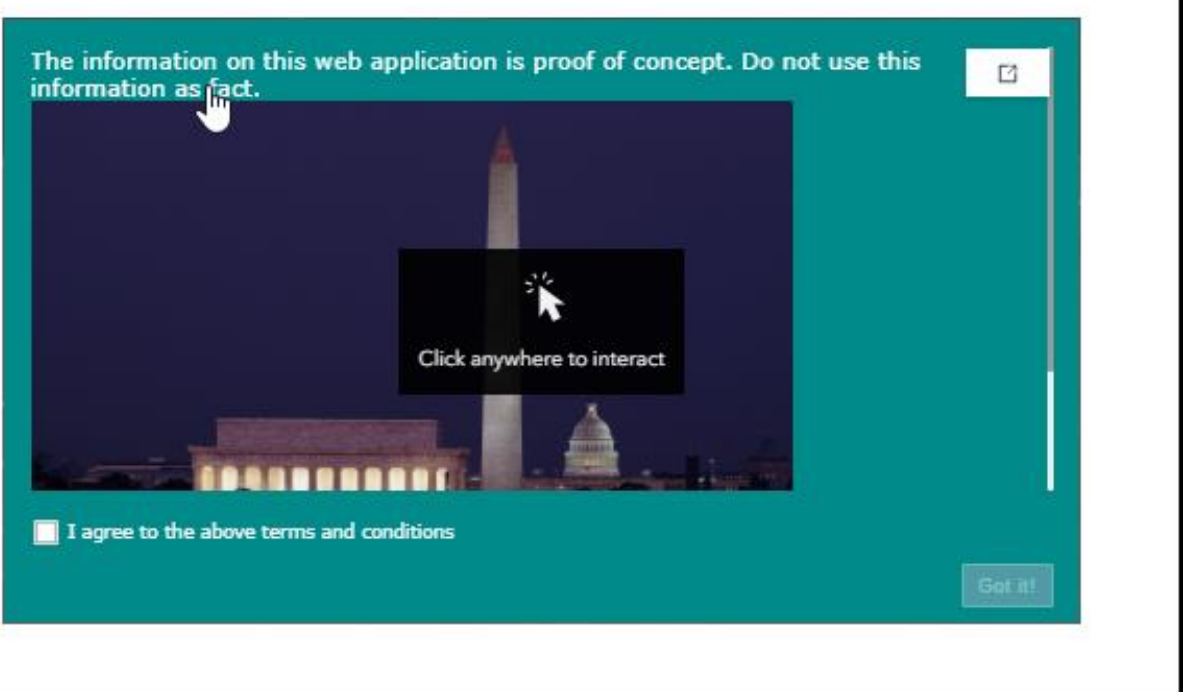

\section{Figure 6-12: Introduction to the WebApp in the Story Map}

\subsection{Web Application}

This project had a web application created to show how GIS not only improves network adequacy for providers, but also allows the patients to explore the providers of their choice. Although the data for this project was fabricated to show proof of concept, it showed that GIS can improve determining location options for patients to receive healthcare.

The use of this web application can help both patients and providers see the accessibility they have to each other. Patients can use the application to find the type of provider they want, within the mileage range they are willing to drive, and that also accepts their insurance. Once the user has chosen which of those applies to them, the program gives them all the providers that fall within the criteria. Once the user chooses which provider they want to see, directions are available for them to print out and use.

If providers are interested in using the application, it can be used to see how many patients have accessibility to them in accordance with network adequacy. This would allow providers to see where their offices need to hire more providers, or which areas they need to look to expand their offices to. Figure 6-13 shows an example of a patient 
looking for cardiologists in a 3-mile drive time from their location.

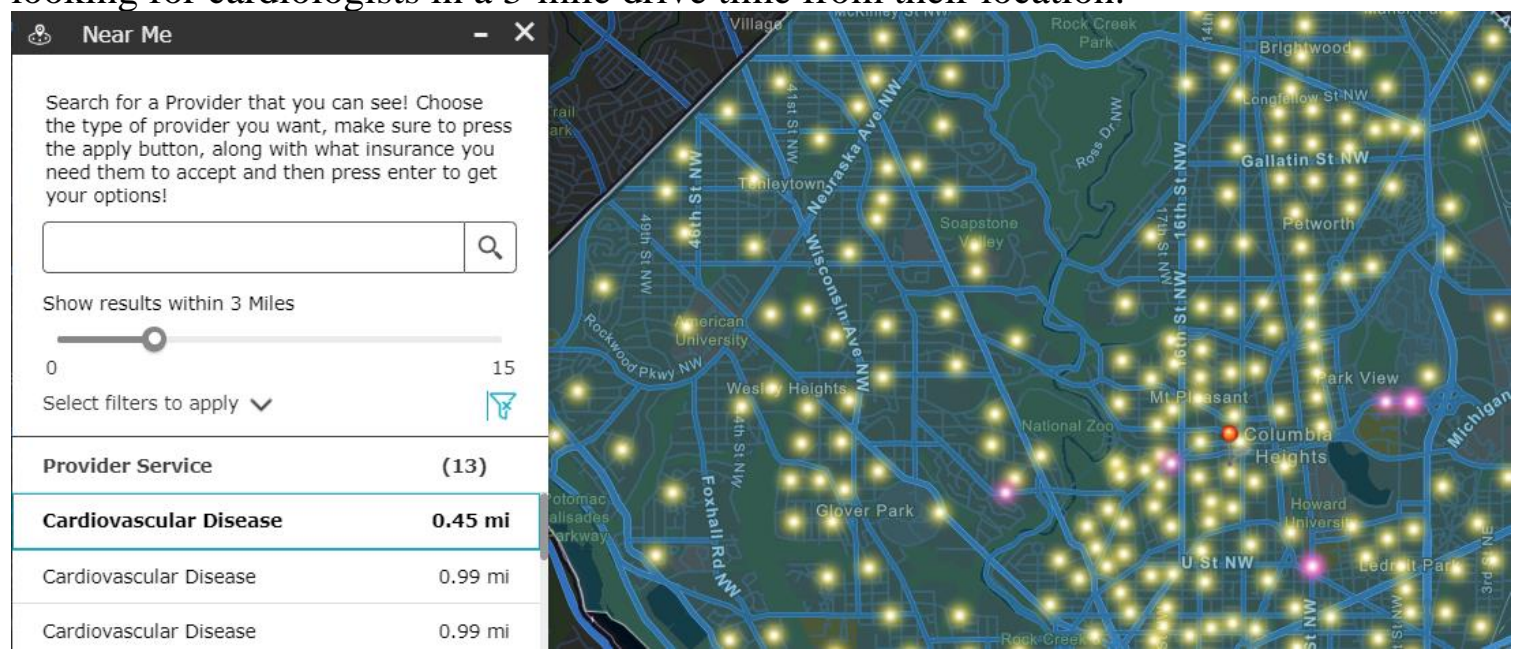

Figure 6-13: Example of a patient using the Near Me tool

Figure 6-14 shows how a provider could see that they are not meeting needs of an area based on the fact that the near me tool shows that no patients would be able to see them in a 3 mile drive time.

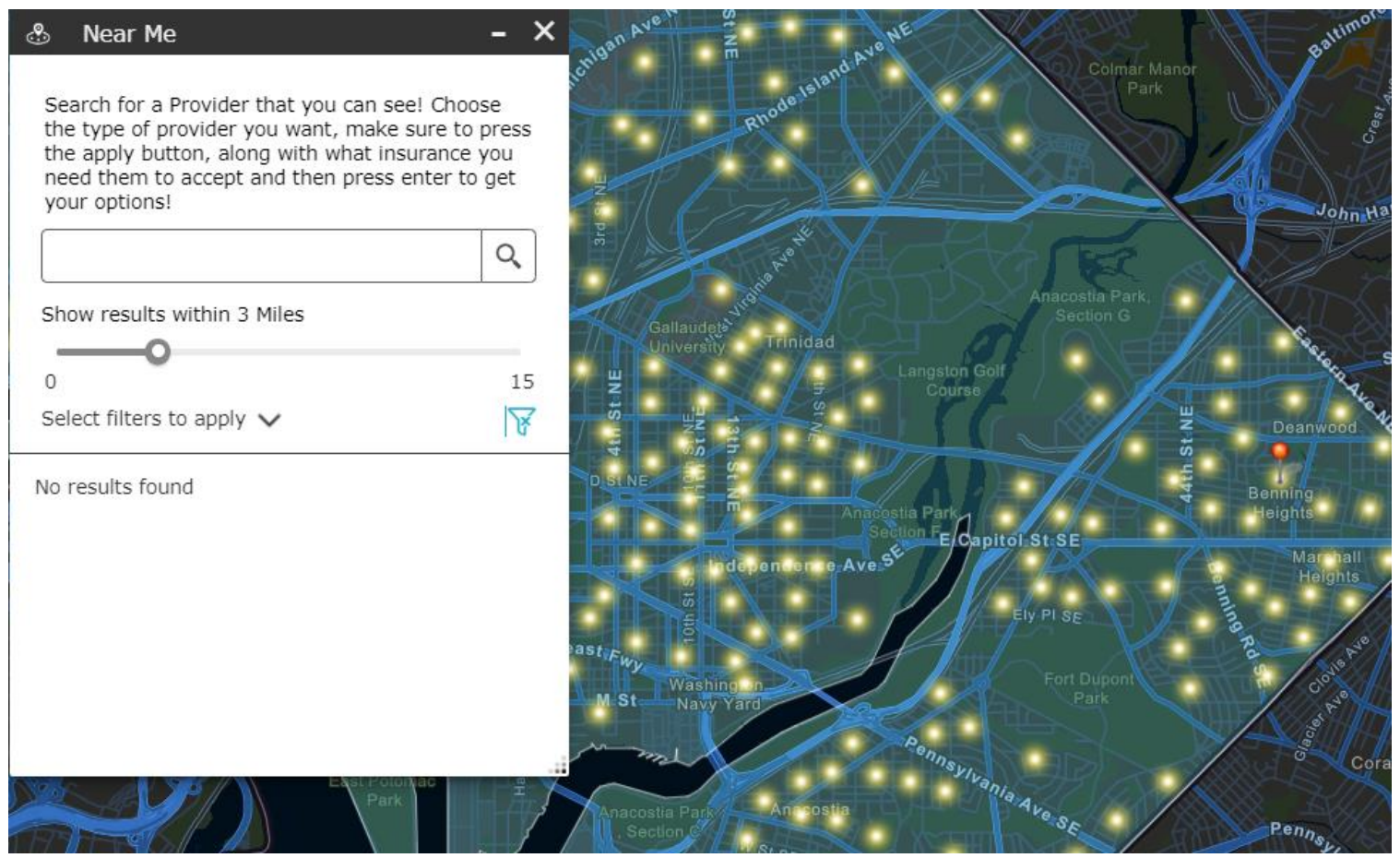

Figure 6-14: Example of a provider using the Near Me tool 


\subsection{Summary}

This chapter discussed the tools that were used to complete this project and how they were successful. These analyses and deliverables were created to show that network adequacy in the health field could be improved through the powerful tools and knowledge that coincide with GIS. This project successfully proved, through analysis and a task, a story map, and a web application, that GIS can improve the process of determining network adequacy in the health field. 


\section{Chapter 7 - Conclusions and Future Work}

The client's goal was to show providers that GIS can help improve problems with network adequacy and help them generate the reports and analyses needed to continue to receive funding from entities like the Centers for Medicare \& Medicaid Services or insurance companies. The analyses were done by using Esri software like ArcGIS Pro to run the 2SFCA method creating a workflow that allows users to input their own data and easily generate their network adequacy reports by combining their information with GIS technology. Through the analyses and the testing done in this project, the conclusion was that the client, Esri, is correct in their assumption that GIS can help improve network adequacy and the time it takes to generate the required reports by payors. This project also proved that GIS can be helpful to patients, to show them their accessibility to the providers they are interested in. This project met the requirements given by the client, and these were demonstrated through the story map and web application created.

\subsection{Conclusions}

Esri is the leading company in GIS and has the most intuitive and outstanding applications to solve spatial problems. The company continues to grow and take on issues throughout the world to solve complex spatial relationships for a wide range of fields. This project showed how GIS was a vital tool in determining network adequacy. GIS can also be used to improve other areas in or related to the health field, such as improving transportation and travel burdens for the patients.

Without GIS and incorporating it with the 2SFCA method, there would be no easy way to solve the problem of network adequacy. Thanks to Esri and the leadership of Jack Dangermond, this project was possible. It was proven that GIS needs to become a part of the health field to help meet all the complicated and quickly changing requirements of entities like the CMS and other regulators. GIS showed to not only help the providers, but to help the patients and improve the ease of access for them.

\subsection{Future Work}

At the time of starting this project, there were ideas of using more than just drive time to calculate the network adequacy. Due to time and resource restraints, this project was only able to focus on driving. In the future, this method could be taken a step further to add more transportation modes. The analyses would use the same 2SFCA method, and the same type of provider and population information, but it would require more detailed street data; it would need to include sidewalks, bus stops and routes, and traffic data. Esri can acquire this data and do the analyses in the future without changing the method.

This project only focused on Washington D.C., in the future a program could be written to look at other states with bigger rural regions to see what types of challenges they meet with network adequacy, it could include multi-model transportation and help patients who do not have cars accessible to them. It could have all the provider and patient data incorporated into it and allow for provider offices to know exactly where they are not adequately meeting their patients needs and accessibility. This could allow 
for providers to also see which areas are not meeting the needs of patients and could help provider offices plan to add new locations for them to see patients, which would improve patient accessibility. Esri could have a product for healthcare providers and payors to purchase that would help facilities become strong competitors and technology leaders by integrating GIS in healthcare. Having outstanding accessibility to patients is something each providers office strives to have, and with the help of GIS, this can be achieved. 


\section{Works Cited}

Corlette, S. (2017, April 05). New Network Adequacy Rules: Less Federal Oversight, More Deference to States. Retrieved August 27, 2020, from http://chirblog.org/new-networkadequacy-rules-less-federal-oversight-deference-states/

Department of Health and Human Services, S. (2018, March 26). Medicaid Managed Care Final Rule:Network Adequacy Standard. 1-37.Retrieved July 15, 2020, from https://www.dhcs.ca.gov/formsandpubs/Documents/FinalRuleNAStandards3-26-18.pdf

Esri. (2020). https://www.esri.com/content/dam/esrisites/en-us/media/whitepaper/locatingcovid19-testing-treatment-resource-distribution-sites.pdf. Retrieved April 8, 2020, from https://www.esri.com/content/dam/esrisites/en-us/media/whitepaper/locating-covid19testing-treatment-resource-distribution-sites.pdf

Ford, A., Barr, S., Dawson, R., \& James, P. (2015). Transport Accessibility Analysis Using GIS: Assessing Sustainable Transport in London. Urban Development for the 21st Century, 201-233. doi:10.1201/b18765-11

Geraghty, E. (2018). Five Steps to Calculating Provider Network Adequacy. An Esri White Paper. Provided by Este Geraghty on April 26, 2020.

Health Benefit Exchange Authority, About the DC Health Benefit Exchange Authority (HBX). (n.d.). Retrieved April 27, 2020, from https://hbx.dc.gov/page/about-dc-healthbenefit-exchange-authority-hbx

Kotavaara, O., Antikainen, H., \& Rusanen, J. (2011). Population change and accessibility by road and rail networks: GIS and statistical approach to Finland 1970-2007. Journal of Transport Geography, 19(4), 926-935. doi:10.1016/j.jtrangeo.2010.10.013

Law, D. (2019). Use Web AppBuilder to Meet Your Organization's Needs Quickly and Easily. Retrieved May 19, 2020, from https://www.esri.com/about/newsroom/arcuser/use-web-appbuilder-to-meet-yourorganizations-needs-quickly-and-easily/

Luo, W., \& Wang, F. (2003). Measures of spatial accessibility to health care in a GIS environment: synthesis and a case study in the Chicago region. Environment and Planning B: Planning and Design, 30(6), 865-884

Luo, W., \& Qi, Y. (2009). An enhanced two-step floating catchment area (E2SFCA) method for measuring spatial accessibility to primary care physicians. Health \& Place, 15(4), 1100-1107. doi: 10.1016/j.healthplace.2009.06.002

Mcgrail, M. R. (2012). Spatial accessibility of primary health care utilising the two step floating catchment area method: An assessment of recent improvements. International Journal of Health Geographics, 11(1), 50. doi:10.1186/1476-072x-11-50

Taravat Najafabadi, A. (2009). Applications of GIS in Health Sciences. Shiraze E Medical Journal, 10(4), 221-230. 



\section{Appendix A. ModelBuilder into Tasks}

Model For Patients:

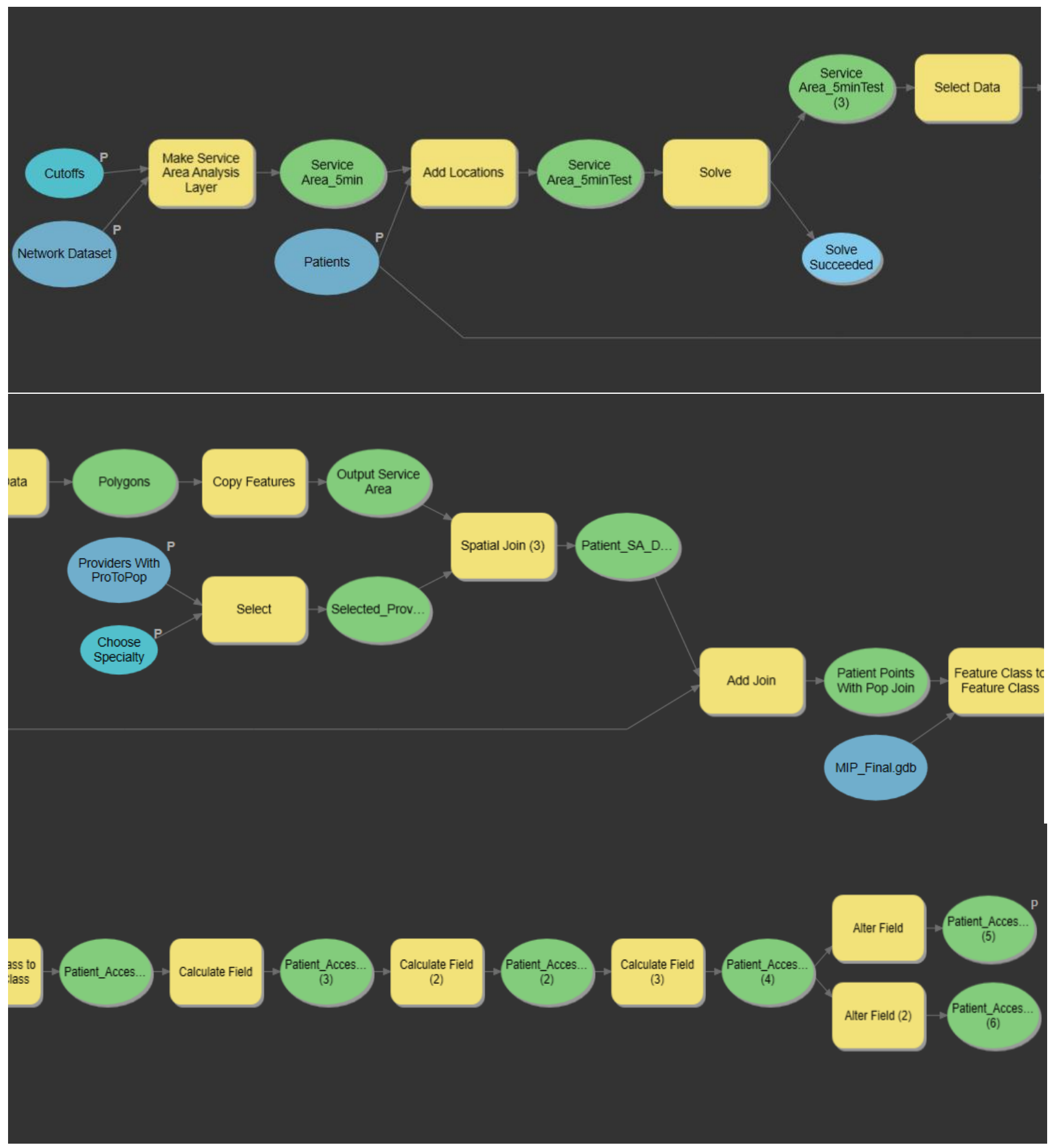


Model for Providers:

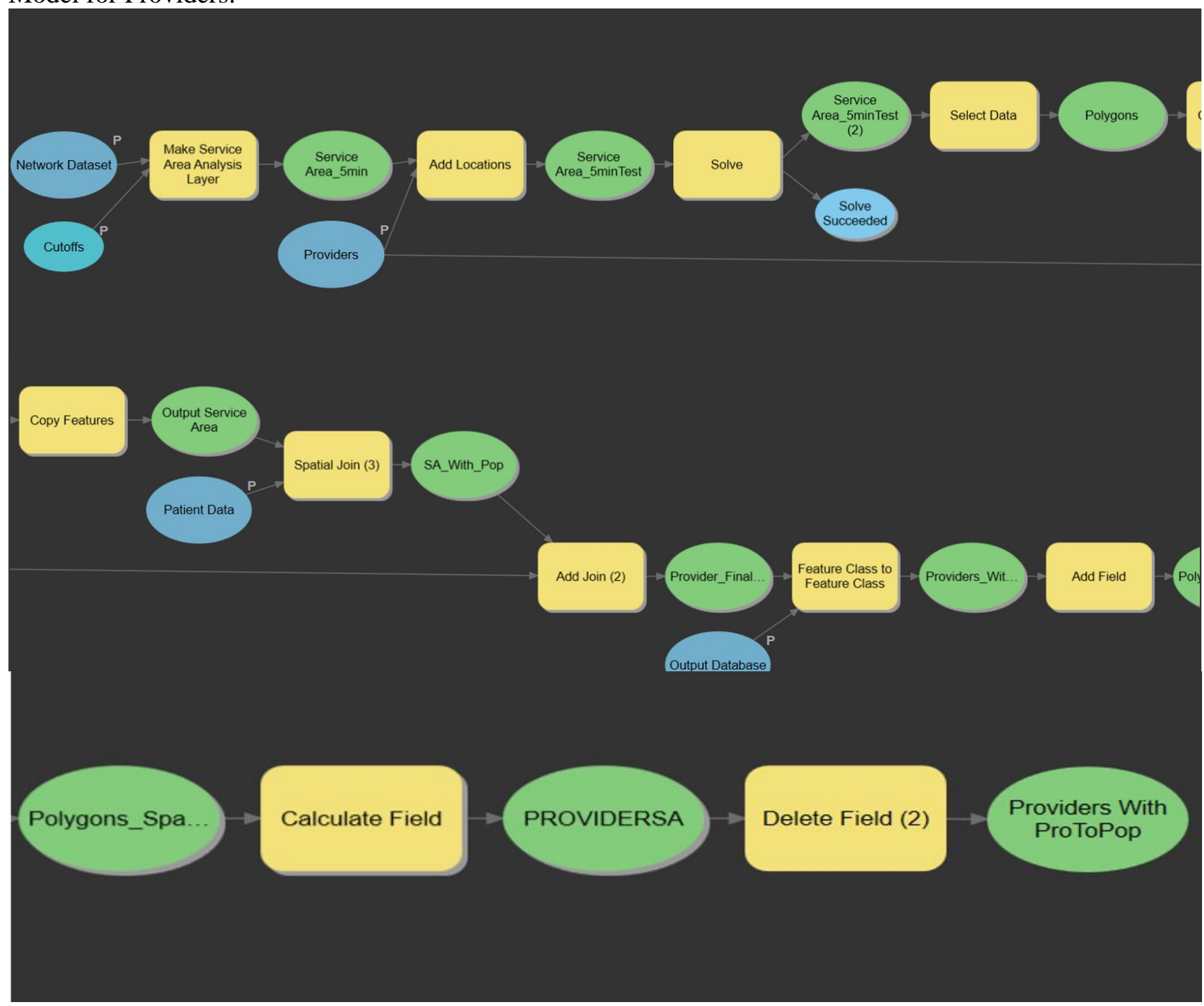


Task Step $1 \& 2$ :

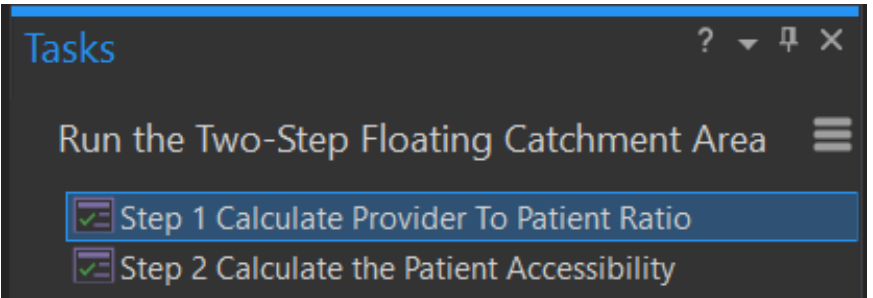

This task is the first step of the 2SFCA method

Step 1 calculates the provider service area and the provider to population ratio

The data must have the following fields:

In the Provider feature class:

Capacity $=$ Number of providers at each facility

In the Patient feature class:

Population $=$ Number of patients at each point 


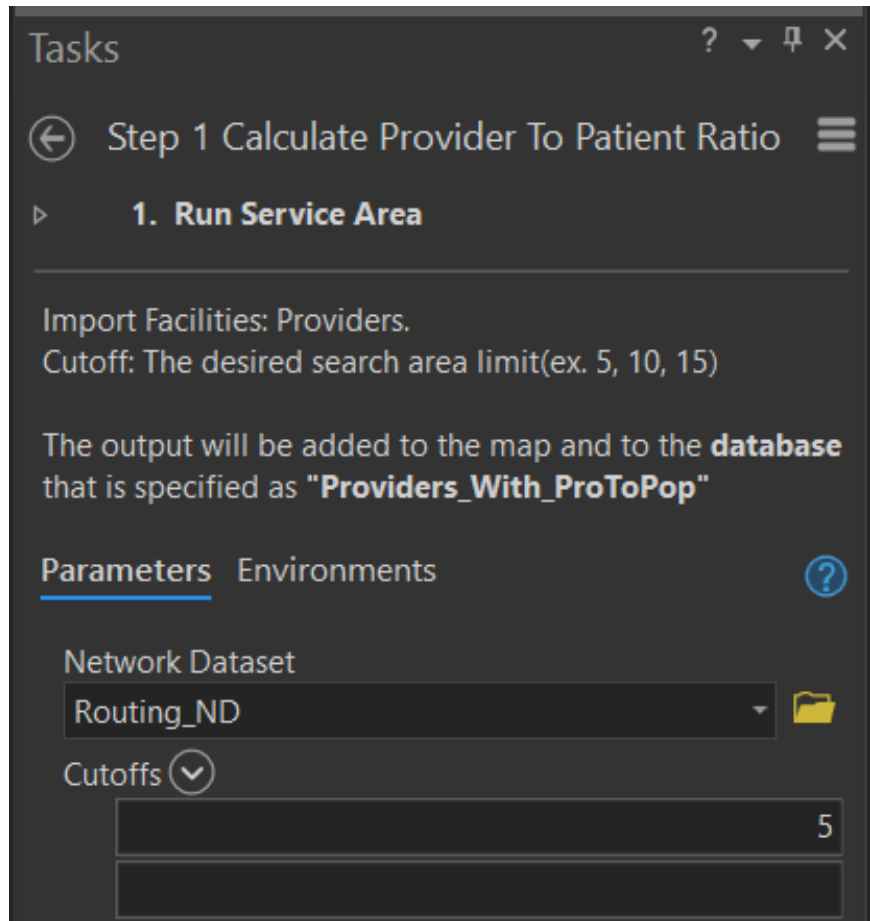

Providers

TRUE_Provider_Locations

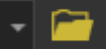

Patient Data

Model_Patient_Data

Output Database

MIP_Final.gdb

After the parameters are selected, press Run

Press Finish to proceed to the second step

K

Run

Progress (1/1) 


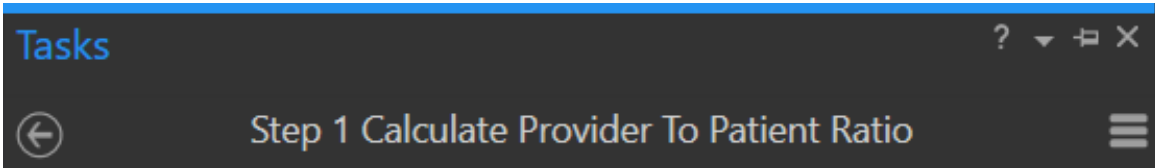

1. Run Service Area

Import Facilities: Providers.

Cutoff: The desired search area limit(ex. 5, 10, 15)

The output will be added to the map and to the database that is specified as

"Providers_With_ProToPop"

Parameters Environments

Network Dataset

;t\US_2019\Data\Streets Data\NorthAmerica.gdb\Routing\Routing_ND

Cutoffs $(\checkmark)$

Providers

TRUE_Provider_Locations

F

Patient Data

Model_Patient_Data

$F$

Output Database

MIP_Final.gdb

After the parameters are selected, press Run

Press Finish to proceed to the second step

K

Progress (1/1) 


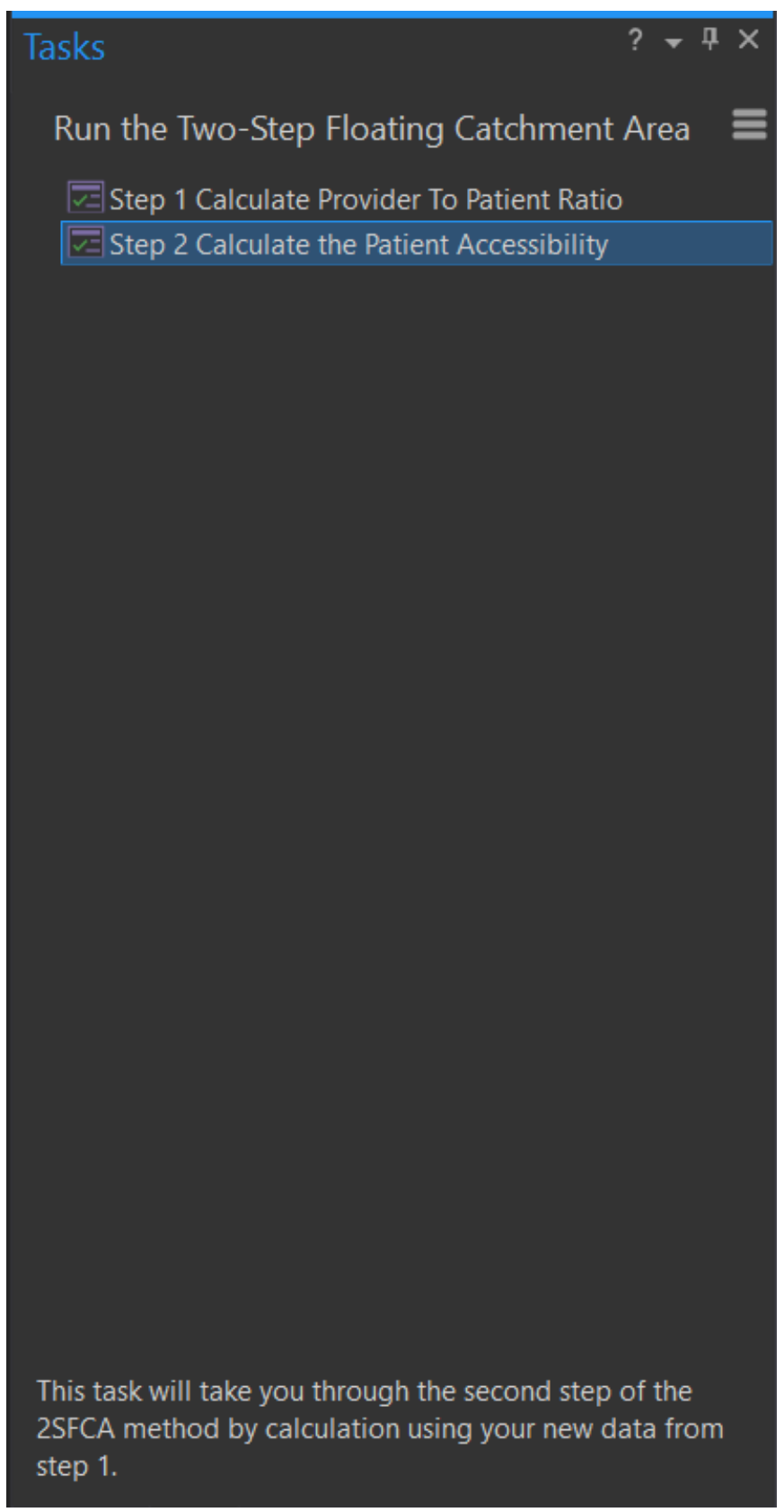


$\Theta \quad$ Step 2 Calculate the Patient Accessibility

1. Calculate Patient Accessibility

Calculate patients accessibility to providers within the calculated service area.

Parameters Environments

Network Dataset

is Data\NorthAmerica.gdb\Routing \Routing_ND Cutoffs $\vee$

Patients

Model_Patient_Data

$-F$

Providers With ProToPop

Updated_Provider_TEst

$-F$

Choose Specialty

\section{Load 皿 Save X Remove}

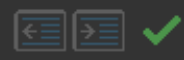

Where DetailedSF * is eq " Cardiovası * $\mathrm{X}$

\section{+ Add Clause}

K 


\title{
Appendix B. Story Map
}

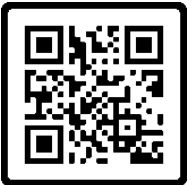

Story Map URL and QR Code: https://arcg.is/0COPLO (1) StoryMap

\section{Spatial Accessibility In Health Care}

\author{
How GIS can be integrated with the 2SFCA method
}

Ashley Pervorse | August 1, 2020

\section{Why is Spatial Accessibility Important?}

Network adequacy is a system that health payors and regulators are required to meet if they receive money from Centers for Medicare \& Medicaid Services (CMS) that is part of the U.S Department of Health and Human Services. Network adequacy will help patients find more efficient routes to get to the providers that they need, which emergency room or hospital will be the optimal choice for that patient, what specialists the patient will have available to them, and what type of transportation is needed or available for each place. Finding the information required by the CMS protocol, such as distances and time between patients and the care, can be difficult. However, a provider must present this information to the CMS regarding how easily accessible its medical care is for its patients such that its network can be certified.

An important factor in evaluating network adequacy is the ease of access to care (Lou and Wang, 2003) [RF1]. A well-known method, two-step floating catchment area (2SFCA) is commonly used to evaluate the ease of access to care. The 2SFCA is a model of spatial interaction used to measure spatial accessibility to a provider. Specifically, it assesses how hard or easy it is for a patient to get to a provider's location by accounting for provider's availability. Having a good application or program in place for health payors to evaluate spatial accessibility of the patients would be beneficial for meeting Network Adequacy requirements. 


\section{Why combine GIS and Health Care?}

Due to the intensity of creating these reports and the complexity of the math involved, a lot of providers and regulators will outsource their work to other companies. This in turn increases cost, time, and resources used. In accessibility literature, GIS has been proved useful by integrating multiple sources of data to implement of the 2SFCA method. Utilizing GIS technologies, healthcare organizations would be able generate the reports economically and quickly. This project focuses on highlighting the possibility of leveraging Esri's technology as a bridge between spatial analysis and the methods healthcare organizations use today to submit network adequacy reports.

\section{What is the Two-Step Floating Catchment Area Method?}

The two-step floating catchment area (2SFCA) method was developed to measure accessibility to providers. The 2SFCA method focuses on two main factors, the providers supply, and the population demand. These are both spatial entities that had to be evaluated and measured spatially in order to correctly calculate patient accessibility (McGrail, M.R., 2012)[RF2].

The calculation of the 2SFCA requires a lot of math that many insurance companies may not want to handle for each provider they have in their company. The calculation processes, developed by Lou and Wang (2003) are explained in Equation (1) and Equation (2). The first step is used to determine an initial ratio to each service area at the physician (supply) location to measure the supply availability. For each physician location $j$, all demands $(P k)$ at locations $k$ that are within a certain time threshold distance do are summed up to calculate the supply-to-demand ratio $R j$ within the catchment area $j$ (Equation (1)). 


$$
R_{j}=\frac{S_{j}}{\sum_{k \in\left\{d_{k} \leq d_{0}\right\}} P_{k}}
$$

Eq.(1)

Equation (2) is the second step in the 2SFCA method. For the demand location $i$, providerto-population ratios $(R j)$ at location $(j)$ that are in the travel time $(d 0)$ location $i$, are summed up to obtain the final accessibility score $A F /$.

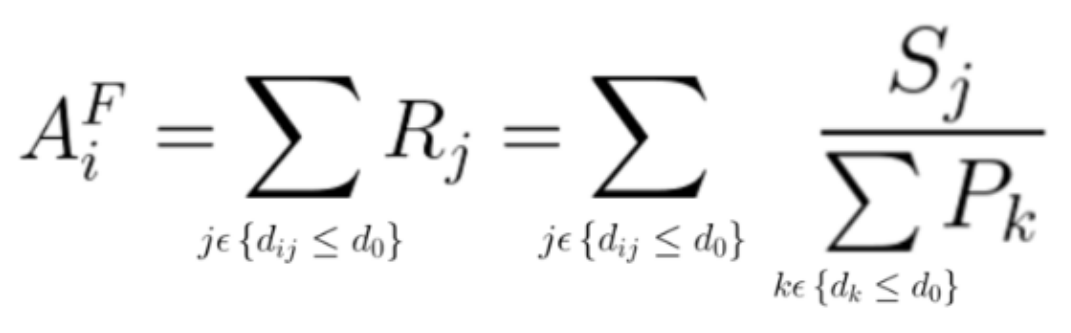

$\mathrm{Eq}(2)$

Using the 2SFCA method could be made easy with ArcGIS Pro. ArcGIS contains the tools that can be used to help do the calculations while allowing the parameters to be set up by the users. ArcGIS Pro can calculate where the patients are, where the providers are, and who is in network with them depending on what travel time the patients are willing to drive. If one wants to go further into the directions, with the right data, ArcGIS Pro can also account for if the patient does not have a car and needs to take buses and walk to the providers office. It will output the providers that patient is willing to travel to and give directions on how to get there. 


\section{What Can the 2SFCA Method Do In the Health Field if combined with GIS?}

The calculation involved in the 2SFCA method is complicated and the final numerical output is not easy to comprehend. Levering the visualization and analytical capabilities of ArcGIS Pro, this project demonstrates the power of GIS software in aiding non-GIS users to conduct spatial analyses. The story map below shows a case study in Washington D.C. There were three main provider types that this project focused on, primary care physicians (PCP), OB/GYNs, and cardiologists. Below, you can follow along with each step that was taken to do the complicated calculations using ArcGIS Pro. You will also be able to see how the program was used to create a visual understanding of the results. Once you have explored the sidecar below, feel free to then explore the web application created as an example of another way GIS can help patients find accessibility to their providers.

\section{The Analysis}

Use the arrow to swipe through the sidecar to see each step of the analysis! 


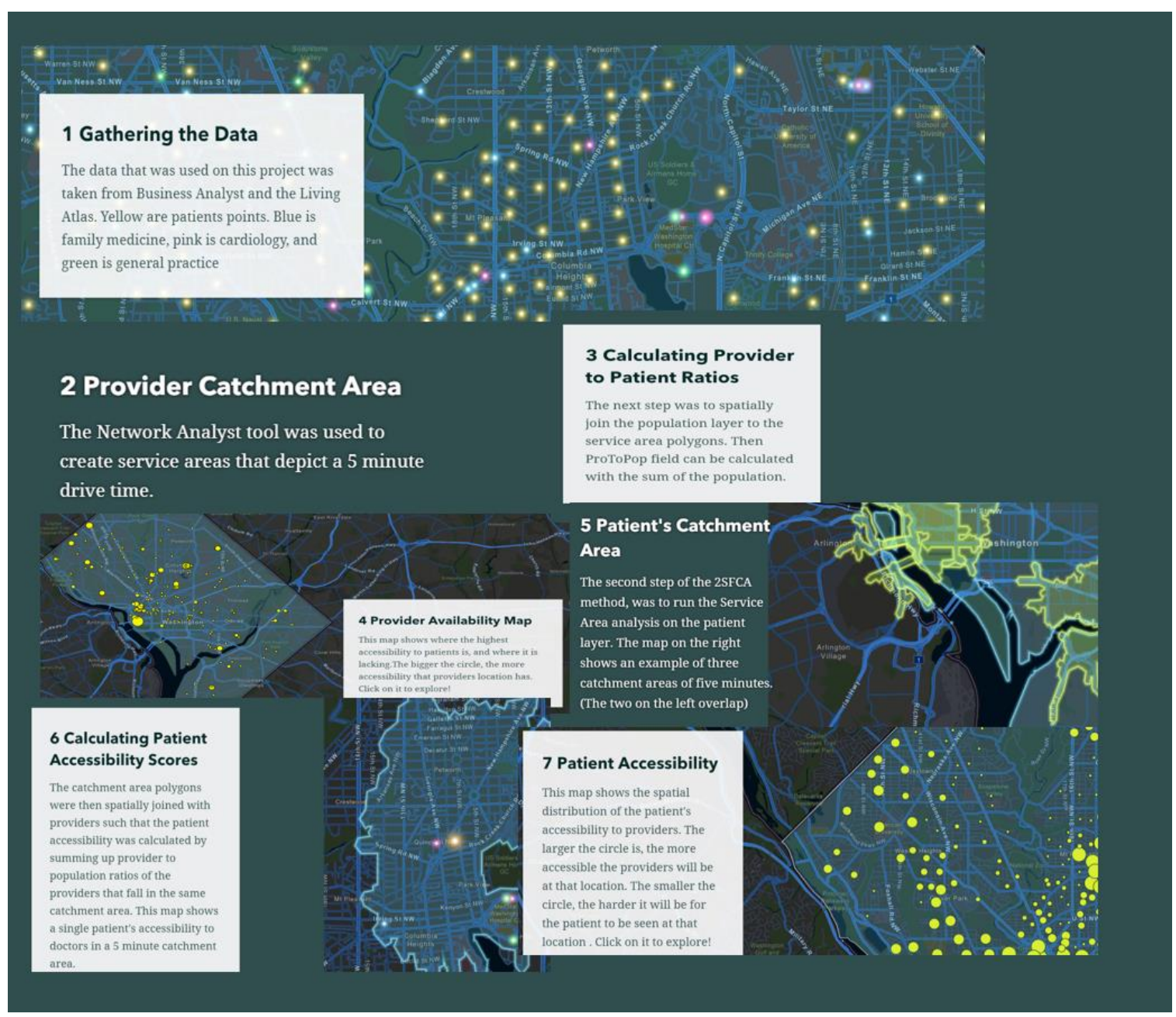




\section{Creating Tasks to Mimic Analyses}

As a part of this project, creating a way for a future user to run the same analysis was vital. This was done by creating a task in ArcGIS Pro. This task allows for the user to run through the 2SFCA method with their own data. Below are pictures of the task.

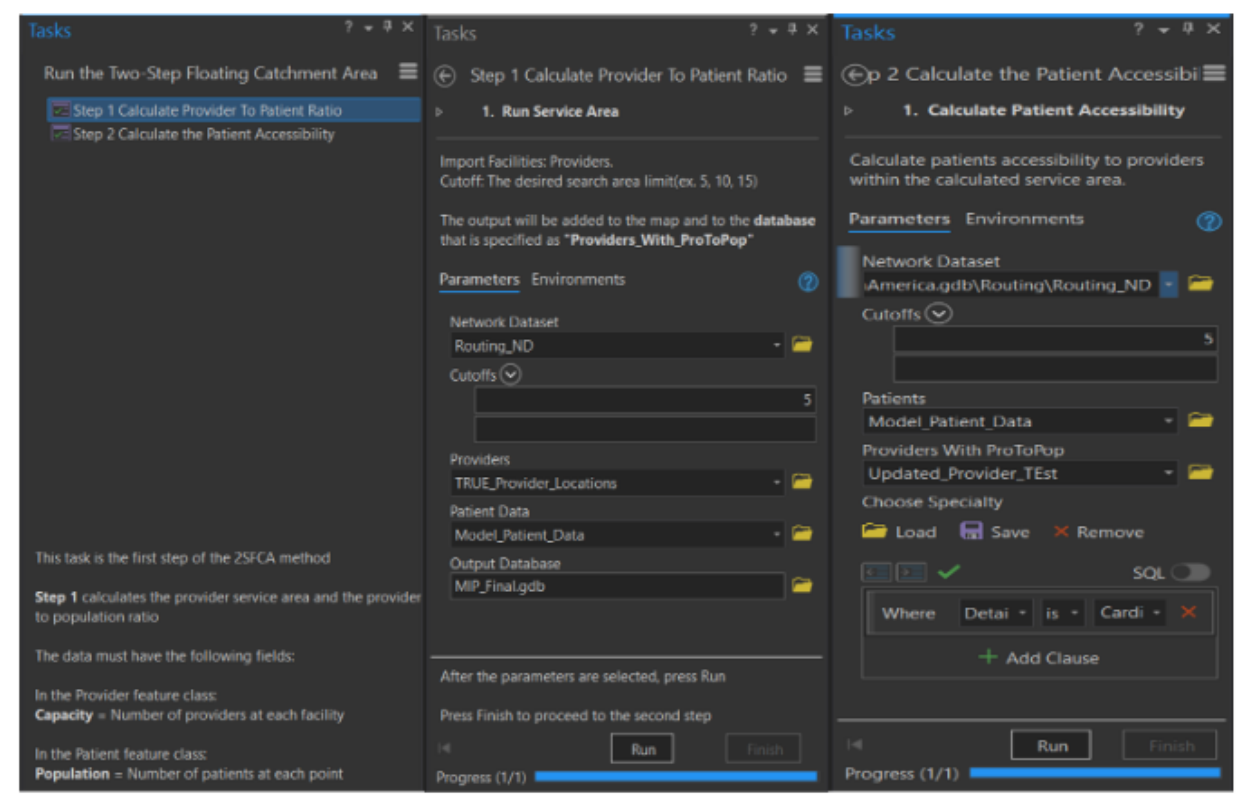




\section{Take Time to Explore the Web Application and See the Accessibility in Washington D.C.}

Click on the image below to open up the web application that was created in tandem with this project. There you can see an example of how this could be useful to users who are looking for a nearby provider that accepts the insurance they have. Make sure to open the application in a new tab to use it full screen!

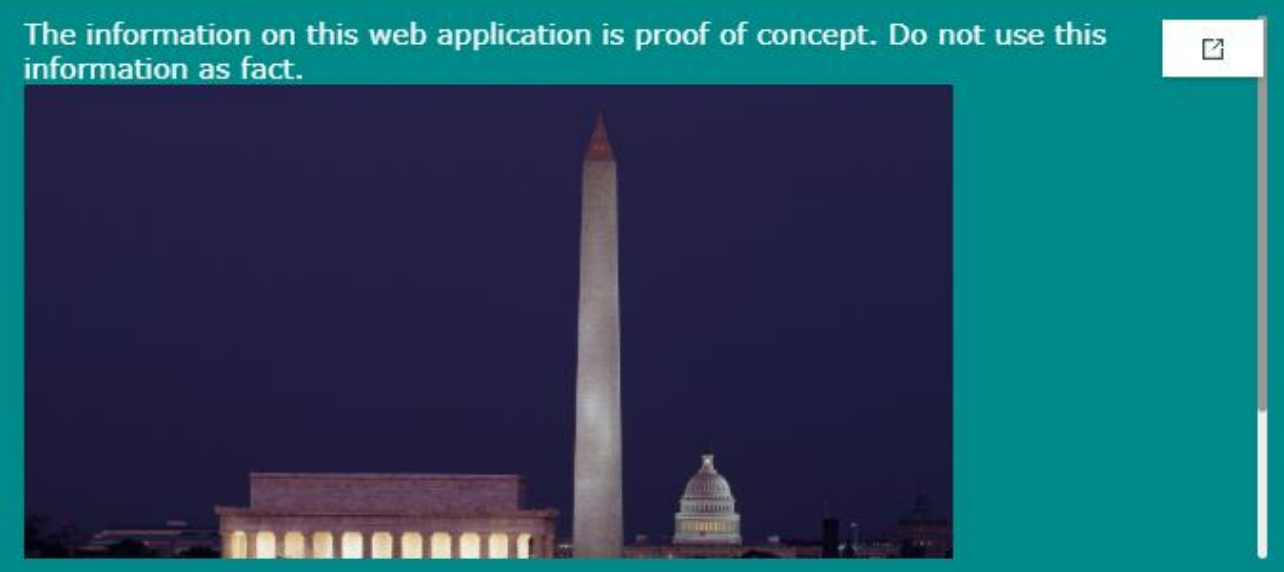

I agree to the above terms and conditions 


\section{Appendix C. Web Application}

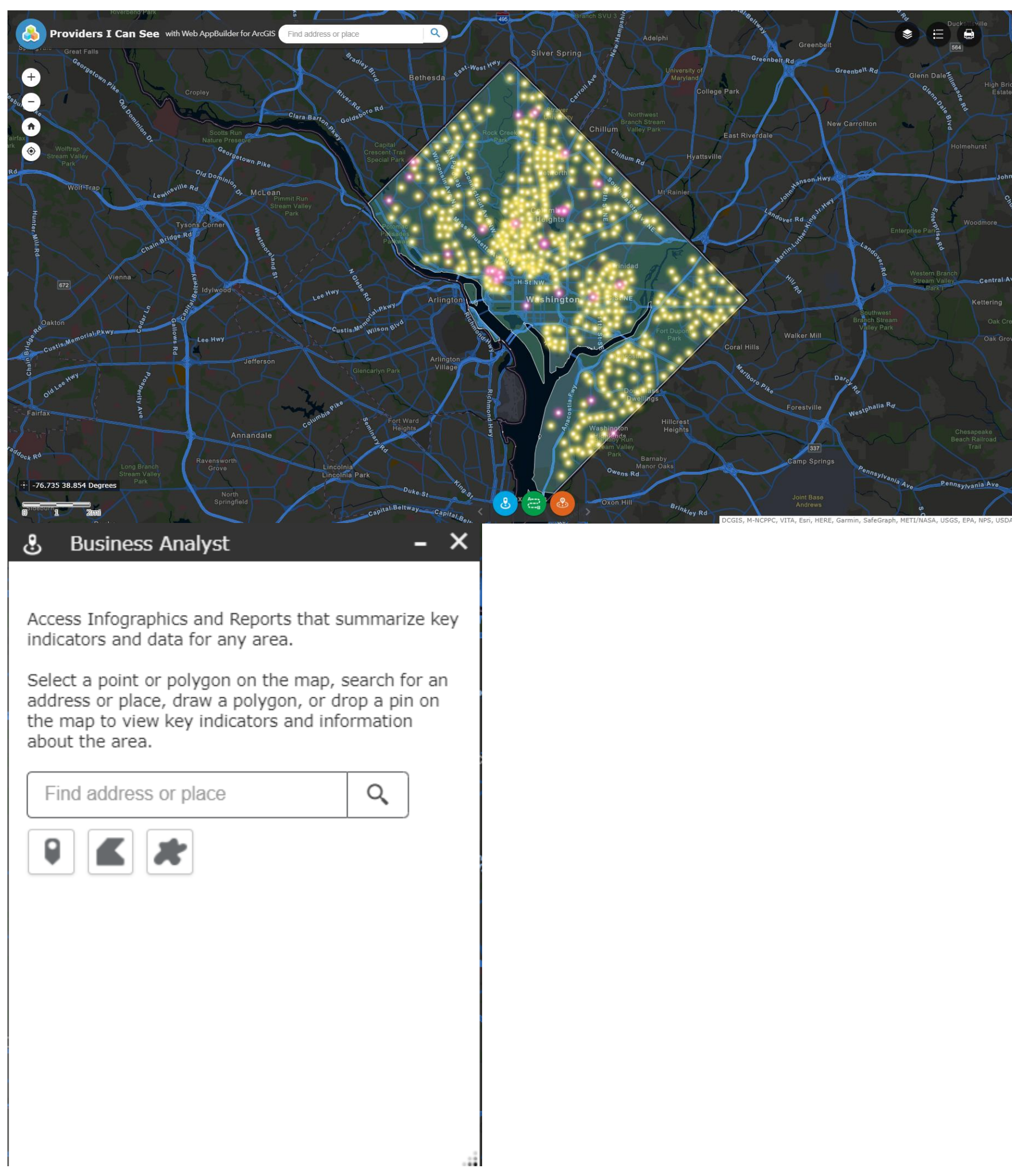




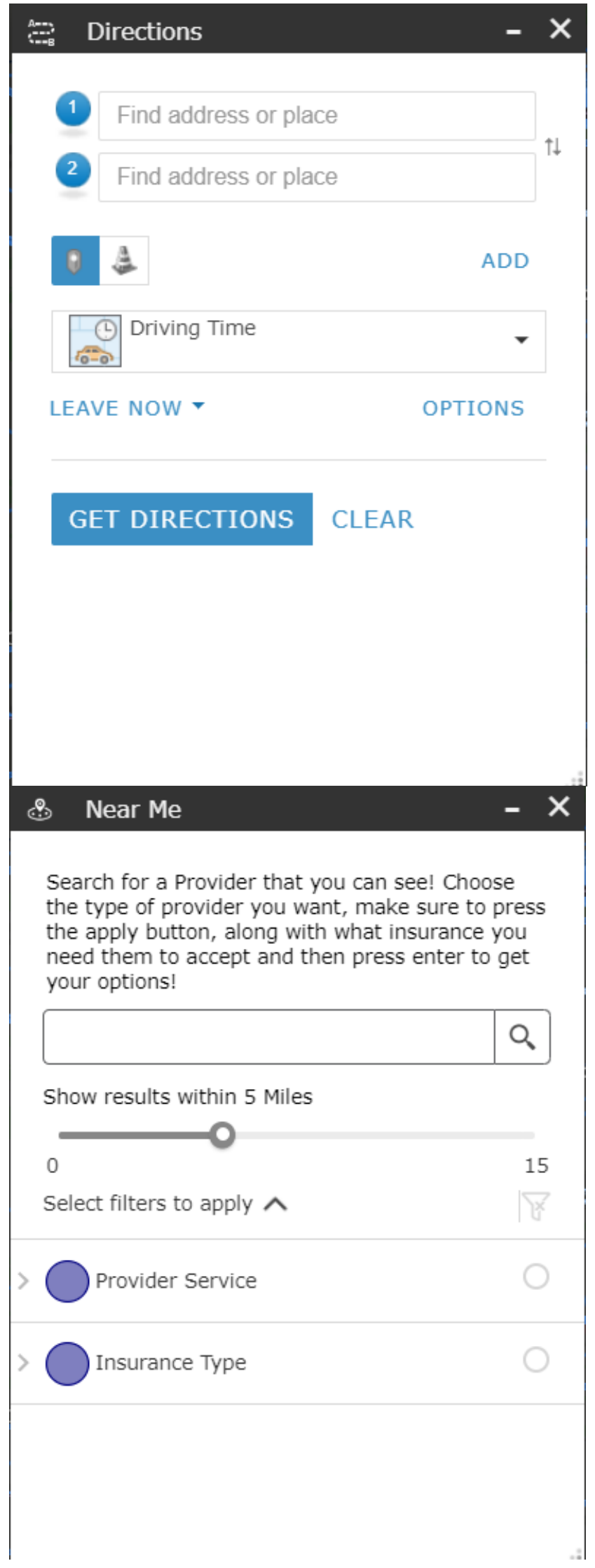

